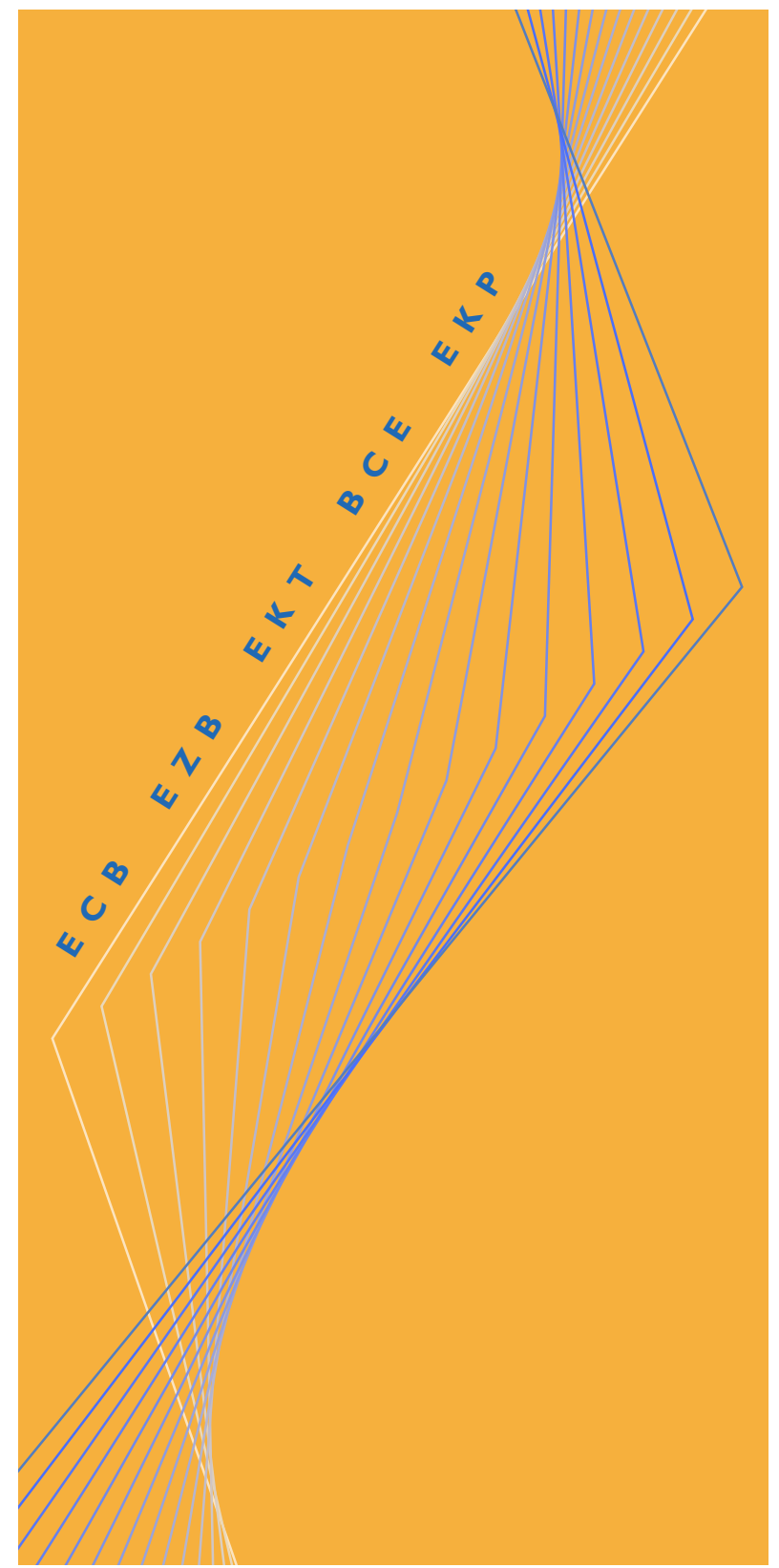

WORKING PAPER NO. 77

CYCLICALLY ADJUSTED BUDGET BALANCES: AN ALTERNATIVE APPROACH

BY CARINE BOUTHEVILLAIN, PHILIPPINE COUR-THIMANN, GERRIT VAN DEN DOOL, PABLO HERNÁNDEZ DE COS, GEERT LANGENUS, MATTHIAS MOHR, SANDRO MOMIGLIANO AND MIKA TUJULA 


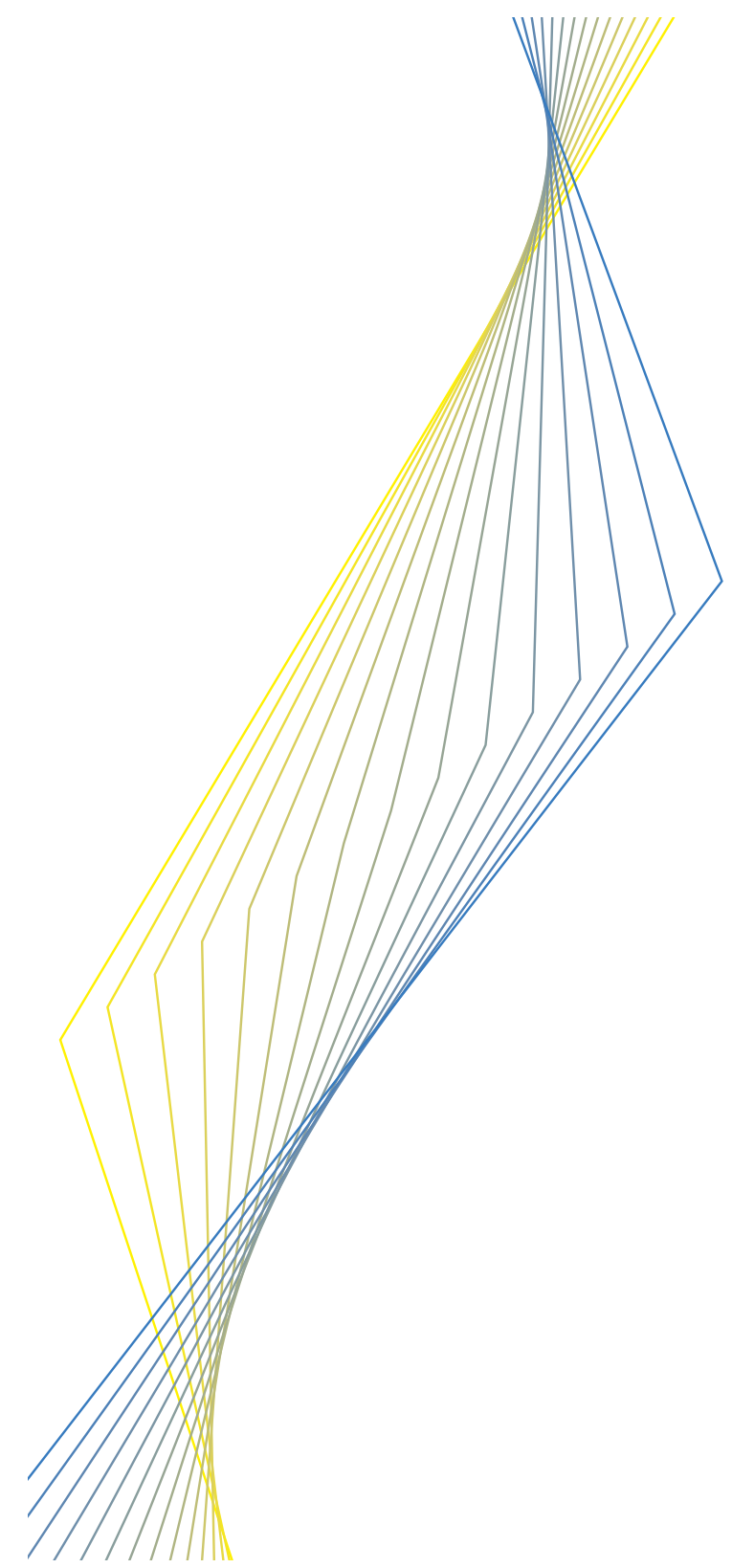

WORKING PAPER NO. 77

\title{
CYCLICALLY ADJUSTED BUDGET BALANCES: AN ALTERNATIVE APPROACH
}

\author{
BY CARINE BOUTHEVILLAIN(1), \\ PHILIPPINE COUR-THIMANN(2), GERRIT \\ VAN DEN DOOL(3), PABLO HERNÁNDEZ \\ DE $\operatorname{COS}^{(4)}$, GEERT LANGENUS ${ }^{(5)}$, \\ MATTHIAS MOHR(6), SANDRO' \\ MOMIGLIANO(7) AND MIKA TUJULA ${ }^{(2) *}$
}

\section{September 2001}

* The authors are grateful for the valuable contribution of Ana Lamo in early stages of the project and the valuable technical support provided by Fabrice Orlandi and Javier J. Pérez, all staff members of the European Central Bank. The paper has greatly benefited from comments of fiscal experts from the European System of Central Banks (ESCB) especially from Daniele Franco of the Banca d'ltalia, from Paul Hiebert and Hedwig Ongena of the European Central Bank as well as from Paul van den Banks (ESCB) especially from Danel Eu Noord of the OECD and the anonymous referee. The views expressed in the paper are those of the authors and do not necessarily reflect those of the ESCB.This concerns both the Bain text of the Working Paper and the

(1) Banque de France, $41-1376$ DEER-SEMEF, 39 Rue Croix de Petits Champs, 75049 Paris Cedex OI, France. E-mail: carine.bouthevillain@banque-france.fr

(2) European Central Bank, Kaiserstrasse 29, D-603 I I Frankfurt am Main, Germany. E-mail: philippine.cour-thimann@ecb.int; mika.tujula@ecb.int

(3) De Nederlandsche Bank, Westeinde I, NL-10I7ZN, Amsterdam. E-mail: gerrit.vandendool@oecd.org

(4) Banco de España, Alcalá, 50, 280I4 Madrid, Spain. E-mail: pabhdez@bde.es

5) National Bank of Belgium, 14, boulevard de Berlaimont, 1000 Brussels, Belgium.E-mail: geert.langenus@nbb.be

6) Deutsche Bundesbank,Wilhelm-Epstein-Strasse I4, D-6043I Frankfurt, Germany.E-mail: matthias.mohr@bundesbank.de

(7) Banca d'Italia, Servizio Studi,Via Nazionale, 91 , 00 184, Roma, Italy. E-mail: momigliano.sandro@insedia.interbusiness.it 
(C) European Central Bank, 200I

Address

Kaiserstrasse 29

D-603 I I Frankfurt am Main

Germany

Postal address

Postfach 160319

D-60066 Frankfurt am Main

Germany

+496913440

Telephone

http://www.ecb.int

Internet

+4969 I3446000

Fax

4 I I | 44 ecb d

All rights reserved.

Reproduction for educational and non-commercial purposes is permitted provided that the source is acknowledged.

The views expressed in this paper are those of the authors and do not necessarily reflect those of the European Central Bank.

ISSN I 56I-08|0 


\section{Contents}

$\begin{array}{lr}\text { I. Introduction } & 9\end{array}$

I.I The need for estimates of cyclically adjusted budget balances 9

$\begin{array}{ll}\text { I.2 General approach followed in the paper } & 10\end{array}$

$\begin{array}{ll}1.3 \text { Main features } & 10\end{array}$

I.4 Structure and contents of the paper II

2. Budget elasticities 13

2.I Computing the elasticities 13

2.I.I Econometric estimation 13

2.1.2 Derivation of elasticities based on tax and benefit laws and detailed revenue $\begin{array}{ll}\text { data } & 15\end{array}$

$\begin{array}{ll}2.2 \text { Budget variables and their macroeconomic bases } & 16\end{array}$

$\begin{array}{ll}2.3 \text { Cross-country comparison of budget elasticities } & 17\end{array}$

$\begin{array}{ll}\text { 2.3.1 Direct taxes on households } & 17\end{array}$

2.3.2 Direct taxes on companies $\quad 17$

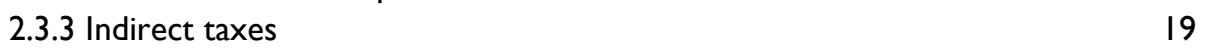

$\begin{array}{ll}\text { 2.3.4 Social security contributions } & 19\end{array}$

2.3.5 Unemployment-related expenditure $\quad 20$

3. Determining trends and gaps with the Hodrick-Prescott filter 21

3.I The Hodrick-Prescott filter 21

3.2 Two problems of the HP-filter: structural breaks and the end-point problem 23

3.2.I Structural breaks $\quad 23$

3.2.2 The end-point problem 24

3.3 Defining the $\lambda$ value of the Hodrick-Prescott filter for the computation of $\begin{array}{ll}\text { cyclically adjusted budget balances } & 25\end{array}$

3.3.I Methodological aspects affecting the choice of the smoothing parameter $\lambda \quad 25$

$\begin{array}{ll}3.3 .2 \text { Implications of low and high values of } \lambda & 27\end{array}$

3.3.3 Choice of the value for $\lambda \quad 30$

4. Cyclically adjusted balances and the sensitivity of the budget balance to the business cycle $\quad 32$

4.I The calculation of cyclically adjusted balances 32

4.2 Comparison with existing methods 33

4.2.1 A simplified approach 33

4.2.2 The European Commission approach $\quad 34$

4.2.3 The OECD approach $\quad 34$

4.2.4 The approach followed in the paper 34

4.3 Cyclically adjusted balances and cyclical components 35

$\begin{array}{ll}\text { 4.3.I Results } & 35\end{array}$

4.3.2 Sensitivity analysis on the value of $\lambda \quad 36$ 
4.3.3 Composition effects

4.3.4 Sensitivity analysis on the extension of the forecasts

5. Conclusions and further developments

6. References 


\section{Tables, Charts and Boxes}

\section{Tables}

Table 2.I Budget elasticities in the EU countries $\quad 18$

Table 4.I Cyclical components of the budget balances in the EU, 1990-2000 (as a percentage of GDP) 35

Table 4.2 Primary cyclically adjusted budget balances in the EU countries, 1990-2000 (as a percentage of GDP) 36

Table 4.3 Sensitivities of the budget balances in the EU countries in $1999 \quad 42$

\section{Charts}

Chart 3.I Weights to calculate $Y^{*}$ for a mid-sample year $\quad 22$

Chart 3.2 The distribution of weights to calculate the trend for year I (front) to year T (back) 23

Chart 3.3 Bias of the HP-trend as a result of a structural break of minus I5\% 24

Chart 3.4 Weights of the HP-filter before and after extension of the series 25

Chart 3.5 Part of cycles included in the estimated cyclical component, for three

different values of $\lambda$

Chart 3.6 Growth rates of HP filtered Spanish real GDP, for different values of $\lambda$ (percentage change over the previous year)

Chart 3.7 Deviations from HP trends of real GDP for Germany (as a percentage of trend GDP), for different values of $\lambda$

Chart 4.I Comparison of cyclical components obtained with $\lambda=10,30$ and 100 (as a percentage of GDP) 37

Chart 4.2 Comparison of cyclical components showing composition effects (as a percentage of GDP)

Chart 4.3 Sensitivity analysis on the extension of the forecasts of the macroeconomic variables (using the cyclical component computed with the aggregated approach)

\section{Boxes}

Box 2.I The elasticity of personal income tax with respect to average compensation of employees: a method based on detailed revenue data

Box 4.I Different methods to calculate the cyclical component of the budget balance 


\section{Abstract}

Estimates of cyclically-adjusted budget balances, correcting actual government budget balances for business cycle fluctuations, are produced by many institutions, including the European Commission, the IMF and the OECD. This paper presents an alternative approach for the cyclical adjustment of budget balances. The approach is based on a disaggregated method for the calculation of the cyclical component of the budget balance. In this approach, the effects of changes in the structure of demand and national income on government revenue and expenditure are captured. Cases where the various macroeconomic bases are in different phases of the cycle or exhibit fluctuations of different magnitude are taken into account in this way. The computation of the cyclical components of these macroeconomic bases is based on the Hodrick-Prescott filter and takes into account the latest evidence presented in the literature about the properties of this filter. The paper also presents new estimates of the elasticities of individual budget items with respect to the relevant macroeconomic variables. The method is used within the ESCB for the estimation of cyclically adjusted budget balances of the EU countries.

JEL classification: E32, E60

Key words: fiscal policy, government budget, cyclical adjustment, business cycles. 


\section{Non-technical summary}

Actual government budget balances are influenced by government decisions but also by influences beyond the direct control of the government. Predominant among these factors are the fluctuations in economic activity. In order to facilitate the analysis of budgetary policies, actual budget balances need to be corrected for these cyclical influences. This is done via the cyclical adjustment of government budget balances. Many institutions - the European Commission, the IMF and the OECD and among them - produce indicators of cyclically adjusted budget balances.

This paper presents an alternative approach for the cyclical adjustment of budget balances. The method presented in the paper follows the usual two steps. First, the cyclical position of the economy is assessed by measuring its deviations from its "normal" growth path. Second, the budgetary impact of such deviations is obtained on the basis of fiscal elasticities, either econometrically estimated or derived from tax or expenditure rules. Multiplying the deviations from the reference path with the various fiscal elasticities yields the corresponding cyclical components of the various budgetary items. The cyclically adjusted balances are then computed by subtracting the cyclical component from the actual budget balance.

While following the above general procedure, the paper departs from standard practice in three respects.

First, the standard procedure usually focuses exclusively on the aggregate output gap, i.e. the deviation of output from its potential level, and therefore cannot fully capture composition effects arising from unbalanced growth. The various macroeconomic bases for government revenue and expenditure might be in different phases of the cycle or exhibit fluctuations of different magnitude. The method proposed in the paper allows for the incorporation of these effects, as it defines the baseline macroeconomic environment in terms of a number of macroeconomic variables that exhibit more direct links to the revenue and expenditure items of the government budget.

Second, to estimate the baseline path of each macroeconomic variable, the method applies a statistical filter (the Hodrick-Prescott filter) to annual data extended with country-specific projections. The choice of the specific features of the filter is based on the desire to capture almost entirely in the estimated cyclical component cycles of up to eight years. This period can be thought of as an appropriate horizon for medium-term fiscal analysis for the EU countries.

Third, the paper carries out a more detailed selection of the budget items subject to cyclical adjustment than is generally done. In particular, the paper excludes those components of revenue which also appear among the expenditure items that are not cyclically adjusted, in order to treat revenue and expenditure items consistently. Other corrections involve, when data are available, the exclusion of tax categories that are not significantly affected by the cycle. 
Caution should be applied when using cyclically adjusted figures. After adjusting for cyclical influences on the budget, other temporary influences should still be considered when interpreting these figures. Furthermore, the estimates obtained when applying various methods often differ, as they depend on the estimated cyclical position of the economy, which is relatively uncertain. Differences in underlying macroeconomic and fiscal projections can also play an important role. As there is no perfect method, point estimates produced using any one method should be seen as indicative rather than precise estimates. 


\section{Introduction}

\section{I.I The need for estimates of cyclically adjusted budget balances}

Actual budget balances are imperfect indicators for assessing public finances and fiscal policies, since they are influenced by a number of factors which are both transitory and beyond the direct control of fiscal authorities. Predominant among those are the fluctuations in economic activity. The indicators of cyclically adjusted budget balances seek to correct the fiscal outcomes for the effects of cyclical variations. In other words, they aim at determining what the budget balance would have been if the economy had been on its "normal" growth path, e.g. characterised by roughly constant increases in output over the medium-term.

Estimates of cyclically adjusted budget balances are routinely used by the European Commission, the IMF and the OECD in their fiscal analyses. The main interpretation of the new framework for fiscal policy created by the Stability and Growth Pact has given a central role to these indicators in assessing and planning budgetary policies in the European Union (EU).'

However, there are a number of shortcomings in the indicators which are available up to now for the EU countries ${ }^{2}$. In particular, the indicators developed by international institutions do not adequately take into account budget effects of fluctuations in the composition of aggregate demand and national income. Furthermore, the cyclically adjusted balances calculated by these institutions are not necessarily consistent with the short-run and medium-term macroeconomic and fiscal forecasts released by other instances.

This paper presents a more disaggregated method, which seeks to adequately capture the effects of changes in the structure of demand and national income. Furthermore, the method includes a more precise selection of the budget items subject to cyclical adjustment than is generally the case and is based on new estimates of fiscal elasticities (which measure the automatic reactions to macroeconomic fluctuations of revenue and expenditure items). Finally, like the indicator used by the European Commission, it allows the calculation of cyclically adjusted balances for the EU countries in a way directly consistent with the set of macroeconomic and public finance projections deemed appropriate.

The method is used within the ESCB for the estimation of cyclically adjusted budget balances of the EU countries.

I This is stated in the Opinion by the Monetary Committee on the Content and Format of Stability and Convergence Programmes, endorsed by the ECOFIN Council on October 12, 1998: An updated version of this opinion was endorsed by the ECOFIN Council of 10 July 2001 .

2 A workshop on this issue was organised by the Banca d'Italia in Perugia in November 1998. The ECB, the EU national central banks, the European Commission, the IMF and the OECD participated in this seminar. All papers presented there were published (Banca d'Italia 1999). 


\section{I.2 General approach followed in the paper}

In this paper, the cyclically adjusted balances of the EU countries are computed on the basis of a standard two-step procedure also followed by the OECD, the IMF and the European Commission.

First, the cyclical position of the economy is assessed by comparing the actual macroeconomic environment with a "normal" one. In line with the method of the European Commission, the estimate of the latter is based upon a statistical smoothing technique (the Hodrick-Prescott filter). It must be pointed out that this kind of statistical smoothing might be inappropriate in the presence of important structural breaks (e.g. in the cases of Sweden and Finland at the beginning of the nineties). Before applying the filter, in order to avoid the well-known end-point bias problem, the macroeconomic series are extended with forecasts.

Second, the impact on the budget of the cyclical position (i.e. the cyclical component of the budget balance) is calculated using fiscal elasticities. As the cyclical position is defined in real terms, fiscal elasticities refer to the impact on the budget of real quantities. Fluctuations in the rate of inflation and in relative prices are excluded from the analysis. These fluctuations also have a significant impact on the budget, but it is difficult to assess their effects in a homogenous way, as they may depend very much on country specific institutional peculiarities (e.g. whether or not wages in the public sector are price indexed, or whether nominal budgetary projections are or are not enforced). Moreover, for some individual countries, it is difficult to identify an automatic and constant impact of prices on the budget, since it depends, among other things, on whether the price fluctuations are expected or unexpected.

The cyclically adjusted balance is then computed by subtracting the cyclical component from the actual budget balance.

\section{I.3 Main features}

While following the above general procedure, the method described in the current paper exhibits a number of differences with respect to standard practice. The main features are the following:

First, in order to achieve a more accurate estimate of the effects on the budget of the macroeconomic environment, the latter is not defined by GDP only but by five macroeconomic variables (restricted, to the extent possible, to the private sector) whose impact on public finances is more direct. These variables are: average compensation of private employees, employment in the private sector, operating surplus of companies, private consumption, and unemployment. The first four variables are relatively close proxies for the tax bases of the main private sector revenue components; the fifth has a direct impact on unemployment-related outlays, the only component of expenditure which is assumed (following a standard practice) to be influenced by the cycle.

The approach makes it possible to take into account composition effects in the presence of unbalanced growth. ${ }^{3}$ Composition effects derive from the fact that tax rates differ across tax bases and that the various macroeconomic bases for government revenue and expenditure might be in different phases of the cycle or exhibit fluctuations of different magnitudes. In certain countries these effects might be far from negligible (Langenus, 1999, Momigliano and Staderini, 1999, and

3 Standard procedures may fail to take into account composition effects as they assume that cyclical fluctuations in GDP have a constant impact on the budget balance. However, the estimates of the elasticity of budget components with respect to GDP are not necessarily based on the assumption of balanced growth. In the case of the OECD, for instance, they include the average response observed in the past of the tax bases to a change in GDP. 
Deutsche Bundesbank, 2000). The European Commission also finds evidence of large composition effects (European Commission, 1999 and 2000).

Second, this paper includes a more precise selection of the budget items subject to cyclical adjustment than is generally done. In particular, the method excludes those components of revenue which also appear on the expenditure side and are not cyclically adjusted (e.g. indirect taxes paid by the general government to itself and to the EU, direct taxes and social contributions based on government wages $^{4}$ and imputed social contributions). Components of direct taxes related to interest income are also excluded, when data are available. This exclusion is motivated by the weak relation of interest income to the cycle, and is consistent with the standard practice of not cyclically adjusting government interest payments.

Finally, to estimate the trend path of each macroeconomic variable, the HP-filter is applied to annual data using a smoothing parameter with a value of 30 . This value lies between that (100) adopted by the European Commission in its method for cyclically adjusting budget balances and those suggested by the recent statistical literature on the issue. The choice of the parameter is mainly tailored to the needs of fiscal policy related analysis, so that within an appropriate time horizon the cyclical component of the budget approximately balances and the filtered macroeconomic series are not too volatile.

It should be pointed out that a few choices regarding the assessment of fiscal elasticities ${ }^{5}$ and the appropriate selection of budget items have been made on a country-specific basis. This limited departure from a harmonisation across countries reflects data availability and institutional peculiarities.

\section{I.4 Structure and contents of the paper}

The remainder of the paper is organised as follows. Chapter 2 focuses on budget elasticities. The first section presents the two general approaches used in the paper to derive these elasticities. A detailed description of the methods adopted for each budget component is provided in the next section. In the final section the results for individual countries are discussed and compared.

Chapter 3 discusses the Hodrick-Prescott filter, which is used to assess macroeconomic trends, and the rationale for the choice of 30 for annual data as the value of the smoothing parameter of the filter.

Chapter 4 describes first how cyclically adjusted balances are computed on the basis of fiscal elasticities and deviations of macroeconomic variables from trends, pointing out the differences between the method described in this paper and the ones used by the European Commission and the OECD. In the third section the results for the cyclically adjusted balances are presented and compared with those of the international institutions. In the final section a measure of the sensitivity of the budget balance to the cycle is derived, which allows a comparison with other methods.

4 Public sector wages were not adjusted for the cycle. Although in some countries institutional mechanisms link the evolution of wages in the public sector with that in the private sector and give rise to high correlation between wages in the two sectors, the response of public wages to cyclical fluctuations does not follow automatic rules in the strict sense in any country. Rather, the degree to which wages in the two sectors evolve uniformly over the cycle depends on outcomes of wage negotiations between government and employees. Consequently, all changes in public sectors wages have been regarded as discretionary by nature.

5 Budget elasticities have been derived either from econometric analysis or from revenue and expenditure laws. Each approach has specific advantages and disadvantages related to many factors, such as characteristics of the budget item, quality of data, frequency of reforms and discretionary actions, etc. Therefore, both sources were used for different items in each country. In some cases, both methods were applied as a check on the results. 
Chapter 5 concludes.

The paper also contains a number of annexes which present more detailed results and provide some methodological background information. Country sections which explain in detail how the method has been applied in each EU country can be found together with this paper on the ECB's website. 


\section{Budget elasticities}

The first section in this chapter describes two approaches followed here to compute budget elasticities and points out their main advantages and shortcomings. The second section discusses the specific budget items and their macroeconomic bases on which the cyclical adjustment of budget balances is based. A final section presents and compares the results for individual countries.

\section{I Computing the elasticities}

In this paper fiscal elasticities are either estimated with econometric regressions or derived from tax or expenditure laws and from detailed information on the distribution of income and revenue. As each approach has specific advantages and disadvantages, it was decided here to select the most appropriate approach on a case-by-case basis, depending on data availability or budget category peculiarities. Moreover, in some cases both methodologies have been used to check the results. The approaches retained for the derivation of budget elasticities in each country are showed in Annex Table A5.

\section{I.I Econometric estimation}

The standard econometric estimation of budget elasticities entails regressing annual data for observed fiscal variables (in this case individual revenue and expenditure items) against a measure of economic activity. Control variables reflecting specific country features, time trends, tax reforms and other discretionary measures, etc., are sometimes used in the regressions.

Traditionally, the definition of economic activity is restricted to GDP. In this paper, however, elasticities are estimated with respect to GDP components and other macroeconomic variables, serving as proxies for the macroeconomic bases of government revenue and expenditure items. The sample period extend in most cases from 1970 or 1975 to 1998 depending on data availability.

It should be noted that elasticities could also have been estimated by a regression of the cyclical components of budget categories on the gaps of tax bases (for revenue categories). The two approaches lead to different interpretations. The first approach, preferred here, is based on percentage changes and thus produces an elasticity, which reflects the response of the budget balance to changes in economic activity. The second one, based on gaps, focuses on the cyclical parts of the budget and economic activity. In principle the latter approach is more appropriate in the computation of cyclically adjusted balances. However, the elasticity estimates would then depend on the method of estimating trends and of correcting for structural breaks.

Two benchmark specifications were selected, the first one being:

$$
\Delta \ln \mathrm{B}_{\mathrm{t}}^{\mathrm{j}}=\alpha+\delta \mathrm{t}+\beta \Delta \ln \mathrm{V}_{\mathrm{t}}^{\mathrm{j}}+\mathrm{A}+\xi
$$

where $B^{j}$ is a revenue or expenditure item, $V^{j}$ is the relevant GDP component or macroeconomic variable in real terms and $A$ captures the discretionary fiscal policy measures and/or some relevant idiosyncratic features of the economy. $\beta$ measures the elasticity of $B^{j}$ with respect to $V^{j}$. $\alpha$ is related to the trend change in fiscal ratios, whilst $\delta$ t captures a change in this trend. Dynamic specifications were sometimes required in order to assess the lags in tax collection and the lagged effects of economic shocks on fiscal variables. 
The existence of cointegration relations between most of the fiscal variables and their relevant macroeconomic variables suggested the need for estimating the error correction model variant; this was the second selected benchmark.

$$
\Delta \ln \mathrm{B}_{\mathrm{t}}^{\mathrm{j}}=\alpha+\beta\left(\ln \mathrm{B}_{\mathrm{t}-1}^{\mathrm{j}}-\gamma \ln \mathrm{V}_{\mathrm{t}-1}^{\mathrm{j}}+\phi+\delta \mathrm{t}+\ldots\right)+\delta_{1} \Delta \ln \mathrm{V}_{\mathrm{t}}^{\mathrm{j}}+\delta_{2} \Delta \ln \mathrm{V}_{\mathrm{t}-1}^{\mathrm{j}}+\mathrm{A}+\xi
$$

where $\gamma$ measures the long-term relationship ${ }^{6}$, and the parameters $\delta_{1}$ and $\delta_{2}$ refer to the shortterm contemporaneous and lagged elasticities.

While the econometric approach is widely used in estimating budget elasticies, some shortcomings should however be kept in mind:

I) The econometric approach has high data requirements with respect to both macroeconomic and fiscal time series. In particular, the regressions should ideally control discretionary measures, as pointed out above, but data on the exact budgetary impact of these measures are generally not available or reliable.

2) Fiscal policy is likely to affect economic activity. The regressions described above neglect this fact, creating problems of consistency due to the possible endogeneity of the explanatory variables. $^{8}$

3) Some bias in the results may be caused by measurement errors in explanatory variables.

Finally, it should be pointed out that in this paper elasticities estimated on nominal quantities are applied to variables in real terms. This entails a problem in the case of taxes levied on real quantities (excises), as long as their rates are not systematically adjusted on the basis of inflation. If rates are not adjusted, the econometric estimation of elasticities based on nominal quantities will lead to results not strictly applicable to real gaps. However, since taxes levied on real quantities are usually a small component of indirect taxes and since rates tend to be adjusted, the impact on the results is limited.

In principle, elasticities could likewise be applied to trend deviations of macroeconomic base variables in nominal terms. In a sense, this would be more appropriate since both price and real effects finally show up in the budgetary balance. In addition, cyclical price movements are generally accepted as a stylised fact characterising business cycles in macroeconomic research. However, it is mainly for two reasons why the authors follow the standard practice and define cyclical patterns of macroeconomic base variables in real terms. First, a proper account of the budgetary impact of cyclical variations of the price level requires a thorough assessment of the price elasticity of all expenditure components. Preliminary investigations point out that these elasticities depend very much on whether price variations are expected or unexpected and on country specific institutional factors. For instance, in some countries nominal budgets may be enforced, but not so in others, transfers may or may not be indexed on the rate of inflation. Second, some countries

6 For France $\gamma$ has been fixed to $I$.

7 Admittedly, a failure to adequately capture important discretionary changes may lead to biased estimates. This problem can in theory be addressed by using step-by-step approaches (recursive and post-recursive estimations) and changing the estimation windows. A possible alternative is to identify periods of rather stable legislation for each revenue item. Sample limitations have however prevented a significant use of this technique. Knowledge of the law should help in specifying the model to be estimated (e.g. the need for dummies) and selecting the sub-sample(s); it may also help in assessing the reliability of estimation results.

8 A possible solution to this problem, not explored in this paper, is to use adequate Instrumental Variable estimators. Another solution is to estimate fiscal elasticities on the basis of simulations with macroeconometric models with a sufficiently detailed structure for the public sector. The latter would also enable to assess the effects of different kinds of demand and supply shocks on fiscal variables. However, the results are highly dependent on the specific properties of the macroeconomic model used.

9 This problem should have a stronger incidence in the estimation of fiscal elasticities with respect to cyclical, and therefore nonobservable, variables. 
(e.g. Italy, Finland and Sweden) experienced a sudden structural jump in the expected rate of inflation in the nineties which would be difficult to account for within the approach adopted here. Thus, additional research is called for and price effects in trend deviations of macroeconomic base variables may be taken into account in a future refinement of the method presented in this paper. Nevertheless, it should be kept in mind that price effects, if included in the definition of the cyclical impact, could alter significantly the results in individual years. For instance, inflationary pressure in the EU area is expected to be comparatively strong in 200I. As it can be probably assumed that the impact on revenue is larger than that on expenditure, including price effects would likely lead to a less favourable (or more unfavourable) assessment of the cyclical impact on the budget than that obtained under the current approach and definitions.

\section{I.2 Derivation of elasticities based on tax and benefit laws and detailed revenue data}

As already mentioned, tax reforms and frequent fiscal innovations can make it extremely difficult to estimate budget elasticities in a reliable way. These problems are particularly significant when the focus of the analysis is on the cyclical adjustment of current and future budget balances and fiscal innovations are important and recent. In these cases it may be preferable to assess budget elasticities on the basis of the tax laws currently being applied.

This approach requires the analysis of the fiscal rules that apply to the relevant taxes and benefits. It is followed here in a number of cases (in particular, for the elasticity of social security contributions of most countries and for most budget elasticities in the cases of Italy, Portugal, Spain and Germany). The method is more reliable the closer the reference macroeconomic variable is to the tax base. It represents a relatively straightforward approach when the system is well represented by a flat rate; this is the case for social security contributions and indirect taxes for many countries. When the tax is based on a progressive system of rates as in the case of the personal income tax, however, an estimate of the elasticity is still possible, based on detailed revenue data by income brackets (see Box 2.1 below and Annex A2).

The assessment of elasticities directly based on the analysis of tax and benefit laws also presents theoretical problems and practical difficulties. Difficulties arise particularly when tax rules are complex and encompass a complicate lag structure like in the case of corporate taxes. Another problem for this approach arises when the structure of the tax base shows cyclical changes. In particular, the elasticity of indirect taxes with respect to consumption can differ from the theoretical value of I (since VAT has flat rates) because higher indirect tax rates are applied to luxury and durable goods, whose demand is highly cyclical.

\section{Box 2.I}

The elasticity of personal income tax with respect to average compensation of employees: a method based on detailed revenue data

The estimation of the aforementioned elasticity $\varepsilon_{R^{W}, \omega}$ can be directly obtained from the distribution of tax revenue $(\mathrm{RW})$ and of the tax base average income $(\omega)$ by income classes. For each income class $\omega_{\mathrm{i}}=\mathrm{W}_{\mathrm{i}} / \mathrm{E}_{\mathrm{i}}$

$\varepsilon_{\mathrm{R}_{\mathrm{i}}{ }^{\mathrm{W}}, \omega_{\mathrm{i}}}=\frac{\Delta \mathrm{R}_{\mathrm{i}}^{\mathrm{W}}}{\Delta \omega_{\mathrm{i}}} \frac{\omega_{\mathrm{i}}}{\mathrm{R}_{\mathrm{i}}^{\mathrm{W}}}=\frac{\Delta \mathrm{R}_{\mathrm{i}}^{\mathrm{W}} / \Delta \omega_{\mathrm{i}}}{\mathrm{R}_{\mathrm{i}}^{\mathrm{W}} / \omega_{\mathrm{i}}}$

with $\Delta \mathrm{R}_{\mathrm{i}}^{\mathrm{W}} / \Delta \omega_{\mathrm{i}}$ as the marginal tax rate of class $\mathrm{i}$ on the earnings distribution, and $\mathrm{R}_{\mathrm{i}}^{\mathrm{W}} / \omega_{\mathrm{i}}$ as average tax rate of class $i$ on the earnings distribution.

To obtain the aggregate elasticity, first the marginal tax rate and the average tax rate are computed for each class of the income distribution. On the basis of the income distribution itself, the weighted average of these 
rates is then calculated. Using actual tax payments data, tax credits and tax allowances can be taken into account. See Annex A2 for a more detailed description of this method and its variants.

In its recent revision of budget elasticities, the OECD has used tax laws and the distribution of revenue to compute the elasticity of each revenue component to its tax base (van den Noord, 2000). As the OECD method requires the elasticity of each revenue component to GDP to be computed, the latter is calculated as the product of the elasticities of the revenue component to the tax base and of the tax base to GDP, which are estimated on the basis of regression analysis. ${ }^{10}$

\subsection{Budget variables and their macroeconomic bases}

In this paper, four broad revenue categories and one expenditure category are identified to be dependent upon the cycle in all countries: direct taxes on households, direct taxes on companies, indirect taxes, social security contributions and unemployment-related expenditure. The latter category does not only consist of unemployment benefits in the strict sense, but also includes all other social transfers, which are deemed to depend on unemployment (e.g. early retirement).

Following a standard practice, other revenue and expenditure items are assumed to exhibit zero elasticities with respect to the business cycle. ${ }^{11}$

For each of the selected budget items an appropriate macroeconomic base is identified. In principle, both direct taxes on households and social security contributions are linked to compensation of private sector employees, indirect taxes to private consumption, direct taxes on companies to gross operating surplus, and unemployment-related expenditure to the number of unemployed. Elasticities are generally determined with respect to these bases. A few refinements are introduced, however.

First, the framework adopted here implies that government revenue includes some revenue items, which are also government expenditure. This is the case for social security contributions paid by general government, imputed social contributions, indirect taxes transferred to the European Union and indirect taxes paid by the general government. Since these items are assumed to have a zero elasticity on the expenditure side, they should also exhibit a zero elasticity on the revenue side. The overall elasticity of each revenue category was therefore derived as a weighted average with the weights being the shares in the category - of the zero elasticity and the non-zero elasticity components.

Second, some taxes and social contributions included in the revenue items to be cyclically adjusted are paid out of income which belongs to general government expenditure, mainly compensation of public employees and replacement incomes (e.g. pensions). Since these expenditure categories were considered not to depend upon the cycle, all taxes they generate should theoretically also be considered as non-cyclical and attributed an elasticity of zero. This correction was carried out for social security contributions and direct taxes paid on wages of government employees. In most cases estimates were used because of a lack of detailed data. However, it was not deemed feasible to correct the results for taxes and social security contributions paid on pension payments. ${ }^{12}{ }^{13}$

10 The same approach is used for unemployment-related expenditure. The elasticity of the latter to GDP is the product of the elasticity of the number of unemployed persons with respect to output and the elasticity of unemployment-related expenditure with respect to unemployment.

II A possibly fruitful area for further research lies in the analysis of the cyclical properties of other parts of the government budget, such as taxes on interest income, government consumption, pensions, interest payments, subsidies and public investment. For some of these items, however, it is relatively difficult to draw a line between discretionary actions and automatic reactions.

12 The impact of this additional correction is not necessarily negligible. Available data for Italy show that assigning a zero elasticity to direct taxes paid by pensioners could decrease the overall elasticity of direct taxes paid by households by around 0.3 .

13 It was also not considered to be feasible to correct for indirect taxes paid by government employees in a sufficiently accurate way. 
Third, tax categories were defined in a very broad way and generally consist of heterogeneous taxes. In some cases a better match between a tax and its tax base could be found.

For some countries it was possible, for example, to single out parts of the tax category which do not depend on the selected tax base. Examples are the Belgian withholding tax on income from immovable property, which is an indirect tax but does obviously not depend directly on consumption, and the Italian and Portuguese withholding tax on interest income, which is a tax on households income but is not directly linked to compensation of employees. A zero elasticity was assigned to all items which depend on a tax base which is not deemed cyclical and is different from the chosen one. Again, the overall elasticity is derived as a weighted average of this zero elasticity and the original one. In some cases, parts of a tax category directly depend on a tax base selected for a different category (for example, the Italian regional tax on productive activities is part of indirect taxes but is levied mainly on labour income). In these cases, the tax component is excluded from its category and included in the one with the same tax base.

Finally, in some cases a somewhat different macroeconomic base, assumed to be a better proxy for the theoretical tax base, is used to estimate the elasticity. This is the case, for example, for indirect taxes in Belgium and Germany where the tax base is corrected so as to include other expenditure generating indirect taxes (e.g. investment in housing in Belgium), or to exclude those parts of indirect taxes which are not affected by the macroeconomic base of private consumption (trade tax in Germany), and/or to exclude parts of private consumption that are exempt from indirect taxes (e.g. rents and financial services in Belgium).

\subsection{Cross-country comparison of budget elasticities}

Results on the budget elasticities in the EU countries can be compared in five main areas. They are presented in Table 2 .I below.

\subsection{Direct taxes on households}

Direct taxes on households, restricted to those levied on the income of the private sector, are assumed to depend on private sector employment and the average compensation of private sector employees. In general, the elasticity to employment is assumed to be $I$ in all countries, and this result is backed by econometric estimation. The second elasticity is typically larger than I, due to the progressivity of income taxation; it exceeds 2 in the Netherlands, where this progressivity is particularly high.

\subsubsection{Direct taxes on companies}

The elasticity of corporate taxes is notoriously difficult to determine. This is primarily due to the complexity of most corporate tax systems (and the lag structure they imply) and the basic nonlinearity of the tax rule, both of which make it extremely difficult to determine an appropriate tax base (here, the gross operating surplus). 


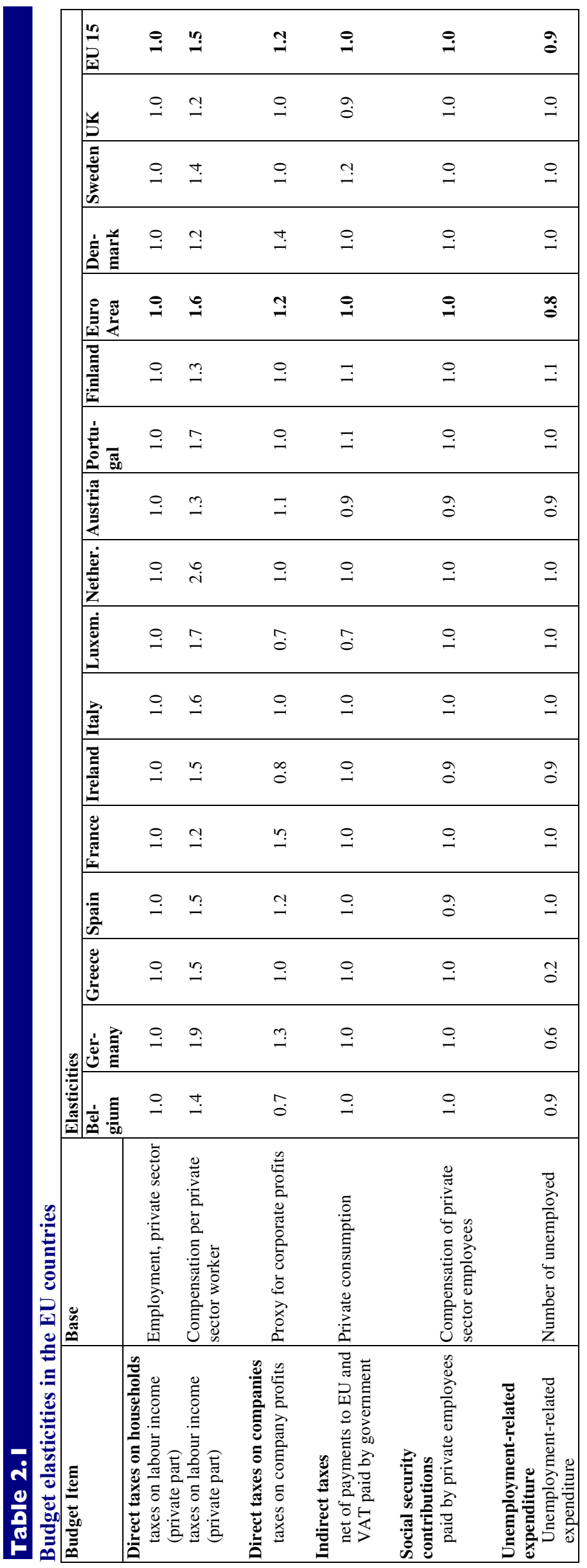


Corporate taxation is typically based upon a nominal flat rate, although average implicit rates tend to be a lot lower due to the existence of various exemptions and abatements. The latter can even pertain to previous losses. This is the case for France, Belgium and the Netherlands, for instance. Also, in many countries implicit tax rates can simply be influenced by companies' result appropriation policies, since different rates apply to distributed and retained earnings. This phenomenon can be all the more important in view of tendency of companies to stabilise distributed earnings over the cycle.

Corporate tax systems are basically non-linear in that losses do not entail negative taxes - at least not during the current year. Since profits and losses are netted out in macroeconomic proxies for corporate income, the relationship between corporate taxes and corporate income on the macroeconomic level is affected by this non-linearity. In addition, the revenue from taxes on profits is subject to considerable and varying time lags which can - if at all - only be estimated very inaccurately.

These problems clearly jeopardise the success of any econometric undertaking designed to establish a stable elasticity for corporate taxes. However, the derivation of the elasticity from the tax law, or following some other method, might not yield more reliable estimates since it would also suffer from the inherently shaky relationship between corporate taxes and operating surplus. Estimates of elasticities of taxes on profits for individual countries vary greatly. For Belgium, Ireland and Luxembourg, results below unity are obtained. Other countries exhibit elasticities of corporate sector direct taxes, which are either at unity or slightly above unity. In the Italian case the current-year elasticity is zero, since taxes are paid by companies with a lag of one year. The elasticity of corporate taxes paid in the following year is set to I.0, as the tax rate is flat. ${ }^{14}$

\subsubsection{Indirect taxes}

In principle, the elasticity of indirect taxes is close to one, as indirect tax rates are generally flat. A possible deviation from one could arise from changes in consumer behaviour over the business cycle, as tax rates are not the same for all products (luxury articles tend to be taxed more heavily and/or basic necessities less heavily). Therefore, cyclical shifts in the composition of private consumption imply changes in the overall implicit tax rate and affect the elasticity. Generally, the share of luxuries is pro-cyclical, which could be one reason why the elasticity of indirect taxes is above one. Note that the average impact of the cyclical shifts in consumption patterns observed in the past should be captured by econometric analysis, while it has not been taken into account when deriving elasticities from tax laws. ${ }^{15}$

\subsubsection{Social security contributions}

The bulk of social security contributions is levied on wage income mostly applying flat rates. In this respect compensation of employees represents a relatively good proxy for the tax base and an assessment based on tax legislation points to an elasticity of close to I. This is also confirmed by results obtained from econometric estimation, which, however, are not very robust. A possible explanation of this shortcoming can stem from frequent discretionary changes of contribution rates, which are difficult to account for in regression analysis. The exclusion of the actual and imputed contributions paid on the public sector wages implies a reduction of around 20 per cent in the value of the elasticity of total contributions.

14 For a different approach to estimate the elasticity of corporate sector direct taxes see e.g. Gropp and Kostial (2000). In particular, these authors take profit shifting of multinational companies into account.

15 The indirect tax elasticity would seem to be higher than I in Portugal, Finland and Sweden. In the latter two countries this can be explained by extremely high taxes on alcoholic beverages and motor vehicles exceeding significantly the VAT rates. The consumption of these items increases considerably during prosperous times. 


\subsubsection{Unemployment-related expenditure}

Unemployment-related outlays include in this paper unemployment benefits and, in some cases, other unemployment-related expenditure, such as early retirement. Typically, this budget category represents only a small part of government expenditure but it shows a relatively high elasticity with respect to economic activity. The number of unemployed has naturally been chosen as the relevant macroeconomic base. The elasticity of unemployment-related expenditure was estimated by regression analysis or, for some countries, assumed to be I. In the case of Portugal, though, the unemployment gap is not obtained by applying the HP-filter to unemployment, but is calculated as the difference between actual and natural unemployment, which leads to a very similar result. ${ }^{16}$

16 In the case of Germany, the elasticity of unemployment outlays with respect to the number of unemployed (0.6) is smaller than the corresponding OECD figure (I.0) since total unemployment outlays have to be adjusted for contained contributions to other public social security funds which represent payments within the government sector. 


\section{Determining trends and gaps with the Hodrick-Prescott filter}

The decomposition of series into a trend and a cyclical part can be based on different methods. Each of them entails some relatively arbitrary decisions and has advantages and drawbacks, depending on its statistical and economic properties and the objective of the analysis. This paper uses the Hodrick-Prescott filter (Hodrick and Prescott, 1980 and Hodrick and Prescott, 1997) to de-trend the macroeconomic bases of revenue and expenditure categories.

The Hodrick-Prescott filter (HP-filter) has been selected on the basis of pragmatic criteria such as simplicity and transparency. While the HP-filter has been frequently criticised in the statistical literature ${ }^{17}$, it continues to be the most commonly used filter in empirical studies and policy analysis to identify trend components in all kinds of macroeconomic series. Indeed, a consensus over an alternative approach has so far not been reached. ${ }^{18}$ Together with other statistical methods, it has the advantage of determining cyclical components, which strictly balance over the estimation period and, given an appropriate value for the smoothing parameter of the filter, tend to also balance over the medium-term. Three other frequently used decomposition methods are the Beveridge-Nelson decomposition, the Unobservable Components Model of Harvey and the Baxter-King filter. They are briefly reviewed in Annex 3.I.

Section 3.1 briefly deals with the decomposition of time series between cycles and trends and gives a general description of the HP-filter. Section 3.2 elaborates on two important problems of the latter and describes the procedure followed to tackle one of them. Section 3.3 gives the rationale for the choice of the value of 30 for the smoothing parameter of the filter.

\section{I The Hodrick-Prescott filter}

The trend and cyclical components of a series $Y$ are defined as $Y^{*}$ and $Y^{c}$, respectively:

$$
Y_{t}=Y_{t}^{*}+Y_{t}^{c}
$$

Hodrick and Prescott (1980) propose the following optimisation procedure to calculate the trend Y*:

$$
\min _{y_{t}^{*}} \sum_{t=1}^{T}\left(\left(Y_{t}-Y_{t}^{*}\right)^{2}+\lambda\left(\Delta Y_{t+1}^{*}-\Delta Y_{t}^{*}\right)^{2}\right)
$$

This formula implies extracting the trend from the original series by minimising the sum of the deviation of $Y$ from its trend (the first term) and the variability of the trend itself (the second term), depending on the weights attributed to these two goals. The relative weight of the second

17 In particular, it has been pointed out in the literature that the HP-filter may generate spurious cycles which do not actually exist, if applied to non-stationary series. On this issue, see Cogley and Nason (1995). This criticism may however be less relevant as spurious cycles are less likely to occur in samples consisting of 30 or more observations, such as those generally used in this paper. The relevance of the "spurious cycles" critique has also been questioned on theoretical grounds, see for instance Kaiser and Maravall (1999).

18 The choice of a specific filter is inevitably related to a number of fundamental questions concerning the nature of business cycles, on which both the empirical literature and economic theory do not show consensus. As pointed out in Canova (1998, pp.475-476): "within the empirical literature, there is a fundamental disagreement on the properties of the trend and on its relationship with the cyclical component of a series. (...) Dynamic economic theory, however, does not indicate the type of economic trend that series may display nor the exact relationship between secular and cyclical components. Models have been proposed where the long run component may be either deterministic or stochastic and may or may not be related to the cyclical component." The same concept is stressed in Kaiser and Maravall (200I, p.6): "Despite the fact that business cycle estimation is basic to the conduct of macroeconomic policy and to monitoring the economy, many decades of attention have shown that formal modeling of economic cycles is a frustrating issue (...)." 
goal is represented by the smoothing parameter $\lambda$. The higher the preference for a smooth trend, the higher one should chose $\lambda$ (for infinite $\lambda$ the trend would be a straight line). On the other hand, a $\lambda$ of zero would imply a trend always equal to the original series $\left(Y=Y^{*}\right)$, since in that case variations of the trend would not be 'penalised' at all. The lower $\lambda$, the closer the trend follows the original series and the smaller the difference, and thus the gap $\left(Y^{c} / Y^{*}\right)$, between the original series and the trend.

Filtering implies calculating a moving average, with the weights depending on the number of observations and $\lambda$, which determines the width of the distribution of weights along with the smoothness of the filtered series. The trend of $Y$ for each year is calculated as a weighted average of all the elements of the original series. The distribution of weights for mid-sample years at different $\lambda$ 's is shown in Chart 3.I where the length T of the sample period is set to 30 . One should note that the weights depend also on $\mathrm{T}$.

\section{Chart 3.I}

Weights to calculate $Y *$ for a mid-sample year

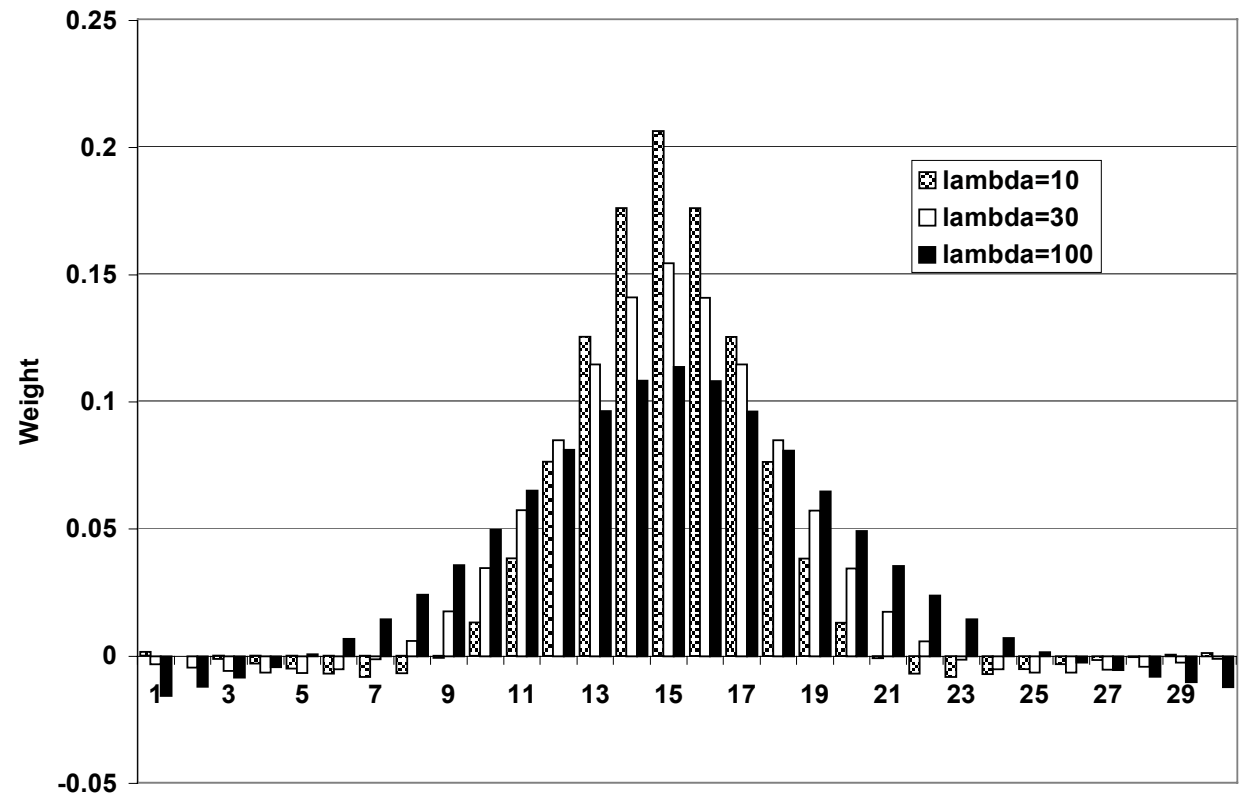

Chart 3.I depicts the distribution of weights for the trend computation in one year only. Chart 3.2 shows the distribution for the whole length of the sample period for $\lambda=30$. 


\section{Chart 3.2}

The distribution of weights to calculate the trend for year 1 (front) to year $\mathbf{T}$ (back)

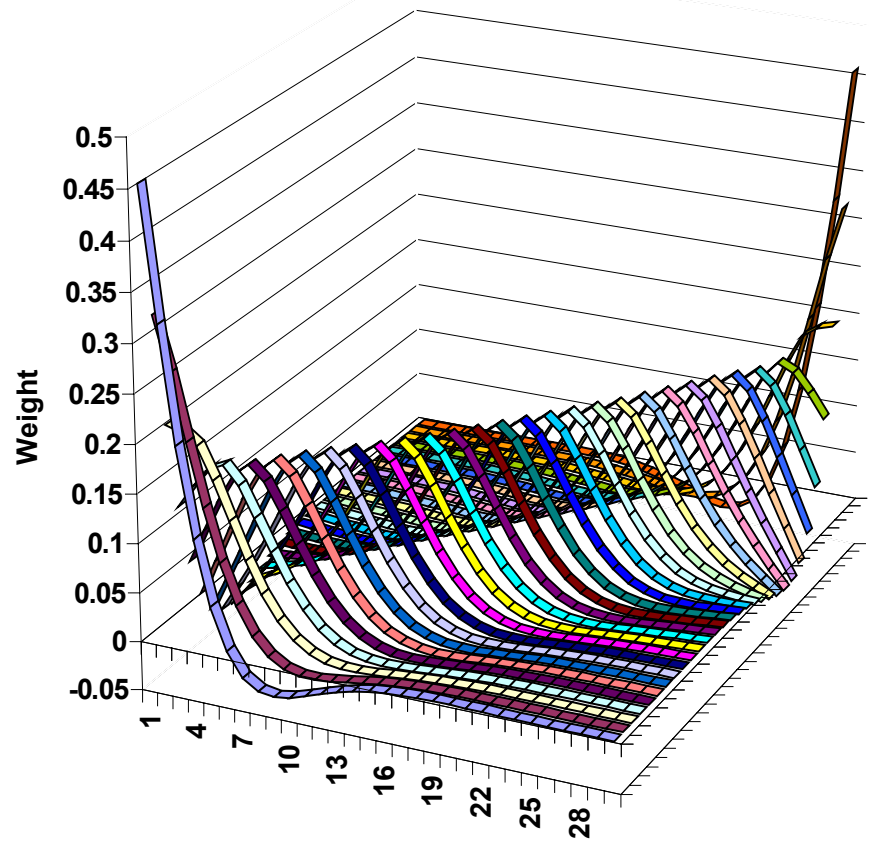

Closer to the end-points $(\mathrm{t}=\mathrm{I}$ and $\mathrm{t}=\mathrm{T})$ the distribution gets gradually more skewed and the trend values become dominated by the actual values in those years (this distortion is discussed below).

\subsection{Two problems of the HP-filter: structural breaks and the end-point problem}

Two important problems in applying the HP-filter pertain to the presence of structural breaks and to the estimation of the trend at the end-points of the series.

\subsection{Structural breaks}

A problem of the HP-filter, and of all trend calculations based on two-sided moving averages, is that it is not able to detect and reflect sudden breaks of trends. The effect of a structural break is spread out over the years before and after the break, which may lead to large differences between the actual trend and the HP-trend, depending on the magnitude of the break. For a break of I5 per cent this is illustrated in Chart 3.3. In the recent past, large structural breaks in macroeconomic trends have taken place in Finland, Ireland and Sweden, leading to a transitory but sometimes very large bias in the HP-trends for a number of years before and after the break, which should then be corrected for (see e.g. Brunila, Hukkinen and Tujula, 1999). The problem is less severe the smaller the value of $\lambda$ used, but is quite difficult to solve in a satisfactory way. 
Chart 3.3

Bias of the HP-trend as a result of a structural break of minus $15 \%$

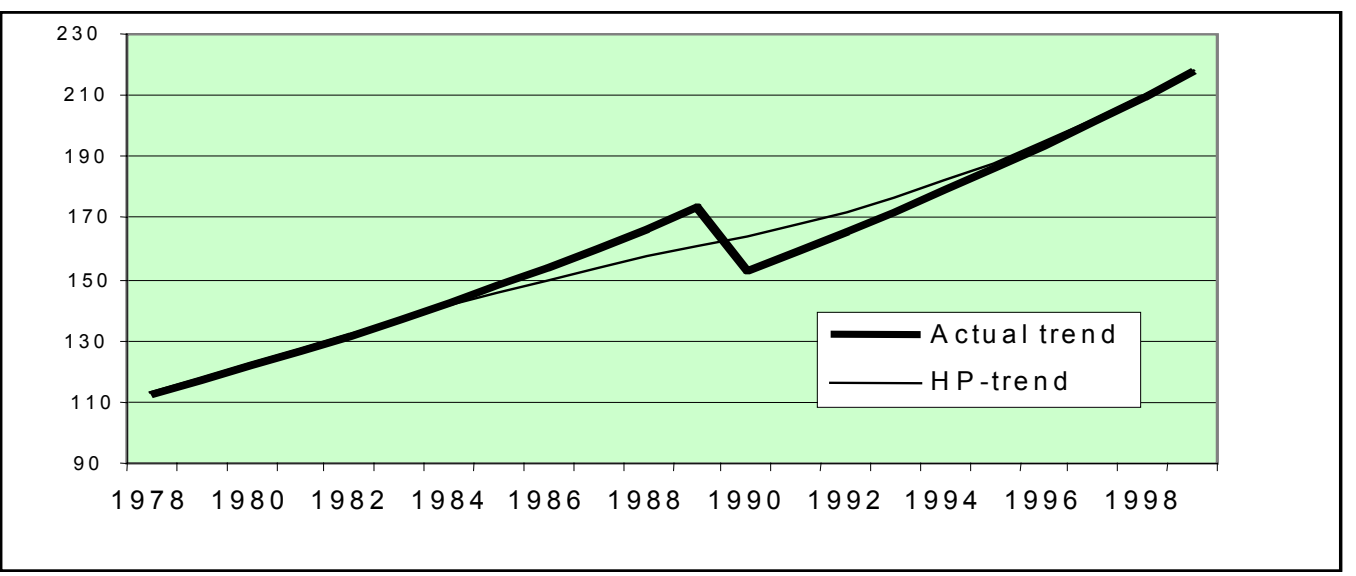

\subsubsection{The end-point problem}

As was already mentioned, $\mathrm{Y}^{*}$ is calculated for each year as a weighted average of the original series with the distribution of weights being symmetric only in the middle of the sample period. At the beginning or at the end of the sample period the distribution gets gradually more skewed, and values of $Y^{*}$ are predominantly determined by the actual values in those years. This distortion is known in the literature as the "end-point problem", since the estimates referring to the beginning of the sample period can usually be disregarded.

Extending a time series by forecasts is a pragmatic solution to this problem. The series used in this paper have been extended on the basis of specific projections for the next three years and, for the following four years, on the basis of trend growth patterns or macroeconometric model simulations. As illustrated in Chart 3.4, for $\lambda$ equal to 30 , it seems sufficient to extend the series by about additional four years beyond the three year forecast horizon. This allows for a calculation of the trend up to the end of the forecast horizon based on a more or less symmetric distribution of weights, which does not differ too much from that for mid-sample years.

Evidently, the more reliable the forecasts, the more reliable the estimates of the trends are for actual years. In Chart 3.4 the trend in year 2000, for instance, depends for about 13 per cent in total on the weights (after extension of the series) in the years 2003 and 2004. Therefore, an error of I per cent in the projection for 2003, not corrected in 2004, has an impact of about 0.13 percentage point on the trend in 2000. 
Chart 3.4

Weights of the HP-filter before and after extension of the series

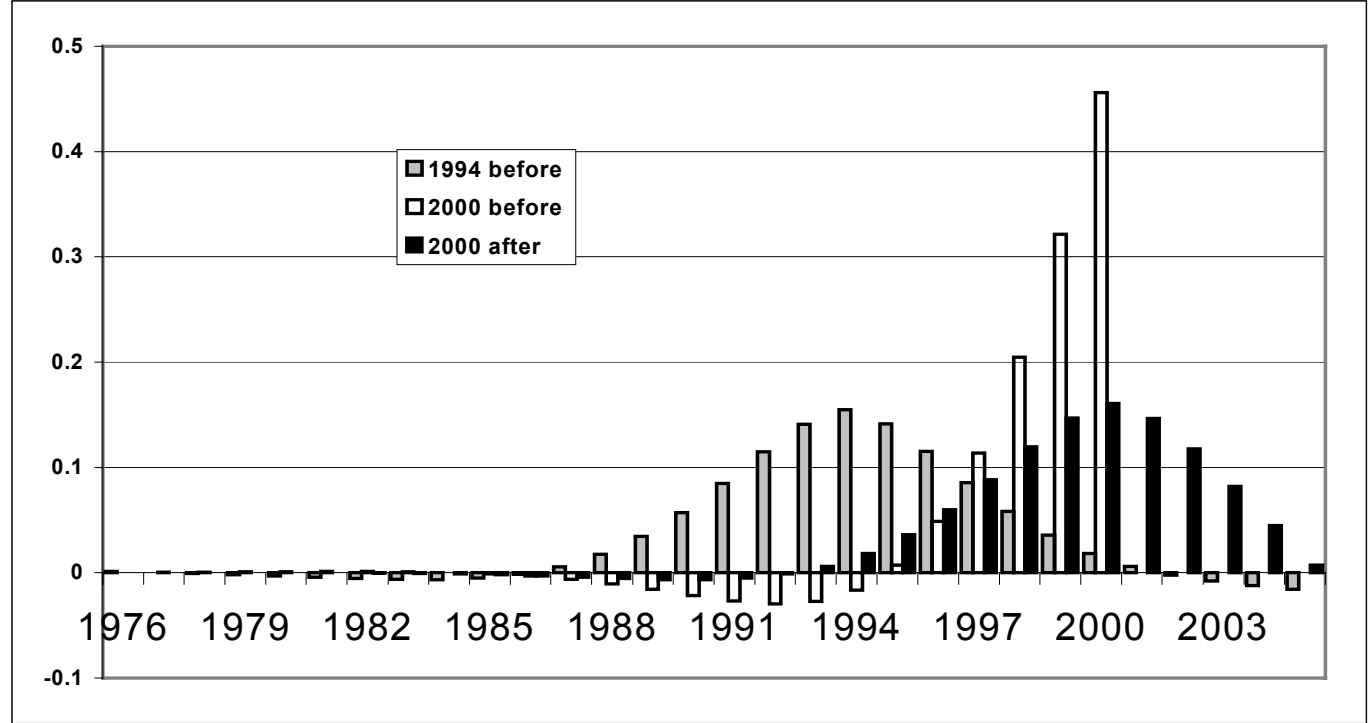

\subsection{Defining the $\lambda$ value of the Hodrick-Prescott filter for the computation of cyclically adjusted budget balances}

As the estimates of deviations from trend depend heavily on $\lambda$, the choice of this parameter is particularly important. In this section, the methodological aspects of the literature on the choice of the parameter are first reviewed. Their implications for the cyclical adjustment of budget balances are then briefly assessed. Finally, a specific criterion on which to base the choice of the value of $\lambda$ is presented and its implication, a harmonised value of 30 for annual data, is discussed.

\subsection{Methodological aspects affecting the choice of the smoothing parameter $\lambda$}

In empirical applications of the HP-filter, different values for $\lambda$ have been used. Within applied research, there seems to be no consensus as to the proper value of the smoothing parameter. For quarterly data, a value of 1600 , recommended by Hodrick and Prescott in their original work, is commonly employed. For annual data, current empirical practice is, according to Baxter and King (1999), to use $\lambda=400$ or 100. Recently, however, some authors have also argued in favour of smaller values of $\lambda$ for annual data. Furthermore, according to Ravn and Uhlig (200I), a value of 1600 for quarterly data corresponds to a value of 6 to 8 for annual data.

Frequency domain analysis of time series and the choice of $\lambda$

Frequency domain analysis shows that any stationary time series can be decomposed into a weighted sum of cyclical series of periodic lengths (or corresponding frequencies). ${ }^{19}$ Based on this decomposition, an ideal filter would allocate cycles with lengths longer than a critical length to the trend component and the cycles of shorter lengths to the cyclical component. As has been pointed out by Kaiser and Maravall, the critical length depends on the objectives of the researcher. "For example, a business cycle analyst involved in policy making may be interested in using 8 or 
10-year cycles; an economic historian, looking at several centuries, may be interested in spreading activity over longer periods" (Kaiser and Maravall, 200I: p.II7).

However, an ideal filter exists only as a theoretical benchmark. When actual, finite time series are being filtered, a separation of cycle lengths below and above the critical length can never be exact, irrespective of the filter being used. This implies that two kinds of "errors" are made, irrespectively of the filter used. ${ }^{20}$ First, the cycles which, on the basis of the chosen critical length, should belong to the cyclical component, are in fact not completely included in the latter but rather affect partially the estimated trend series. Hence, the variability of the cyclical component is underestimated and, consequently, that of the trend series is overestimated. This bias is called the compression effect. Second, cycles which should belong to the trend are in fact not completely included in the latter but rather affect the cyclical component. Hence, the variability of the cyclical component is overestimated, and the trend component is underestimated. This is called the leakage effect.

Given a critical length, a lower value of $\lambda$ would increase the bias due to compression effects and decrease that due to leakage effects, and vice versa for a higher value of $\lambda$. Hence, there is a tradeoff between compression and leakage effects entailed in the choice of $\lambda$, which is shown in Chart 3.5.

\section{Chart 3.5}

Part of cycles included in the estimated cyclical component, for three different values of $\lambda$

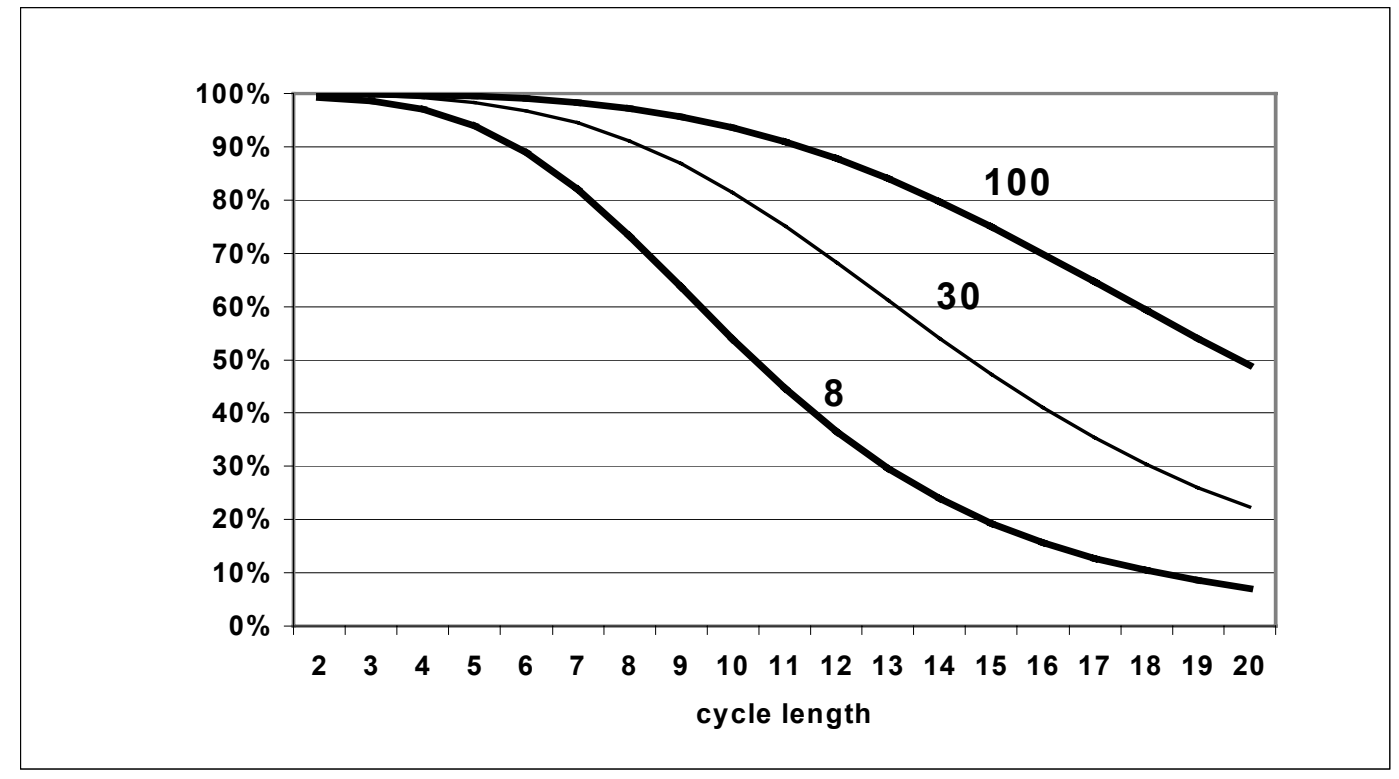

Note: For a given length of the periodic fluctuation of the original time series (horizontal axis), the chart shows, depending on the smoothing parameter $\lambda$, to which extent this cycle is accounted for in the estimated cyclical component of the filtered series (vertical axis). ${ }^{21}$

For instance, if the preferred critical length is 8 years and a value of 8 for $\lambda$ is chosen (as proposed by Kaiser and Maravall, 1999), Chart 3.5 shows that about 73 per cent of the amplitude of the 8year cycle goes into the cyclical component, while 27 per cent does not appear in the cycle and is allocated to the trend. This misallocation corresponds to the compression effect.

20 It should be stressed that they represent "errors" only with reference to situations in which the researcher either knows with certainty the length of the business cycle or in whicha defined critical length of the cycle follows from the purpose of research.

21 This part captured by the HP-filter actually corresponds to the (unsquared) filter gain. 
This effect can be reduced by increasing the value of $\lambda$. For instance, with a value of 100 (currently used by the European Commission in its method for cyclically adjusting budget balances), only about 3 per cent of the amplitude of the 8-year cycle would be included in the trend series, implying a much smaller compression effect and a smoother trend.

However, with such a high value of $\lambda$, leakage effects would become large. For instance, if $\lambda=100$, as much as about 70 per cent of a 16-year cycle would appear in the cyclical component. Marked leakage effects lead to an overestimation of deviations from trends since they contain components of very long cycles.

The statistical literature that deals explicitly with the choice of $\lambda$ does not answer the question of how to select a critical length of the business cycle. However, it focuses on the relationships between critical lengths and $\lambda$. Two proposed approaches are presented in Annex A.3.4: the ones of Pedersen (1998a) and of Kaiser and Maravall (1999). ${ }^{22}$ Both approaches lead to relatively low values of $\lambda$ compared to current empirical practice, implying that relatively short cycles are to a large degree left in the trend component. ${ }^{23}$ In other words, they give rise to relatively high compression effects.

This literature has an important outcome in so far as, assuming a common critical length of the cycle in all EU countries, it gives support to a value of $\lambda$ that is common for all EU countries and macroeconomic series to be filtered. Indeed, the relationship between the critical length and the appropriate value of $\lambda$ as proposed by Kaiser and Maravall can be generalised to all time series, which share the same degree of integration. This means that, once a common critical length has been chosen, the same value of $\lambda$ can be used for all EU countries and for different macroeconomic series, e.g. real GDP and its components which are typically regarded as being integrated of order one. Additionally, empirical evidence seems to indicate that average lengths of cycles are quite similar between EU countries. ${ }^{24}$

\subsubsection{Implications of low and high values of $\lambda$}

As has already been argued above, two kinds of errors, leakage and compression effects, occur in the application of filters. Choosing a specific value of $\lambda$ requires finding an appropriate balance between these two types of costs. The European Commission, by choosing a relatively high value of $\lambda=100$ seems to favour controlling compression; the concern for leakage effects appears to be weaker (cf. Chart 3.5 above). In deciding over a balance between these two errors, the objectives of public finance analysis and policy arguments need to be considered.

22 The contribution of Baxter and King (1999) could be considered as a third proposal, as it identifies the appropriate $\lambda$ on the basis of closeness of the results to their preferred filter.

23 A concern for an excessively large variability being left in the trend component is expressed in the conclusions of King and Rebelo (1993, p.230): "...macroeconomic research focusing on the component of the time series that is isolated by the HP-filter [using $\lambda=$ 1600 for quarterly data] (...) is likely to capture only a subset of the time series variation that most economists associate to cyclical fluctuations."

24 A typical length of the business cycle of 5 to 7 years for real GDP was detected in the GIO countries (see Bouthevillain, 1996). This is also true for the EU countries, with the exception of Luxembourg, where cycles are difficult to define and would appear to be shorter. Pedersen (1998b), using the criterion of Burns and Mitchell (1946) for the selection of peaks and troughs, assesses the maximum length of the business cycle to be of about 12 years, and the average length to be at most about 10 years, for a group of six EU countries (Denmark, Spain, France, the United Kingdom, Italy and the Netherlands). Pedersen also notes that "more than two thirds of the classical business cycles have a duration less than 8 years and 22 out of 35 cycles have a duration of 6 years or shorter." However, according to the author the Burns-Mitchell measure "overstates the true duration of business cycles when distinguishing between business cycles and economic growth". Correcting for this bias, Pedersen suggests "an upper limit on the duration of the cyclical component of 6 years for II OECD countries for the post-war period, possibly with the exception of Spain", where it would reach 7 and a half years. 
The costs of compression effects

The higher the compression effect, the smaller the deviations between the actual and the trend series will be. Large compression effects therefore imply two drawbacks: relatively volatile trends and the risk of underestimating gaps.

Regarding the first drawback, the use of such volatile trends as benchmarks can make an assessment of policy actions difficult, especially if the trend displays some correlation with the cyclical component. Selecting a benchmark that changes significantly from one year to the next contradicts the very purpose of cyclically adjusting budget balances, which is to assess public finances against a more stable economic environment than that described by the original, unfiltered set of macroeconomic data.

Moreover, a trend with these characteristics, only obtained on the basis of a statistical tool, may be considered implausible. Chart 3.6 below shows how the volatility of trend growth rates depends on different values for $\lambda$ taking Spain as an example (this pattern is also very similar for other EU countries).

\section{Chart 3.6}

Growth rates of HP filtered Spanish real GDP, for different values of $\lambda$ (percentage change over the previous year)

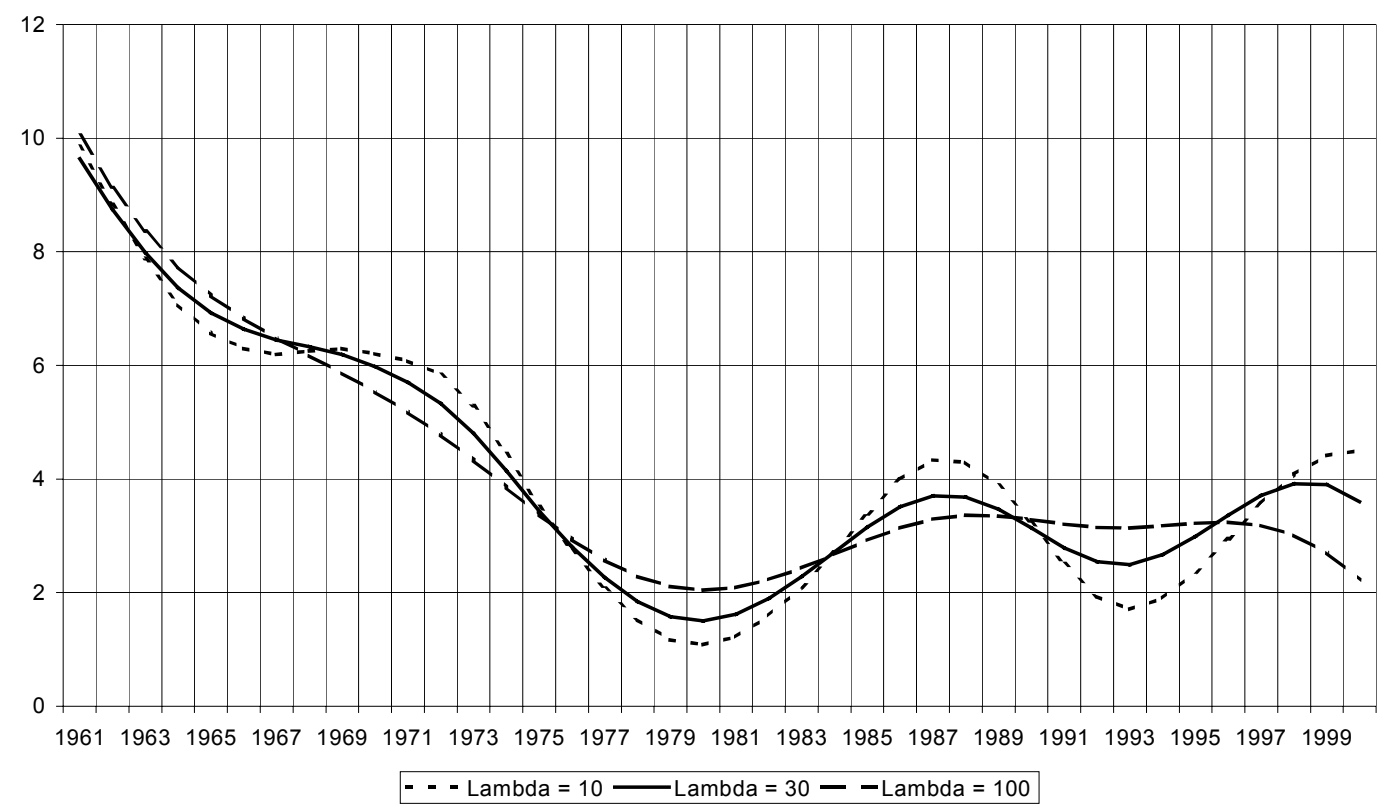

The second drawback concerns the underestimation of gaps. Unduly small deviations from trends can convey a biased picture in periods of high growth as they potentially suggest an overly positive assessment of fiscal policies, making it difficult to detect expansionary policies. In general, compression effects lead to an underestimation of the impact of automatic fiscal stabilisers.

The effect of the different values of $\lambda$ on the output gap is illustrated in Chart 3.7 below relating to Germany (this effect would be very similar for other EU countries). As expected, a higher value of $\lambda$ corresponds to larger gaps. 


\section{Chart 3.7}

Deviations from HP trends of real GDP for Germany (as a percentage of trend GDP), for different values of $\lambda$

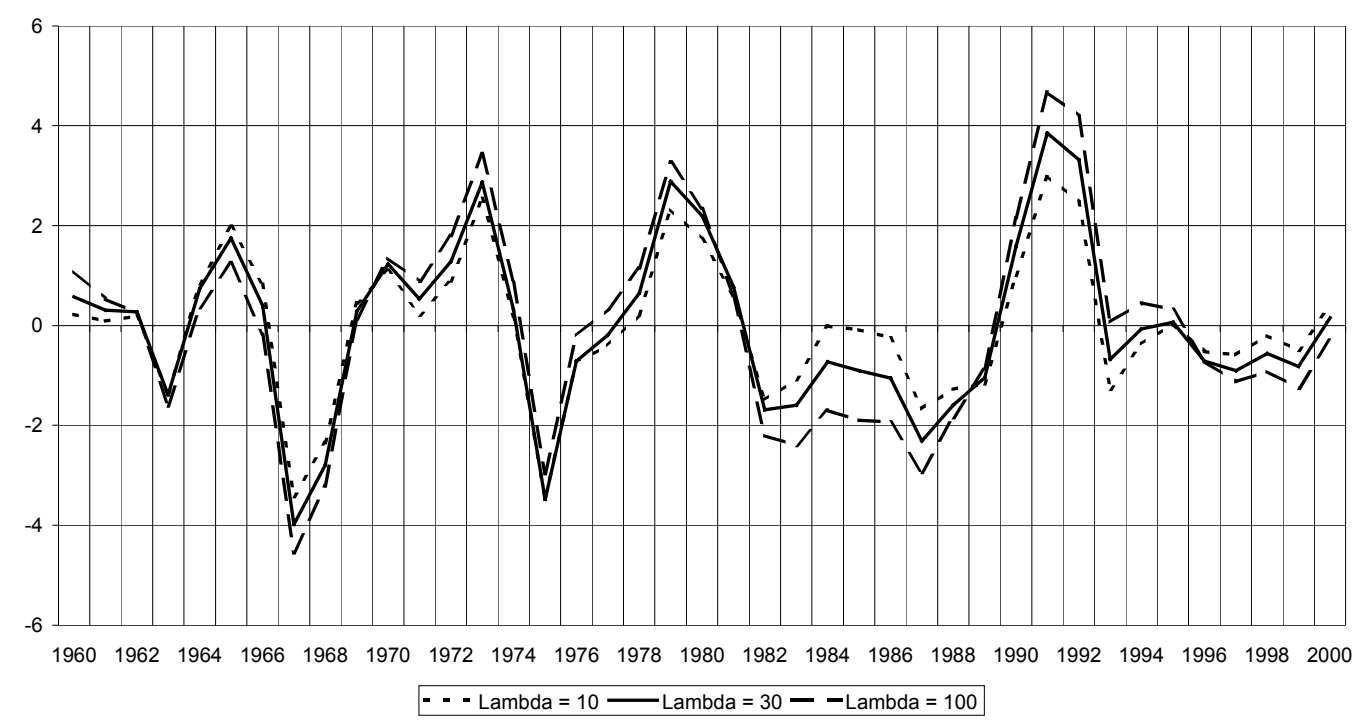

The costs of leakage effects

However, there are also policy costs related to erring on the side of unduly large gaps, as a consequence of overly large leakage effects. In particular, by overestimating gaps in periods of low growth, a deterioration in the underlying budgetary position may not be detected, thus increasing the risk of exceeding the 3 per cent deficit limit. In addition, the horizon over which gaps will average to zero may in this case exceed any realistic views about the length of the business cycle. This issue is especially relevant given the aim of a balanced budget over the "medium-term" as formulated in the Stability and Growth Pact (SGP), since the medium-term is interpreted as referring to the length of the business cycle. Adjusting budget balances with an HP-filter which incorporates large leakage effects softens this aim of the SGP, as applying such a filter would allow for excessively long periods over which the budget is supposed to balance. Hence, it could let the budget to remain in a deficit for long periods.

Besides this, large leakage effects may disregard actual changes in the growth rate of the trend component of the series due, for instance, to non-temporary jumps in productivity growth. This is undesirable from a policy point of view, since it amounts to an imperfect recognition that the benchmark against which budgetary outcomes are to be measured has changed. 


\subsubsection{Choice of the value for $\lambda$}

As discussed above, the appropriate value of $\lambda$ depends on the objectives of the analysis, which are relevant to define the critical length of the cycle and the trade-off between compression and leakage costs. However, neither of the criteria proposed in the statistical literature nor common empirical practice appear to give appropriate guidance to determine the trends of the macroeconomic variables for the cyclical adjustment of budget balances.

In this paper, lacking an adequate external reference, a specific criterion for the choice of $\lambda$, based also on the analysis of the preceding sub-section, is used. Specifically, the value of $\lambda$ is set so that compression effects do not exceed 10 per cent of the amplitude of cycles of up to 8 years. ${ }^{25}$

The choice of a critical length of 8 years is partly based on a common understanding of what currently represents an adequate upper limit for the length of business cycles (see e.g. the references in footnote 24). More importantly, as the critical length tends to correspond to the period over which the cyclical component of the budget approximately balances, the choice reflects what appears to be an appropriate horizon for medium-term fiscal analysis. Indeed, it attempts to avoid distortions in the analysis, as within that horizon corrections to the actual balances should be close to zero on average.

This critical length is not differentiated across countries, for three main reasons:

i) available evidence does not point to large differences in business cycle length across the European Union, and the lengths may have changed over the recent years;

ii) cyclical patterns are likely to converge even further in the future; and

iii) a common time span for fiscal analysis seems to be desirable.

The constraint on compression effects included in the criterion (that they do not exceed 10 per cent of the amplitude of cycles shorter than the critical length) represents an operational translation of the discussion in sub-section 3.3.2 of the relative costs of compression and leakage effects, taking into account the value set for the critical length. ${ }^{26}$ On the one hand, the discussion makes clear the overriding importance of including medium-term economic fluctuations almost entirely in the cyclical component. Otherwise, the benchmark macroeconomic environment against which government finances are assessed would be highly unstable, contradicting the very purpose of cyclically adjusting budget balances. On the other hand, it is argued that limited compression effects should be accepted, when they bring sizeable reductions of leakage effects. The main reason to avoid the latter is probably the need for prudence, since leakage effects entail the risk of not recognising a structural deterioration in the economy, which may lead to large deficits and a build-up of debt.

The criterion used in this paper has led to the choice of a value of $\lambda$ equal to 30 for annual data for all countries. This value lies between that advocated by the statistical literature and that used in the method currently followed by the European Commission - and appears to strike a satisfactory balance between the relative costs of compression and leakage effects. It implies that short cycles are included almost completely in the cyclical component, resulting in a relatively

25 As this criterion refers only to the so-called "frequency response function" of the filter, the resulting value of lambda does not vary across countries.

26 It also reflects the difficulty in defining an explicit weighting of the two effects. 
smooth profile of the trend component, but it also ensures that longer cycles only slightly affect the cyclical component.

Reducing $\lambda$ from 100 to 30 entails significant benefits in terms of less leakage effects. Using a $\lambda$ of 30 instead of 100 means, for instance, that the weight with which a 16-year cycle appears in the cyclical component falls from about 70 to $4 \mathrm{I}$ per cent. These benefits appear to be large compared to the costs related to the increase in compression effects, as the extent to which an 8year cycle appears in the trend rises only from about 3 to 9 per cent. A $\lambda$ of 30 therefore still guarantees that cycles of up to 8 years are almost entirely taken into account in gaps; this would not be the case for a $\lambda$ of 8 , where the weight assigned to the 8-year cycle in the cyclical component reaches only 73 per cent. ${ }^{27}$

However, the criterion recommended here is not without drawbacks. In particular, compression and leakage effects are measured only with reference to the weighting scheme of the filter (the frequency response function of the filter) without taking into account the properties of the time series being filtered. Consequently, the criterion does not directly refer to the actual contribution of cycles of different lengths to the variance of the estimated cyclical component. ${ }^{28}$ Although a criterion referring to the variance components of the estimated cyclical component would also be reasonable, its implementation would be more difficult and less transparent since the spectrum of every time series being filtered would need to be estimated.

27 Evidently, using $a \lambda$ of 30 instead of 8 has a cost in terms of leakages: in particular, 16-year cycles are included to a larger extent in the cyclical component (4I instead of 16 per cent).

28 In the case of real GDP, the share of the variance of the cyclical component which would be generated by cycles of more than eight years length is 0 per cent for the ideal filter but - due to leakage effects - typically amounts to about 50 per cent in the case of an HP-filter with a value of $\lambda$ of 30 . As a consequence of compression effects, only about 6 per cent of the total variance of the ideal cyclical component do not show up in the variance of the cyclical component as estimated with an HP-filter $(\lambda=30)$. If the compression effect is expressed in terms of variance shares and limited to 10 per cent, the resulting value of $\lambda$ would be typically around 16 (which would give rise to a leakage effect of some 43 per cent of the variance of the estimated cyclical component). 


\section{Cyclically adjusted balances and the sensitivity of the budget balance to the business cycle}

This chapter describes how the results obtained in chapters 2 and 3 can be combined to obtain cyclically adjusted budget balances and what are the main differences to other approaches. In addition, it deals with the overall sensitivity of the budget balance to fluctuations of GDP. The cyclically adjusted balances and the sensitivities calculated in this chapter are also compared with the results of other international institutions.

\section{I The calculation of cyclically adjusted balances}

The cyclically adjusted budget balances ( $C A B s$, expressed in nominal terms) are obtained by subtracting the cyclical component from the actual budget balance (B).

$$
C A B=B-B_{c}=B-\sum_{j} B_{c}^{j}
$$

with

$B=\sum_{j} B^{j}$

The cyclical component of each budget category, ${ }^{\mathrm{c}}{ }^{\mathrm{j}}$, is computed using the gap of the macroeconomic variable which is assumed to be directly related to it, and the relevant elasticity:

$B_{c}^{j}=B^{j^{*}} \cdot \varepsilon_{B^{j}, V^{j}} \cdot v_{c}^{j}$

where

$v_{c}^{j}$ is the gap of the corresponding macroeconomic variable $\mathrm{V}$ in real terms $\mathrm{V}_{\mathrm{c}}^{\mathrm{j}}=\left(\mathrm{V}^{\mathrm{j}}-\mathrm{V}^{\mathrm{j}^{*}}\right) / \mathrm{V}^{\mathrm{j}^{*}}$

$\varepsilon_{B^{j}, V^{j}}$ denotes the elasticity of $B^{j}$ relative to the corresponding variable ${ }^{29} V^{j}$

$\mathrm{B}^{\mathrm{j}^{*}}$ denotes the trend of $\mathrm{B}^{\mathrm{j}}$, which can be approximated by the actual value of $\mathrm{B}^{\mathrm{j}}$.

After substituting (4.2) into (4.I) and replacing $\mathrm{B}^{\mathrm{j}^{*}}$ by $\mathrm{B}^{\mathrm{i}}$, the cyclically adjusted budget balance in year $t$ becomes:

$C A B_{t}=B_{t}-\sum_{j} B_{t}^{j} \cdot \varepsilon_{B^{j}, V^{j}} \cdot v_{c, t}^{j}$

Equation (4.3) reflects the impact of fluctuations in macroeconomic variables on the budget balance. It establishes direct links between budget categories and the associated macroeconomic bases. Therefore, it does not allow for a simple interpretation in terms of responses to

29 It is assumed that the elasticity of Bj with respect to the macroeconomic base in real terms is the same as the elasticity with respect to the nominal macroeconomic base. 
fluctuations in GDP. That would only be possible if the gaps of all macroeconomic variables were always equal to the output gap.

\subsection{Comparison with existing methods}

In this section the method opted for is compared with some alternatives. As was explained before, these other approaches are based on the assumption of a constant elasticity of revenue and expenditure bases relative to GDP. In order to compare them with the method used in this paper, approximated formulas capturing the main characteristics of each approach are presented in Box 4.1 and discussed below.

\section{Box 4.I}

\section{Different methods to calculate the cyclical component of the budget balance ${ }^{30}$}

1) Simplified approach

$$
B_{c, t} / Y_{t}=\sigma_{B} \cdot y_{r, c, t}
$$

with $\sigma_{B}=$ the sensitivity of the budget balance to the cycle. The budget balance and its components are expressed as a percentage of GDP

2) European Commission

$$
B_{c, t} / Y_{t}=\frac{R_{t}}{Y_{t}} \varepsilon_{R, Y_{r}} y_{r, c, t}-\overline{\left(\frac{X^{U}}{Y}\right)} \varepsilon_{X^{U}, Y_{r}} y_{r, c, t},
$$

whereby $\varepsilon_{R, Y_{r}}$ is the output elasticity of revenue and $\left(\mathrm{X}^{\mathrm{U}} / \mathrm{Y}\right)$ denotes the "average between 1970 and 1994".

3) $\mathrm{OECD} \quad \mathrm{B}_{\mathrm{c}, \mathrm{t}} / \mathrm{Y}_{\mathrm{t}}=\sum_{\mathrm{j}} \frac{\mathrm{R}_{\mathrm{t}}^{\mathrm{j}}}{\mathrm{Y}_{\mathrm{t}}} \varepsilon_{\mathrm{R}^{\mathrm{j}}, \mathrm{V}^{\mathrm{j}}} \varepsilon_{\mathrm{V}^{\mathrm{j}, Y_{\mathrm{r}}}} \mathrm{y}_{\mathrm{r}, \mathrm{c}, \mathrm{t}}-\frac{\mathrm{R}_{\mathrm{t}}^{\mathrm{U}}}{\mathrm{Y}_{\mathrm{t}}} \varepsilon_{\mathrm{R}^{\mathrm{U}}, \mathrm{U}} \varepsilon_{\mathrm{U}, \mathrm{Y}_{\mathrm{r}}} \mathrm{y}_{\mathrm{r}, \mathrm{c}, \mathrm{t}}$

$$
\text { with } \varepsilon_{R^{U}, U}=1
$$

4) method followed in this paper

$$
B_{c, t} / Y_{t}=\sum_{j} \frac{R_{t}^{j}}{Y_{t}} \varepsilon_{R^{j}, V^{j}} v_{c, t}^{j}-\frac{X_{t}^{U}}{Y_{t}} \varepsilon_{X^{U}, U} u_{c, t}-\frac{X_{t}^{G}}{Y} \varepsilon_{\omega_{g}, \omega_{p}} \omega_{p, c, t}
$$

with $\mathrm{V}^{\mathrm{j}}$ any macroeconomic base variable in real terms, $\mathrm{u}$ number of unemployed persons and real compensation of employees.

See Annex A1 for more detailed explanations of the notations.

\subsection{A simplified approach}

A very rough approach is to use a constant overall sensitivity, $\sigma_{B}$, of the budget balance to fluctuations of real GDP. This sensitivity might, for instance, be derived from a regression of the budget balance on the output gap. The cyclical component of the budget balance, as a percentage of GDP, is then the product of the output gap and the overall sensitivity. 


\subsubsection{The European Commission approach}

For longer periods, it is necessary to make allowance for such factors as the growth of the public sector, since the sensitivity of the general government balance does not only depend on the elasticities of revenue and unemployment outlays but also on their shares in GDP. In the case of revenue, the method adopted by the European Commission makes explicit allowance for this, using the actual yearly revenue share of GDP. This implies that the output gap is multiplied by a time-specific factor (European Commission, 1995). By contrast, the cyclical component of expenditure is calculated by multiplying the output gap by a constant parameter estimated over a long period. This parameter is the product of the inverse Okun coefficient (which relates the unemployment rate to the output gap) and the marginal budgetary cost of an increase in the unemployment rate.

\subsubsection{The OECD approach}

As the elasticities of the various categories relative to GDP may differ significantly, shifts in the composition of government revenues and expenditure may also lead to a bias in the computation of cyclical budget balances. In order to overcome this problem, the OECD calculates cyclical components for four individual revenue categories ${ }^{31}$ (contrary to the European Commission which merges the individual elasticities into one weighted average estimate constant over the entire period). On the expenditure side, unemployment-related outlays are corrected for the cycle taking into account changes over time in the trend of the unemployment rate. ${ }^{32}$

\subsubsection{The approach followed in the paper}

The approach taken in this paper follows the OECD in allowing for changes in the relative weights of different budget categories. In addition, it tries however to capture the impact on the budget of changes in the composition of aggregate demand and of distribution of income. These effects derive from the fact that tax rates differ across tax bases and that the macroeconomic bases for government revenue and expenditure might be in different phases of the cycle or exhibit fluctuations of different magnitudes.

Both the OECD and the European Commission do not account for composition effects as they assume that cyclical fluctuations in GDP have a constant impact on the budget balance. However, it should be pointed out that their estimates of the elasticity of budget components with respect to GDP - explicitly (OECD) or implicitly (European Commission) - are not based on the assumption of a proportional response of tax bases to a change in GDP. They incorporate instead an "average composition effect", as they include the average reactions observed in the past of the macroeconomic bases to changes in GDP. Obviously, these average reactions, based on past comovements, are generally not representative for individual years. In the approach followed in this paper the cyclical adjustment of fiscal balances is instead based upon the actual evolution of the macroeconomic bases. 


\subsection{Cyclically adjusted balances and cyclical components ${ }^{33}$}

\subsection{Results}

The analysis of the large fiscal efforts undertaken in the run-up to EMU and in the following years can be enhanced by taking into consideration cyclically adjusted balances.

Limiting the analysis at the euro area, for which the results presented here start from 1995, the overall impact of the cycle on the budgets is estimated to be negative until 1998, reaching a peak in 1997 (when it increases deficits, on average, by 0.7 per cent of GDP). The impact is negligible in 1999 and becomes positive in 2000 (see Table 4.I).

These results tend to confirm that the economic environment was relatively unfavorable in the run-up to EMU, leading to pro-cyclical fiscal policies in many EU countries, but, in line with the assessment of the European Commission, tend to downsize the level of the negative impact of the cycle on the budgets compared to the estimates published by the IMF and the OECD.

In terms of changes, the results point out that to gauge the fiscal efforts in the euro area countries between 1995 and 1997, it is necessary to add to the 1.7 per cent of GDP improvement registered in actual primary balances around 0.3 per cent of GDP of measures which offset the impact of the cyclical worsening (see Table 4.2).

From 1998 to 2000, the overall improvement in the cyclical component of the aggregated euro area budget is of similar magnitude of that estimated over the same period by the European Commission, the IMF and the OECD ( 0.5 per cent of GDP against, respectively, $0.4,0.6$ and 0.6 percentage point). However, within the period, the results in the paper differ from those of the international institutions, as they take into account the composition effects which positively affected budgets in the first year and partly reversed in 2000 (see sub-section 4.3.3). In particular, in this paper the estimated improvement of the cyclical component for 1999 is 0.3 per cent of GDP against, respectively, $0,0.2$ and 0.1 percentage point, for the aforementioned institutions, while in 2000 it is 0.2 per cent of GDP against, respectively, $0.4,0.4$ and 0.5 percentage point (see Annex 7 Table A9).

Table 4.I

Cyclical components of the budget balances in the EU, 1990-2000 (as a percentage of GDP)

\begin{tabular}{|c|c|c|c|c|c|c|c|c|c|c|c|c|c|c|c|c|c|}
\hline & $\begin{array}{l}\text { Bel- } \\
\text { gium }\end{array}$ & $\begin{array}{l}\text { Ger- } \\
\text { many }\end{array}$ & $\begin{array}{l}\text { Greec } \\
\mathrm{e}\end{array}$ & $\begin{array}{l}\text { Spain } \\
*\end{array}$ & France & $\begin{array}{l}\text { Irelan } \\
\text { d }\end{array}$ & Italy & $\begin{array}{l}\text { Luxe } \\
\text { m- } \\
\text { bourg }\end{array}$ & $\begin{array}{l}\text { Nether } \\
\text {-lands }\end{array}$ & $\begin{array}{l}\text { Austri } \\
\text { a }\end{array}$ & $\begin{array}{l}\text { Portu- } \\
\text { gal }\end{array}$ & $\begin{array}{l}\text { Fin- } \\
\text { land }\end{array}$ & $\begin{array}{l}\text { euro } \\
\text { area }\end{array}$ & $\begin{array}{l}\text { Den- } \\
\text { mark }\end{array}$ & $\begin{array}{l}\text { Swe- } \\
\text { den }\end{array}$ & UK & EU 15 \\
\hline 1990 & 1.3 & NA & 1.1 & NA & 1.1 & 0.5 & 0.6 & 0.5 & 1.2 & 0.6 & NA & 4.0 & NA & -0.2 & NA & 1.2 & NA \\
\hline 1991 & 1.2 & 1.0 & 0.4 & NA & 1.0 & -0.1 & 1.0 & 1.1 & 1.5 & 0.9 & NA & 1.6 & 1.0 & -0.5 & NA & 0.1 & 0.8 \\
\hline 1992 & 1.2 & 1.2 & 0.2 & NA & 0.8 & -0.4 & 1.0 & 2.0 & 1.3 & 0.9 & NA & -2.6 & 0.9 & -0.6 & NA & -0.6 & 0.6 \\
\hline 1993 & 0.0 & -0.2 & -0.7 & NA & -0.2 & -0.6 & -0.2 & -0.1 & 0.2 & 0.2 & NA & -6.4 & -0.3 & -1.8 & -4.5 & -0.8 & -0.5 \\
\hline 1994 & -0.2 & -0.4 & -0.7 & NA & -0.5 & -0.8 & -0.6 & 0.3 & -1.1 & -0.2 & NA & -5.3 & -0.6 & -0.8 & -2.9 & -0.3 & -0.6 \\
\hline 1995 & 0.0 & 0.1 & -0.4 & -0.8 & -0.3 & -1.0 & -0.8 & -0.3 & -1.5 & -0.2 & -0.6 & -2.3 & -0.4 & -0.3 & -1.5 & -0.5 & -0.5 \\
\hline 1996 & -0.8 & -0.3 & -0.5 & -0.9 & -0.7 & -0.9 & -0.7 & -0.9 & -1.3 & -0.5 & -0.6 & -1.2 & -0.6 & -0.2 & -1.1 & -0.3 & -0.6 \\
\hline 1997 & -0.7 & -0.8 & 0.0 & -0.6 & -0.9 & -0.5 & -0.4 & -1.0 & -0.8 & -0.4 & -0.9 & 0.0 & -0.7 & 0.5 & -1.3 & 0.1 & -0.6 \\
\hline 1998 & -0.3 & -0.4 & 0.2 & -0.2 & -0.6 & 0.3 & 0.0 & -1.0 & -0.1 & -0.1 & 0.0 & 1.2 & -0.3 & 0.9 & -0.2 & 0.3 & -0.2 \\
\hline 1999 & -0.4 & 0.0 & 0.1 & 0.2 & -0.2 & 0.5 & 0.0 & -0.5 & 0.3 & 0.0 & 0.6 & 1.3 & 0.0 & 0.6 & 0.7 & 0.3 & 0.1 \\
\hline 2000 & 0.0 & 0.0 & 0.0 & 0.5 & 0.1 & 0.7 & 0.1 & 0.1 & 0.6 & 0.1 & 0.6 & 1.2 & 0.2 & 0.3 & 0.9 & 0.0 & 0.2 \\
\hline
\end{tabular}

Note: Estimates for the euro area and EU15 aggregates exclude Spain and Portugal before 1995, and Sweden before 1993. 
Table 4.2

Primary cyclically adjusted budget balances in the EU countries, 1990-2000 (as a percentage of GDP)

\begin{tabular}{|c|c|c|c|c|c|c|c|c|c|c|c|c|c|c|c|c|c|}
\hline & $\begin{array}{l}\text { Bel- } \\
\text { gium }\end{array}$ & $\begin{array}{l}\text { Ger- } \\
\text { many }\end{array}$ & Greece & $\begin{array}{l}\text { Spain } \\
*\end{array}$ & France & Ireland & Italy & $\begin{array}{l}\begin{array}{l}\text { Luxem } \\
\text {-bourg }\end{array} \\
\end{array}$ & $\begin{array}{l}\text { Nether } \\
\text {-lands }\end{array}$ & $\begin{array}{l}\begin{array}{l}\text { Aus- } \\
\text { tria }\end{array} \\
\end{array}$ & $\begin{array}{l}\text { Portu- } \\
\text { gal }\end{array}$ & $\begin{array}{l}\text { Fin- } \\
\text { land }\end{array}$ & \begin{tabular}{|l|} 
euro \\
area
\end{tabular} & $\begin{array}{l}\text { Den- } \\
\text { mark }\end{array}$ & \begin{tabular}{|l}
$\begin{array}{l}\text { Swe- } \\
\text { den }\end{array}$ \\
\end{tabular} & UK & EU 15 \\
\hline 1990 & 3.9 & NA & -7.7 & NA & 0.2 & 4.5 & -1.8 & 4.6 & -0.4 & 1.0 & NA & 2.7 & NA & 6.5 & NA & 1.0 & NA \\
\hline 1991 & 2.8 & -1.1 & -3.4 & NA & -0.1 & 4.9 & -0.9 & 0.6 & 2.1 & 0.3 & NA & -0.8 & -0.3 & 5.3 & NA & 0.3 & -0.1 \\
\hline 1992 & 2.0 & -0.5 & -2.3 & NA & -1.6 & 4.6 & 1.0 & 0.9 & 1.2 & 1.4 & NA & -0.4 & -0.1 & 5.0 & NA & -2.8 & -0.5 \\
\hline 1993 & 3.8 & 0.4 & -1.5 & NA & -2.4 & 4.5 & 2.9 & 5.5 & 3.1 & -0.1 & NA & 3.6 & 0.7 & 6.2 & -6.5 & -4.1 & -0.3 \\
\hline 1994 & 4.8 & 1.3 & 3.4 & NA & -1.9 & 4.9 & 2.7 & 4.7 & 3.3 & -0.7 & NA & 3.8 & 1.2 & 5.0 & -6.0 & -3.1 & 0.3 \\
\hline 1995 & 5.0 & 0.2 & 1.4 & -0.6 & -1.4 & 4.1 & 4.7 & 3.9 & 3.2 & -0.6 & 2.0 & 2.6 & 1.1 & 4.4 & -3.6 & -1.6 & 0.6 \\
\hline 1996 & 5.9 & 0.5 & 3.6 & 1.3 & 0.6 & 5.4 & 5.1 & 3.8 & 5.0 & 0.8 & 2.0 & 2.3 & 2.1 & 5.3 & 0.9 & -0.4 & 1.7 \\
\hline 1997 & 6.9 & 1.7 & 4.2 & 2.2 & 1.1 & 5.5 & 7.0 & 5.0 & 4.9 & 2.6 & 2.5 & 2.8 & 3.1 & 5.6 & 2.9 & 1.6 & 2.9 \\
\hline 1998 & 7.1 & 1.9 & 5.2 & 1.9 & 1.5 & 5.2 & 5.2 & 4.5 & 4.3 & 1.7 & 1.1 & 3.6 & 2.9 & 5.5 & 5.1 & 3.8 & 3.1 \\
\hline 1999 & 6.9 & 2.1 & 5.6 & 2.2 & 2.0 & 5.9 & 5.0 & 5.5 & 5.1 & 1.4 & 0.5 & 3.6 & 3.1 & 7.1 & 3.6 & 4.0 & 3.3 \\
\hline 2000 & 7.0 & 2.3 & 6.3 & 2.5 & 1.8 & 5.9 & 4.8 & 5.5 & 4.9 & 1.9 & 0.8 & 8.2 & 3.2 & 6.3 & 5.4 & 4.9 & 3.6 \\
\hline
\end{tabular}

\subsubsection{Sensitivity analysis on the value of $\lambda$}

As explained in chapter 3 , the choice of the value of $\lambda$ has a significant impact on the estimates of the deviations from trend of tax and expenditure bases and through this channel affects the assessment of the cyclical component of budget balances. A sensitivity analysis is presented below, where the estimates of the cyclical component for the euro area and its six largest countries (based on a value of 30 for $\lambda$ ) are compared with those resulting from applying a value of 100 for $\lambda$, used by the European Commission (see Chart 4.I). The difference between the estimates is generally smaller than 0.4 per cent of GDP. Conclusions are very similar when comparing the estimates to results obtained with a value of 10 for $\lambda$, advocated by the relevant recent literature (cf. Section 3.4). The impact on the assessment of the orientation of fiscal policy, which takes into account the changes (and not the levels) of (primary) cyclically adjusted budget balances is even smaller.

In the case of Finland and Sweden, the results are nevertheless highly sensitive to the chosen smoothing parameter value (see Annex 9). This concerns particularly the results in terms of levels in the past years, since the estimates of total cyclical components have deviated by as much as $11 / 2-$ 2 per cent of GDP from each other in some years. The profiles have also differed significantly from each other and the changes in the total cyclical components have sometimes even had different signs. The differences mainly owe to the severe economic recession these countries faced in the early 1990s. 
Chart 4.I

Comparison of cyclical components obtained with $\lambda=10,30$ and 100 (as a percentage of GDP)
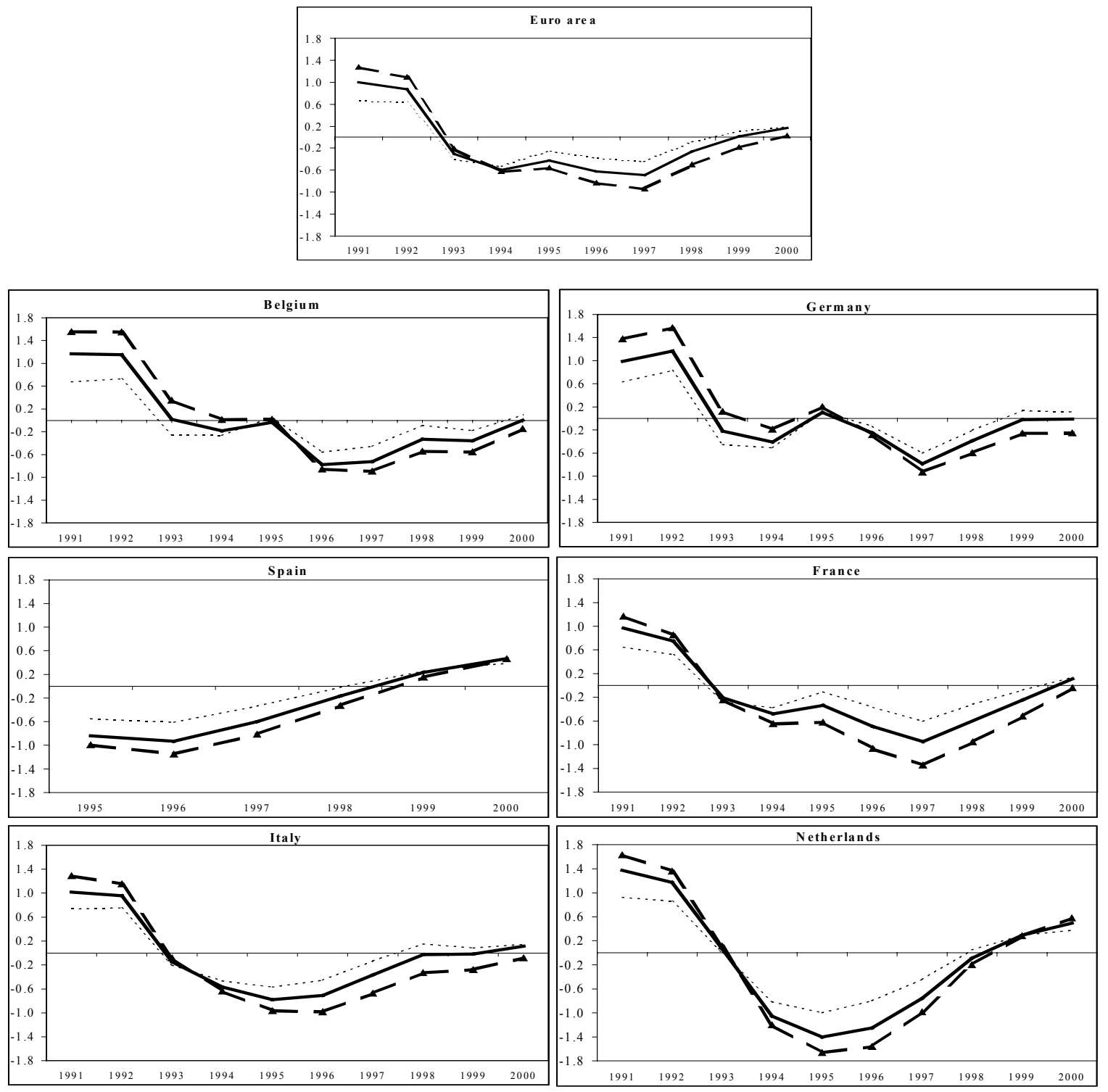

Note: The cyclical component estimated with a lambda of 30 retained in the method (continuous line) is compared with the cyclical components estimated with a lambda of 10 (light broken line) and 100 (marked broken line). 


\subsubsection{Composition effects}

Chart 4.2 compares the estimated cyclical components of the budget balances with estimates obtained by considering a constant composition of output for the euro area and the largest six countries. It appears that composition effects stemming from unbalanced growth have been rather small for the euro area as a whole, with the exception of 1999, when they amounted to 0.3 per cent of GDP. However, they can be particularly important at the country level. Chart 4.2 reveals that for Belgium, Italy and the Netherlands, composition effects have been most noticeable, whilst for Spain and France they have been less significant.

An extreme example of composition effects at work can be found in Italy in 1995. In that year, GDP increased by 2.9 per cent, significantly above trend. Accordingly, the cyclical component estimated on the basis of the output gap improved from a deficit of 0.5 per cent of GDP in 1994 to a surplus of 0.1 in 1995. However, the strong growth in GDP was mainly led by export and investment, components of aggregated demand which are VAT exempt; the dynamic of wages, characterised by high effective tax rates, was negative in real terms; employment reached the bottom level of the decade; the number of unemployed increased. On the basis of the disaggregated approach, which takes into account these composition shifts, the cyclical component worsened from a deficit of 0.6 per cent of GDP to 0.8 per cent. 


\section{Chart 4.2}

Comparison of cyclical components showing composition effects (as a percentage of GDP)
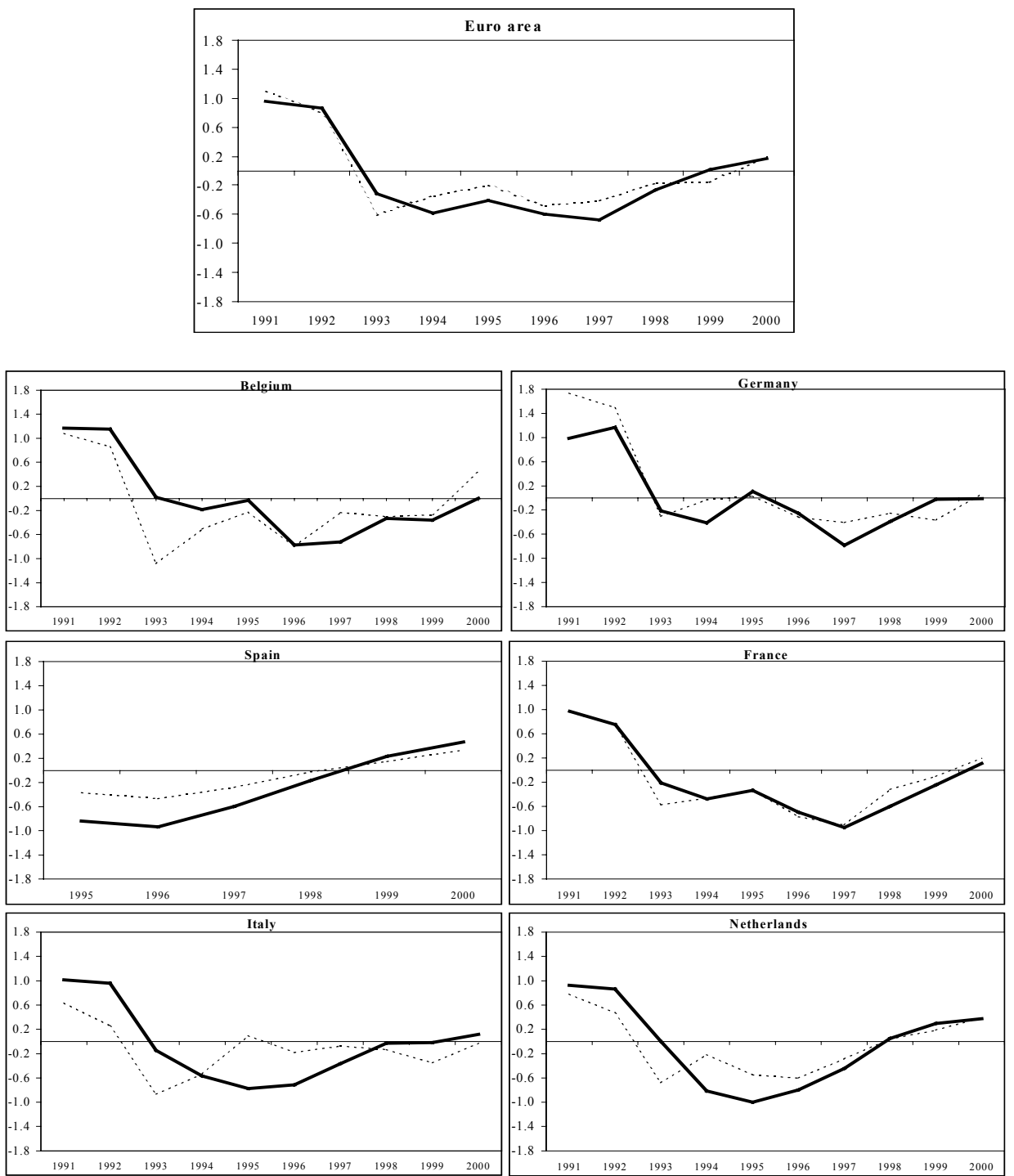

Note: The cyclical component estimated with the current approach (continuous line) is compared with the cyclical component estimated with an aggregated approach (broken line). In the latter, the budget elasticities to the various macroeconomic variables are replaced by the budgetary sensitivities to GDP itself, and the cyclical components of the macroeconomic variables are replaced by the output gap. For the euro area aggregate, over the period 1991-94, estimates for Spain and Portugal are missing. This represents 13 per cent of the euro area aggregate. Consequently, the results before 1995 should be interpreted cautiously. 


\subsubsection{Sensitivity analysis on the extension of the forecasts}

In order to solve the end-point problem of the HP-filter (see Section 3.3), the five macroeconomic variables are extended to 2007 before applying the HP-filter, using countryspecific forecasts. ${ }^{34}$ To assess the sensitivity of the estimates with regard to the extension used beyond 2000, a simple sensitivity analysis is conducted on the cyclical component of the budget balance computed using the aggregated approach (i.e. applying the budget sensitivity to the output gap - see footnote to Chart 4.3). As can be seen in Chart 4.3 for the euro area, the estimates are not very sensitive to the method of extension used in this exercise. This result holds also at the country level. The way the macroeconomic variables have been extended at the country level is usually close to a scenario of going back to past trends, so that the respective lines for the reference extension and the first scenario on Chart 4.3 are practically confounded for the euro area.

\section{Chart $\mathbf{4 . 3}$}

Sensitivity analysis on the extension of the forecasts of the macroeconomic variables (using the cyclical component computed with the aggregated approach)

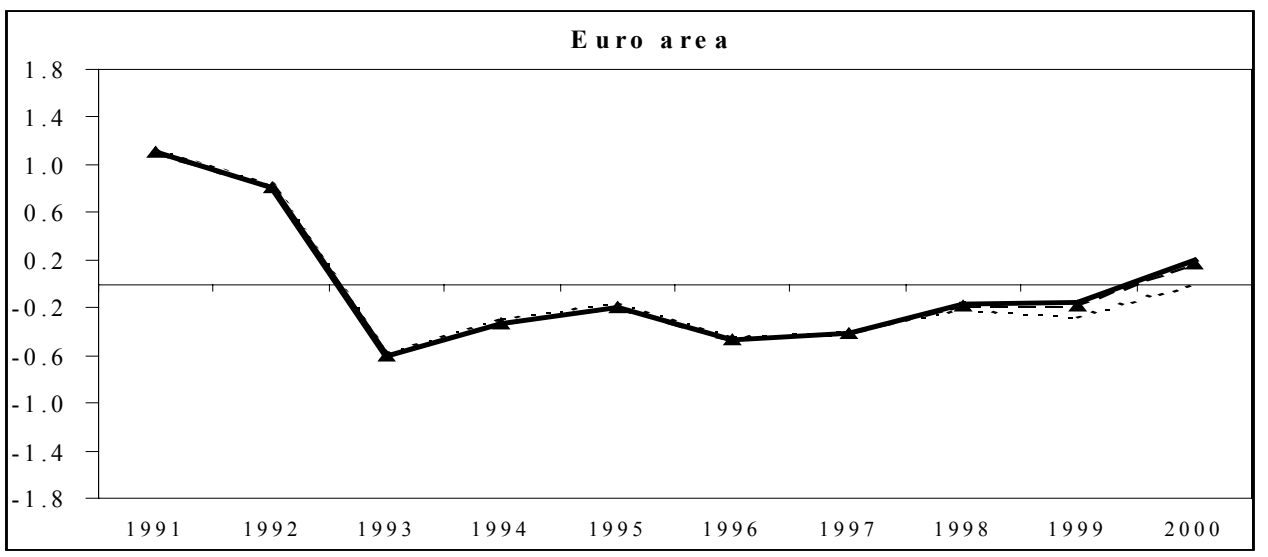

Note: The cyclical component computed with the aggregated approach (using the output gap) and the retained forecast extension (continuous line) is compared with cyclical components obtained with two alternative scenarios of forecast extension. In both scenarios, the level of real GDP is extrapolated by growth rates such that the trend value of the growth rate is reached in 2007. The growth rates for the period 20012007 are linearly interpolated between the rate for 2000 and the targeted trend growth rate in 2007. The scenarios differ by the targeted trend growth rate in 2007. In scenario 1 (marked broken line), the targeted trend growth rate in 2007 equals the average rate of growth between 1986 and 2000 (i.e. the last 15 years known). In scenario 2 (light broken line), the targeted trend growth rate in 2007 equals the average rate of growth between 1986 and 2000 plus 1 percentage point.

34 ARIMA forecasts would consitute an alternative, mechanical method to extend the macroeconomic series beyond the forecasting period of three years. ARIMA forecasts are adopted by the European Commission in this way. Both methods have their pros and cons. ARIMA forecasts are standardised and can be easily reproduced. They exploit, however, only the limited set of information contained in the times series up to the end of the forecast period. As far as reliable additional information concerning the period beyond the forecast exist, they can in principle be better exploited by country specific expert projections. 


\subsection{Sensitivity of the budget balance to the business cycle}

The sensitivity of the budget balance to output measures the change of the budget balance (as a ratio to GDP) arising from a I per cent change in real GDP.

$$
\sigma_{B}=\frac{\Delta(B / Y)}{\Delta Y_{r} / Y_{r}}
$$

This aggregate measure is also referred to as a 'semi-elasticity' since the numerator is an absolute rather than a relative change. By definition, the budget sensitivity does not take into account changes in the composition of output or in the distribution of income. Any budgetary sensitivity can therefore only be a crude indicator. However, the need was felt to translate into a synthetic indicator of the cyclical responsiveness of the budget, independent from the way the output gap is measured, the different assumptions used in the paper with respect to fiscal elasticities and to the definition of cyclical budget items. This allowed us to assess the overall impact of the differences between these assumptions and those adopted by the OECD.

Expanding the sensitivity as defined in (4.4a) yields ${ }^{35}$

$$
\sigma_{\mathrm{B}}=\frac{\mathrm{R}}{\mathrm{Y}}\left(\varepsilon_{\mathrm{R}, \mathrm{Y}_{\mathrm{r}}}-1\right)-\frac{\mathrm{X}}{\mathrm{Y}}\left(\varepsilon_{\mathrm{X}, \mathrm{Y}_{\mathrm{r}}}-1\right)
$$

Alternatively, the sensitivity can also be defined as the cyclical component of the balance to GDP ratio arising from a I per cent gap of real output. ${ }^{36}$ Decomposing overall revenue and expenditure into the respective budgetary items leads to an even more elaborate form ${ }^{37}$ of $\sigma_{B}$ :

$\sigma_{B}=\sum_{j} \frac{R^{j}}{Y} \varepsilon_{R^{j}, Y_{r}}-\sum_{j} \frac{X^{j}}{Y} \varepsilon_{X^{j}, Y_{r}}-\frac{B}{Y}$

Equation (4.4c) shows that under the simplifying assumptions made here, the sensitivity depends on the output elasticities and GDP-shares of all individual budget categories.

In the European Commission approach the elasticities are estimated directly whereas in the OECD approach they are the product of the elasticities of the budgetary items with respect to their macroeconomic bases $\left(\varepsilon_{B^{j}, V^{j}}\right)$ and the elasticities of these macroeconomic bases with respect to output $\left(\varepsilon_{B^{j}, Y_{r}}\right)$ (see Section 4.2). Since in this paper the cyclical deviations from trend of macroeconomic bases are directly estimated, it is not necessary to define $\varepsilon_{B^{j}, Y_{r}}$ to cyclically adjust fiscal variables. The elasticities of macroeconomic bases need to be computed only to obtain a measure for the aggregated budget sensitivity.

35 Refer to Annex A.4 for a detailed derivation.

36 This alternative definition of $\widetilde{\sigma}_{\mathrm{B}}=\mathrm{b}_{\mathrm{c}} / \mathrm{y}_{\mathrm{r}, \mathrm{c}}$ would amount to approximately the same result: $\widetilde{\sigma}_{\mathrm{B}} \approx \sigma_{\mathrm{B}}$.

37 The right hand side of (4.4c) shows that the overall sensitivity can also be derived by summing only the contributions of budget items with a non-zero elasticity, provided that the result is corrected by subtracting the balance. This latter correction, however, is not made by most international institutions. The sensitivities reported for individual countries by the European Commission, for instance, are based only on the summation terms. As long as deficit ratios are small the bias implied is small. 
The Sensitivity can be derived in different ways, depending on the design of the change in the macroeconomic environment (corresponding to a change of I per cent in output) deemed appropriate. One possibility is to estimate the co-movements between macroeconomic bases and GDP observed in the past (as, for instance, the OECD does). The sensitivities derived here are based, instead, upon a simple, stylised scenario which is convenient for shock analysis in a harmonised way. On the demand side of GDP, real public consumption and real public investment, and on the distribution side of GDP, real public wages are assumed constant. This implies that the output elasticities of private-sector GDP components are generally larger than I in order to obey adding-up restrictions of the national accounts. The ratios by which the I per cent GDP shock is mapped onto the private sector components is generally inversely related to the private sector's share in GDP.

Table 4.3

Sensitivities of the budget balances in the EU countries in 1999

\begin{tabular}{|c|c|c|c|c|c|}
\hline & \multicolumn{5}{|c|}{ Budgetary sensitivities 1) } \\
\hline & \multirow[t]{2}{*}{ Our approach } & \multirow[t]{2}{*}{ OECD } & \multicolumn{2}{|c|}{$\begin{array}{l}\text { Difference with respect to OECD estimates } \\
\text { 2) }\end{array}$} & \multirow[t]{2}{*}{\begin{tabular}{|l} 
European \\
Commission 4)
\end{tabular}} \\
\hline & & & Total & $\begin{array}{l}\text { Difference due to } \\
\text { macroeconomic } \\
\text { elasticities 3) }\end{array}$ & \\
\hline Belgium & 0.56 & 0.61 & -0.05 & 0.00 & 0.65 \\
\hline Germany 5), 6) & 0.45 & 0.51 & -0.06 & 0.10 & 0.50 \\
\hline Greece & 0.38 & 0.44 & -0.06 & 0.00 & 0.35 \\
\hline Spain & 0.40 & 0.40 & 0.00 & 0.02 & 0.40 \\
\hline France & 0.53 & 0.42 & 0.11 & 0.18 & 0.45 \\
\hline Ireland & 0.42 & 0.31 & 0.11 & 0.16 & 0.40 \\
\hline Italy 6) & 0.48 & 0.48 & 0.00 & 0.10 & 0.40 \\
\hline Luxembourg & 0.33 & NA & NA & NA & 0.60 \\
\hline The Netherlands & 0.69 & 0.64 & 0.05 & 0.20 & 0.85 \\
\hline Austria & 0.47 & 0.31 & 0.16 & 0.16 & 0.30 \\
\hline Portugal & 0.50 & 0.39 & 0.11 & 0.18 & 0.30 \\
\hline Finland & 0.55 & 0.64 & -0.09 & -0.01 & 0.65 \\
\hline euro area & 0.49 & 0.48 & 0.01 & 0.11 & 0.48 \\
\hline Denmark & 0.67 & 0.75 & -0.08 & 0.10 & 0.85 \\
\hline Sweden & 0.75 & 0.68 & 0.07 & 0.11 & 0.80 \\
\hline United Kingdom & 0.65 & 0.50 & 0.15 & 0.15 & 0.45 \\
\hline EU 15 & 0.53 & 0.49 & 0.03 & 0.12 & 0.50 \\
\hline
\end{tabular}

Notes:

1) The sensitivity is the change in the budget balance as a percentage of GDP in response to a 1\% change in GDP. The latter is obtained via a calibrated shock on all private sector components of the same magnitude, so that the total shock on GDP adds up to $1 \%$. Results are based on budgetary weights for 1999. Averages for the euro area and the EU are computed by excluding the missing estimates. Aggregates for the OECD and the European Commission figures are computed using own weights.

2) OECD website http://www.oecd.org/eco/Sources-and-Methods/structural_budget_calculation.htm. Note that these estimates have been slightly revised compared to the ones published in van den Noord (2000).

Interpretation of the OECD estimates: change in the budget balance as a percentage of GDP for a 1\% change in the output gap.

3) The part of the difference due to macroeconomic elasticities is equal to the difference between the estimates presented in this paper and results obtained by replacing the calibrated output elasticities of the macroeconomic bases by the respective elasticities of the OECD. These OECD estimates are documented in van den Noord (2000).

4) Source: Public Finances in EMU - 2000, Report of the DG II, European Commission, 24 May 2000.

5) In Germany and Austria, cyclical revenue in the contribution to the public pension system are cancelled out by cyclical expenditure on pensions as a consequence of an institutionalised, automatic adjustment of contribution rates. In Germany, without this specific factor, the sensitivity estimate would be 0.52 instead of 0.45 . It would be 0.58 instead of 0.47 in Austria.

6) In Germany and Italy, elasticities of corporate taxes have been estimated with respect to lagged bases. The total sensitivity is obtained by summing the elasticities with respect to different years.

The sensitivities derived here (see Table 4.3) are generally in a range of $0.4-0.6$, with higher values for the Netherlands, Denmark, Sweden and the United Kingdom. They are on average very close to the estimates published recently by the OECD. 
Finally, it should be stressed that these sensitivity estimates are based upon a stylised shock scenario which may not be the most likely one. If these estimates were to be used to determine budgetary safety margins, possibly a specific kind of shock may have to be considered, basing the selection on relative likelihood. Alternatively, a cautious approach may lead to consider a value of the sensitivity related to a particularly unfavourable composition of the shock. 


\section{Conclusions and further developments}

The cyclical adjustment of budget balances is a useful tool for assessing fiscal policies in the euro area and the EU, especially in the framework of the Stability and Growth Pact. The method proposed in this paper has some advantages when compared with the other approaches. In particular, it accounts for composition effects stemming from unbalanced growth. Moreover, it is based on a more precise selection of the budget items to be cyclically adjusted and treats individual government revenue and expenditure items in a more consistent way.

The method is not innovative with respect to the approach to determine the baseline macroeconomic environment. Following the European Commission, the Hodrick Prescott filter, which is widely used to compute the trend of macroeconomic variables, was chosen. Together with other statistical methods, it has the advantage of determining cyclical components which strictly balance over the estimation period and, given an appropriate value for the smoothing parameter of the filter, tend to balance over the medium-term. Problems associated with the adopted filter include its inability to model structural breaks and the sensitivity of the results to the choice of the value of the smoothing parameter. In the paper a criterion to select the parameter is set forth, which has led to a value (30 for annual series) which lies between those recently advocated in the statistical literature and that used in the method currently followed by the European Commission. The selected value implies that short cycles are included almost completely in the cyclical component, resulting in a relatively smooth profile of the trend component, but it also ensures that longer cycles only slightly affect the cyclical component. However, it should also be mentioned that, as for any other method, the estimation of trends of macroeconomic variables is subject to a significant degree of uncertainty and results based on it should be used with caution.

The method outlined in this paper is now being used in the ESCB to compute cyclically adjusted budget balances for the EU countries. The method has the advantage of allowing for further developments in the future. They could include: (I) the analysis of the impact of fluctuations in relative prices on government finances and (2) a more refined assessment of the impact of the business cycle on expenditure and revenue items that are currently not cyclically adjusted, such as government consumption, public investment, interest payments, subsidies and pensions. In addition, efforts could be devoted to find a more satisfactory instrument to assess the cyclical position of the economy, while not loosing the composition effects. Further work could also be done with respect to the harmonisation of the data used, to improve the econometric estimation of fiscal elasticities. This would be facilitated by longer time series for fiscal variables, which are currently limited due to the transition to ESA95. 


\section{References}

Banca d'Italia ed. (1999), "Indicators of structural budget balances".

Baxter, M. and King, R.G. (1999), "Measuring Business Cycles: Approximate Band-Pass Filters for Economic Time Series", Review of Economics-and Statistics, 8I (4), November : 575-93.

Bouthevillain, C. (1996), "Les cycles des grands pays industrialisés. Des croissances plus proches mais des zones déphasées”, Economie et Statistique 298 (8): 7I-9I.

Brunila, A., Hukkinen, J. and Tujula, M. (1999), "Indicators of the Cyclically Adjusted Budget Balance: The Bank of Finland's Experience”, Bank of Finland Discussion Papers 1/99, January.

Burns, A.F. and Mitchell W.C. (1946), "Measuring Business Cycles”, New York, National Bureau of Econcomic Research.

Canova, F. (1998), "Detrending and business cycles facts", Journal of Monetary Economics, 4I (3), June.

Cogley, T. and Nason, J. M. (1995), "Effects of the Hodrick-Prescott Filter on Trend and Difference Stationary Time Series: Implications for Business Cycles Research", Journal of Economic Dynamics and Control 19: 253-78.

Deutsche Bundesbank (2000), "Cyclical adjustment of the public sector financial balance in Germany - a disaggregated approach", Monthly Report, April.

European Commission (1995), "The Commission services' method for the cyclical adjustment of government budget balances - Technical Note", European Economy, nr. 6, November.

European Commission (2000), "Public Finances in EMU - 2000", European Economy Reports and Studies, nr. 3, Directorate General for Economic and Financial Affairs, May.

European Commission (200I), "Public Finances in EMU - 2000", European Economy Reports and Studies, nr. 3, Directorate General for Economic and Financial Affairs, June.

Gropp, R. and Kostial, K. (2000), "The disappearing tax base: is foreign direct investment eroding corporate income taxes?", ECB Working Paper No. 3I, September.

Harvey, A.C. (1993), "Time Series Models”, Harvester Wheatsheaf, New York.

Hodrick, R.J. and Prescott, E.C. (1997), "Post-war U.S. Business Cycles: an Empirical Investigation”, Journal of Money, Credit and Banking, 29(I): I-16.

Hodrick, R.J. and Prescott, E.C. (1980), "Post War U.S. Business Cycles: An Empirical Investigation”, Carnegie-Mellon University, Discussion Paper No. 451.

Kaiser, R. and Maravall, A. (200I), “Measuring Business Cycles in Economic Time Series”, SpringerVerlag (forthcoming). 
Kaiser, R. and Maravall, A. (1999), "Estimation of the Business Cycle: A Modified Hodrick-Prescott Filter”, Banco de Espana - Servicio de Estudios, Documento de Trabajo No. 99।2.

King, R. G. and Rebelo, S.T. (1993), “Low Frequency Filtering and Real Business Cycles”, Journal of Economic Dynamics and Control 17, North Holland.

Langenus, G. (1999), “The NBB's Work on Structural or Cyclically Adjusted Fiscal Indicators, in Banca d'Italia, Indicators of Structural Budget Balances.

Momigliano, S. and Staderini, A. (1999), "A New Method of Assessing the Structural Budget Balance: Results for the Years 1995-2000” in Banca d'Italia, Indicators of Structural Budget Balances.

Nelson, C. and Plosser, C. (1982), "Trends and Random Walks in Macroeconomic Time Series: some Evidence and Implications", Journal of Monetary Economics I0(2), I39-62.

Pedersen, T. M. (1998a), "The Hodrick Prescott Filter, the Slutzky Effect, and the Distortionary Effect of Filters”, University of Copenhagen, Institute of Economics, Working Paper.

Pedersen, T. M. (1998b), "How Long are Business Cycles? Reconsidering Fluctuations and Growth”, University of Copenhagen, Institute of Economics, Discussion Paper 98/24, December.

Ravn, M. O. and Uhlig, H. (200I), “On Adjusting the HP-Filter for the Frequency of Observations”, Centre of Economic Policy Research, Discussion Paper No. 2858.

van den Noord, P. (2000), "The size and role of automatic fiscal stabilisers in the 1990s and beyond”, OECD Working Paper 230, January. 


\section{Contents of the Annexes}

AI. Definitions of variables and basic equations

A2. The elasticity of personal income tax with respect to average compensation of employees: methods based on detailed revenue data

A3. Determining trends and gaps

A4. Derivation of the sensitivity of the budget balance in a shock scenario

A5. An alternative derivation of the sensitivity

A6. Comparison to OECD sensitivity estimates: adjusting macroeconomic elasticities for the private sector

A7. Tables

64

A8. References 


\section{Tables, charts and boxes}

\section{TABLES}

Table AI Monte Carlo simulation to check for spurious correlation between deviations from HP-trends 55 Table A2 Relationship between the critical length of the cycle and $\lambda$ for annual data (for I(I) data) 56 Table A3 Fiscal ratios for the EU countries in 1999

Table A4 Approaches retained for the derivation of budget elasticities in the EU countries 65 Table A5 Budget elasticities in the EU countries 66

Table A6 Budget elasticities compared to the OECD estimates 68

Table A7 Elasticities of budgetary macroeconomic bases with respect to output compared to the OECD 69

Table A8 Cyclically adjusted balances in the EU, 1998-2000 (as a percentage of GDP) 70

Table A9 Cyclical components of the budget balances in the EU, 1998-2000, compared to the EU Commission, the $\begin{array}{ll}\mathrm{OECD} \text { and the IMF (as a percentage of GDP) } & 7 \text { I }\end{array}$

\section{BOXES}

Box Al Output elasticities of macroeconomic base variables in a shock scenario 


\section{AI. Definitions of variables and basic equations}

\section{Definitions of symbols used}

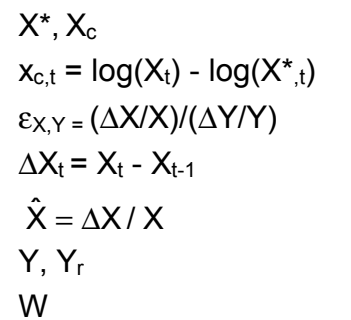

trend and cyclical component of variable $X$ relative deviation from trend of variable $X$ in year $t$ elasticity of variable $X$ with respect to $Y$ absolute change of variable $X$ in year $t$ relative change of variable $X$

GDP, real GDP real compensation of employees

E, L $\omega=W / E$ $\omega_{\mathrm{n}}$ $\mathrm{F}$

C $\mathrm{U}, \mathrm{u}$ $\mathrm{V}$ or $\mathrm{V}^{\mathrm{j}}$ dependent employment, labour force ( = labour supply) real average compensation of employees average negotiated wage, real real operating surplus ${ }^{1}$ real private consumption number of unemployed, unemployment rate any macroeconomic base variable in real terms

$R, R^{H}, R^{F}, R^{E}, R^{V}, R^{S}, R^{Z}$ total receipt, direct taxes on household income, direct taxes on operating surplus and mixed income, excise duties, value added tax, social security contributions, other revenue (all in nominal terms)

$R^{D}=R^{H}+R^{F}$

$R^{\prime}=R^{V}+R^{E}$

$X, X^{G}, X^{U}, X^{i}, X^{Z}$

nominal direct taxes

nominal indirect taxes

total expenditure, compensation of public sector employees, unemployment-related expenditure, interest expenditure, other expenditure (all in nominal terms)

$\mathrm{B}=\mathrm{R}-\mathrm{X}$ budget balance, nominal

$\mathrm{b}=\mathrm{B} / \mathrm{Y}$

$B^{j}, b^{j}=B^{j} / Y$ budget balance in relation to GDP any budgetary item in nominal terms, absolute and as a GDP ratio. $B^{i} \geq 0$ if $B^{j}$ is a revenue item; $B^{j} \leq 0$ if $B^{j}$ is an expenditure item.

I With country specific modifications.

\section{Subscripts:}

$\begin{array}{ll}\mathrm{t} & \text { year } \mathrm{t} \\ \mathrm{r} & \text { Real } \\ \mathrm{c} & \text { cyclical component } \\ \mathrm{p}, \mathrm{g} & \text { private, government sector } \\ \mathrm{d}, \mathrm{m} & \text { domestic, imported }\end{array}$

\section{Superscripts}

\section{Additional definitions}

$\begin{array}{ll}\text { D } & \text { real domestic demand } \\ M & \text { real imports } \\ \text { Ex } & \text { real exports } \\ Z & \text { capital depletion, real }\end{array}$




\section{Cyclical components of revenue and expenditure categories}

(I) value added tax

(2) excise duties

(3) social security contributions

(4) direct taxes on household income

(5) direct taxes on operating surplus and mixed income (with a lag of $N$ $\mathrm{R}_{\mathrm{c}, \mathrm{t}}^{\mathrm{v}}=\mathrm{R}_{\mathrm{p}, \mathrm{t}}^{\mathrm{V}} \cdot \varepsilon_{\mathrm{R}^{\mathrm{v}}, \mathrm{C}} \mathrm{c}_{\mathrm{p}, \mathrm{c}, \mathrm{t}}$ periods included)

(6) other revenue

(7) total revenue

(8) compensation of public sector employees

(9) interest payments

(10) unemployment expenditure

(II) other expenditure

(I2) total expenditure

$$
\begin{aligned}
& \mathrm{R}_{\mathrm{c}, \mathrm{t}}^{\mathrm{E}}=\mathrm{R}_{\mathrm{p}, \mathrm{t}}^{\mathrm{E}} \cdot \varepsilon_{\mathrm{R}^{\mathrm{E}}, \mathrm{C}} \cdot \mathrm{c}_{\mathrm{p}, \mathrm{c}, \mathrm{t}} \\
& \mathrm{R}_{\mathrm{c}, \mathrm{t}}^{\mathrm{S}}=\mathrm{R}_{\mathrm{p}, \mathrm{t}}^{\mathrm{S}} \cdot \varepsilon_{\mathrm{R}^{\mathrm{S}, \mathrm{W}}} \mathrm{W}_{\mathrm{p}, \mathrm{c}, \mathrm{t}}+\mathrm{R}_{\mathrm{g}, \mathrm{t}}^{\mathrm{S}} \cdot \varepsilon_{\mathrm{R}^{\mathrm{S}, \omega}} \cdot \varepsilon_{\omega_{\mathrm{g}}, \omega_{\mathrm{p}}} \cdot\left(\mathrm{w}_{\mathrm{p}, \mathrm{c}, \mathrm{t}}-\mathrm{e}_{\mathrm{p}, \mathrm{c}, \mathrm{t}}\right) \\
& \mathrm{R}_{\mathrm{c}, \mathrm{t}}^{\mathrm{H}}=\mathrm{R}_{\mathrm{p}, \mathrm{t}}^{\mathrm{H}} \cdot\left(\varepsilon_{\mathrm{R}^{\mathrm{H}, \omega}} \cdot\left(\mathrm{w}_{\mathrm{p}, \mathrm{c}, \mathrm{t}}-\mathrm{e}_{\mathrm{p}, \mathrm{c}, \mathrm{t}}\right)+1 \cdot \mathrm{e}_{\mathrm{p}, \mathrm{c}, \mathrm{t}}\right)+\mathrm{R}_{\mathrm{g}, \mathrm{t}}^{\mathrm{H}} \cdot \varepsilon_{\mathrm{R}^{\mathrm{H}}, \omega} \cdot \varepsilon_{\omega_{\mathrm{g}}, \omega_{\mathrm{p}}} \cdot\left(\mathrm{w}_{\mathrm{p}, \mathrm{c}, \mathrm{t}}-\mathrm{e}_{\mathrm{p}, \mathrm{c}, \mathrm{t}}\right) \\
& \mathrm{R}_{\mathrm{c}, \mathrm{t}}^{\mathrm{F}}=\mathrm{R}_{\mathrm{t}}^{\mathrm{F}} \sum_{\mathrm{i}=0}^{\mathrm{N}} \varepsilon_{\mathrm{R}_{\mathrm{t}}^{\mathrm{F}}, \mathrm{F}_{\mathrm{t}-\mathrm{i}}} \mathrm{f}_{\mathrm{c}, \mathrm{t}-\mathrm{i}}
\end{aligned}
$$

(13) budget balance

$$
\mathrm{R}_{\mathrm{c}, \mathrm{t}}^{\mathrm{Z}}=0
$$$$
\mathrm{R}_{\mathrm{c}, \mathrm{t}}=\mathrm{R}_{\mathrm{c}, \mathrm{t}}^{\mathrm{V}}+\mathrm{R}_{\mathrm{c}, \mathrm{t}}^{\mathrm{E}}+\mathrm{R}_{\mathrm{c}, \mathrm{t}}^{\mathrm{S}}+\mathrm{R}_{\mathrm{c}, \mathrm{t}}^{\mathrm{H}}+\mathrm{R}_{\mathrm{c}, \mathrm{t}}^{\mathrm{F}}+\mathrm{R}_{\mathrm{c}, \mathrm{t}}^{\mathrm{Z}}
$$

$X_{c, t}^{\mathrm{G}}=X_{t}^{\mathrm{G}} \cdot 1 \cdot \varepsilon_{\omega_{\mathrm{g}, \omega_{\mathrm{p}}}} \cdot \omega_{\mathrm{n}, \mathrm{p}, \mathrm{c}}$

$\mathrm{X}_{\mathrm{c}, \mathrm{t}}^{\mathrm{i}}=\mathrm{X}_{\mathrm{t}}^{\mathrm{i}} \cdot \varepsilon_{\mathrm{X}^{\mathrm{i}}, \mathrm{Y}} \cdot \mathrm{y}_{\mathrm{r}, \mathrm{c}, \mathrm{t}}$, assumption: $\varepsilon_{\mathrm{X}^{\mathrm{i}}, \mathrm{Y}}=0$

$\mathrm{X}_{\mathrm{c}, \mathrm{t}}^{\mathrm{U}}=\mathrm{X}_{\mathrm{t}}^{\mathrm{U}} \cdot \varepsilon_{\mathrm{X}^{\mathrm{U}}, \mathrm{U}} \cdot \mathrm{u}_{\mathrm{c}, \mathrm{t}}$

$\mathrm{X}_{\mathrm{c}, \mathrm{t}}^{\mathrm{Z}}=0$

$X_{c, t}=X_{c, t}^{U}+X_{c, t}^{G}+X_{c, t}^{i}+X_{c, t}^{Z}$

$\mathrm{B}_{\mathrm{c}, \mathrm{t}}=\mathrm{R}_{\mathrm{c}, \mathrm{t}}-\mathrm{X}_{\mathrm{c}, \mathrm{t}}$

Output elasticities of revenue and expenditure items and output sensitivity of the balance

(14) value added tax

(I5) excise duties

(I6) indirect taxes

(17) social security contributions

(18) direct taxes on household income

(19) direct taxes on operating surplus and mixed income

(20) direct taxes

(2I) other revenue

$$
\begin{aligned}
& \varepsilon_{R^{v}, Y_{r}}=\frac{R_{p}^{V}}{R^{V}} \cdot \varepsilon_{R_{p}^{v}, C_{p}} \varepsilon_{C_{p}, Y_{r}} \\
& \varepsilon_{R^{E}, Y_{r}}=\frac{R_{p}^{E}}{R^{E}} \cdot \varepsilon_{R_{p}^{E}, C_{p}} \varepsilon_{C_{p}, Y_{r}} \\
& \varepsilon_{R^{1}, Y_{r}}=\frac{R^{v}}{R^{1}} \cdot \varepsilon_{R^{v}, Y_{r}}+\frac{R^{E}}{R^{I}} \cdot \varepsilon_{R^{E}, Y_{r}} \\
& \varepsilon_{R^{S}, Y_{r}}=\frac{R_{p}^{S}}{R^{S}} \cdot \varepsilon_{R^{s}, W} \varepsilon_{W_{p}, Y_{r}}+\frac{R_{g}^{S}}{R^{S}} \cdot \varepsilon_{R^{s}, W} \cdot \varepsilon_{\omega_{g}, \omega_{p}} \cdot\left(\varepsilon_{W_{p}, Y_{r}}-\varepsilon_{E_{p}, Y_{r}}\right)
\end{aligned}
$$$$
\varepsilon_{R^{H}, Y_{r}}=\frac{R_{p}^{H}}{R^{H}} \cdot\left(\varepsilon_{R^{H}, \omega} \cdot\left(\varepsilon_{W_{p}, Y_{r}}-\varepsilon_{E_{p}, Y_{r}}\right)+1 \cdot \varepsilon_{E_{p}, Y_{r}}\right)+\frac{R_{g}^{H}}{R^{H}} \cdot \varepsilon_{R^{H}, \omega} \cdot \varepsilon_{\omega_{g}, \omega_{p}} \cdot\left(\varepsilon_{W_{p}, Y_{r}}-\varepsilon_{E_{p}, Y_{r}}\right)
$$$$
\varepsilon_{R^{\mathrm{F}}, \mathrm{Y}_{\mathrm{r}}}=\varepsilon_{\mathrm{F}, \mathrm{Y}_{\mathrm{r}}} \sum_{\mathrm{i}=0}^{\mathrm{N}} \varepsilon_{\mathrm{R}_{\mathrm{t}}^{\mathrm{F}}, \mathrm{F}_{\mathrm{t}-\mathrm{i}}}
$$$$
\varepsilon_{R^{D}, Y_{r}}=\frac{R^{H}}{R^{D}} \cdot \varepsilon_{R^{H}, Y_{r}}+\frac{R^{F}}{R^{D}} \cdot \varepsilon_{R^{F}, Y_{r}}
$$$$
\varepsilon_{\mathrm{R}^{\mathrm{z}}, \mathrm{Y}_{\mathrm{r}}}=0
$$ 
(22) total revenue

$$
\varepsilon_{R, Y_{r}}=\frac{R^{I}}{R} \cdot \varepsilon_{R^{1}, Y_{r}}+\frac{R^{s}}{R} \cdot \varepsilon_{R^{s}, Y_{r}}+\frac{R^{D}}{R} \cdot \varepsilon_{R^{D}, Y_{r}}+\frac{R^{Z}}{R} \cdot \varepsilon_{R^{Z}, Y_{r}}
$$

(23) compensation of public sector employees

$$
\varepsilon_{X^{G}, Y_{r}}=1 \cdot \varepsilon_{\omega_{g}, \omega_{p}} \cdot\left(\varepsilon_{W_{p}, Y_{r}}-\varepsilon_{E_{p}, Y_{r}}\right)
$$

(24) interest payments

assumption $\varepsilon_{\mathrm{X}^{\mathrm{i}}, \mathrm{Y}_{\mathrm{r}}}=0$

(25) unemployment benefits

$\varepsilon_{\mathrm{X}^{\mathrm{U}}, \mathrm{Y}_{\mathrm{r}}}=-\varepsilon_{\mathrm{X}^{\mathrm{U}}, \mathrm{U}} \cdot \varepsilon_{\mathrm{E}_{\mathrm{p}}, \mathrm{Y}_{\mathrm{r}}} \frac{\mathrm{E}_{\mathrm{p}}}{\mathrm{U}}$

(26) other expenditure

$\varepsilon_{X^{z}, Y_{r}}=0$

(27) total expenditure

$\varepsilon_{X, Y_{r}}=\frac{X^{U}}{X} \cdot \varepsilon_{X^{U}, Y_{r}}+\frac{X^{i}}{X} \cdot \varepsilon_{X^{i}, Y_{r}}+\frac{X^{G}}{X} \cdot \varepsilon_{X^{G}, Y_{r}}+\frac{X^{Z}}{X} \cdot \varepsilon_{X^{Z}, Y_{r}}$

\section{Sensitivity with respect to a GDP shock of I\%}

(28) revenue

(29) expenditure

(30) balance

$$
\sigma_{\mathrm{R}}=\left(\varepsilon_{\mathrm{R}, \mathrm{Y}_{\mathrm{r}}}-1\right) \frac{\mathrm{R}}{\mathrm{Y}}
$$$$
\sigma_{\mathrm{X}}=\left(\varepsilon_{\mathrm{X}, \mathrm{Y}_{\mathrm{r}}}-1\right) \frac{\mathrm{X}}{\mathrm{Y}}
$$

$$
\sigma_{\mathrm{B}}=\sigma_{\mathrm{R}}-\sigma_{\mathrm{X}}
$$




\section{A2. The elasticity of personal income tax with respect to average compensation of employees': methods based on detailed revenue data}

This annex describes two methods of estimating the elasticity of personal income tax with respect to average compensation of employees using data on tax revenues by income brackets. Both methods are based on an analysis of the tax schedule effective in the respective years and thus allow for the calculation of "static" elasticities which refer to one year only. The methods are used in the cases of some countries (e.g. in the cases of Germany and Spain in the version a) and in the case of Italy in the version b) presented below) as alternatives to econometric estimation.

\section{A2.I Definition of the concept of elasticity used}

Let $\mathrm{R}^{\mathrm{W}}$ be a differentiable function of average income $\omega$. The income elasticity of the income tax is defined as the relative change in the tax divided by the relative change in average income $\omega$.

$\varepsilon_{R^{W}, \omega} \frac{\Delta R^{W} / R^{W}}{\Delta \omega / \omega}=\frac{\Delta R^{W} / \Delta \omega}{R^{W} / \omega}$.

This is equivalent to the income elasticity the marginal tax rate divided by the average tax rate.

Since the elasticity of income tax revenue with respect to average income depends on the income distribution due to progressive tax schedules, data on the income tax liability (number of taxfilers, tax base and tax paid) by income bracket is required. These data allow for a direct calculation of average and average marginal tax rates for each income bracket.

\section{A2.2 Two methods to compute the average elasticity of income taxes to labour income}

Two possibilities for the estimation of the average income elasticity of income tax revenue as defined above are discussed in this section.

a) The elasticity can be estimated as a function of the average tax paid for each year in terms of the tax bases within the income bracket $\mathrm{i}$ :

$R_{i}^{W}=f\left(\omega_{i}\right)$

Once this function has been adjusted, it can be obtained, through differentiation, the effective marginal rates corresponding to each income bracket. Dividing these effective marginal rates by the average tax rates elasticities for every income bracket are obtained and can be aggregated to the total elasticity by:

$\varepsilon_{R^{W}, \omega}=\frac{\sum_{i} \Delta R_{i}^{W} / \sum_{i} \Delta \omega_{i}}{\sum_{i} R_{i}^{W} / \sum_{i} \omega_{i}}$

I The elasticity of personal income tax with respect to labor income can be split into two components. The first, the employment component of the elasticity, measures how changes of the tax revenue are affected by changes in employment assuming that average income is constant. This elasticity can assumed to be unity. The second component, the wage component, measuring the elasticity of the personal income tax with respect to average income, is addressed in this appendix. 
where the index i refers to income bracket $\mathrm{i}$.

Thus, the aggregated elasticity is equal to the change in total tax revenue divided by the change in total income. However, the value of the total elasticity depends on the distribution of the increases in income. Assuming that all these increases are a constant rate of the tax base, $\Delta \omega i=$ c $\omega$ i, the expression can be transformed into:

$\varepsilon_{R^{W}, \omega}=\frac{1}{\sum_{i} R_{i}^{W}} \sum_{i} R_{i}^{W} \varepsilon_{R_{i}^{W}, \omega_{i}}$

The aggregated elasticity for each year is then calculated as the average of the elasticities of each income bracket $\mathrm{i}$, weighted by the ratio of the tax revenue paid within this income bracket.

b) The tax paid within income bracket $\mathrm{i}$ can be described as a function of wi:

$\mathrm{R}_{\mathrm{i}-1}^{\mathrm{W}}=\mathrm{k} \omega_{\mathrm{i}-1}^{\varepsilon}$.

If the elasticity $\varepsilon$ does not change significantly between two consecutive income brackets and can be assumed to remain approximately constant, the same function must hold for the income bracket i-l:

$\mathrm{R}_{\mathrm{i}-1}^{\mathrm{W}}=\mathrm{k} \omega_{\mathrm{i}-1}^{\varepsilon}$.

Dividing these two expressions and using logarithms yields the elasticity within income bracket i:

$\varepsilon_{\mathrm{i}}=\frac{\log \mathrm{R}_{\mathrm{i}}^{\mathrm{W}}-\log \mathrm{R}_{\mathrm{i}-1}^{\mathrm{W}}}{\log \omega_{\mathrm{i}}-\log \omega_{\mathrm{i}-1}}$

This method obviously poses the problem of calculating the elasticity of the first income bracket. If this elasticity is simply ignored, it is assumed that it is equal to a weighted average of the other income brackets (in the analysis of Italian personal income tax, as the number of brackets for which the information was available was substantial, more than 30 , the approximation inherent in this solution was considered acceptable). The marginal rate calculated with the first method for that income bracket can also be used. The aggregation to the total elasticity can then be performed as described in a). 


\section{A3. Determining trends and gaps}

\section{A3.I Three of the most widely used decomposition methods}

\section{A 3.I.I The Beveridge-Nelson (BN) approach}

The method proposed by Beveridge and Nelson (198I) relies on an explicit statistical model of the trend/cycle decomposition. It is based on the assumptions that the trend can be described as a random walk and that the trend and the cyclical component are driven by the same series of shocks. Since the parameters of the implied stochastic model are obtained by tailoring an ARIMA model to the actual series, this has the favourable implication that the approach takes stochastic properties of the time series being filtered into account. However, the approach has the theoretically implausible implication that the cyclical component is highly correlated with the first differences of the original series especially in the typical case of a positively autocorrelated original series (Mc Morrow and Roeger, 200I:16).

\section{A3. I.2 The unobservable component (UC) approach}

This method has been put forward by Harvey (1989). It is based on the estimation of an explicit statistical model which incorporates variables which can and which cannot be observed, like actual charts for GDP, its trend, the cyclical component and a residual. The relationship between observed and unobservable components is generally described by a small model, including several variables, which is estimated by an iterative procedure guaranteeing that the sum of the components equals the actual series. The implementation of an UC-model is less transparent than that of an univariate filter and, depending on the hypothesis underlying the relationships assumed, the same macroeconomic series may be represented by different models. This approach has the advantage, with respect to univariate moving average filters, that gaps can be given an interpretation based on the economic theory underlying the estimated model.

\section{A3. I.3 The Baxter-King (BK) filter}

The filter proposed by Baxter and King (1995) is constructed as a specific approximation to an ideal band pass filter, given a certain, finite length of the data sample ${ }^{2}$. An ideal band pass filter lets pass through only frequencies within a certain range of wave lengths and filters out very long and very short waves thereby isolating the cycles within the critical range. ${ }^{3}$ The filter weights of the Baxter-King filter are chosen such that the sum over the squared differences between the power transfer functions of the ideal and the approximate filter in the frequency domain is minimised. When applying the Baxter-King filter, the critical frequency band (or the critical range of wave lengths) which is to be allocated to the cyclical component has to be exogenously determined; this requirement is comparable to the exogenous definition of the value of the smoothing parameter in the application of the Hodrick-Prescott filter. The Baxter-King filter has some properties in common with the Hodrick-Prescott filter: both represent finite order, two sided and symmetric moving averages able to eliminate stochastic and deterministic trends. In addition, both have an end point problem so that the resulting trend and cyclical series are biased at the fringes of the sampling period. Usually, they both lead to very similar results (Mc Morrow and Roeger, 200I:I2).

2 The concept of an ideal filter exists only as a theoretical construction based on the fiction of an infinite time horizon. Ideal filters, which are not obtainable with time series of finite length, serve as a theoretical benchmark against which feasible constructions of filters can be evaluated. Since the Baxter-King filter is only an approximation to an ideal filter, it shows errors in the form of compression and leakage effects like every other filter. The reader is referred to section 3.3 of the main text for a more detailed explanation of the concept of an ideal filter and of compression and leakage effects.

3 Although the original version of the Baxter-King filter was of the band pass type, the high pass version which - like the Hodrick-Prescott filter - allocates all waves below a certain critical length to the cyclical component is also being used. 


\section{A3.2 A Monte Carlo simulation to check on spurious cross correlation in the application of the HP-filter}

In this exercise, 1000 random walks (without drift) for sample sizes 28, 38 and 108 are filtered using a $\lambda$ of 30 (the first and last four observations are deleted from the respective samples because of the end-point problem as discussed in section 3.2). Correlation coefficients are calculated between the deviations from trend for each of the 1000 simulations. These deviations should not be correlated, since the original series consist of independent random drawings.

Correlation coefficients of -0.5 and 0.5 are chosen as "critical" values (implying that $25 \%$ of the variance of trend deviation obviously has to be "explained" by the deviation of yet another independent random walk). If at least $5 \%$ of the 1000 simulation trials exhibit correlation coefficients smaller than -0.5 or larger than 0.5 , the evidence of spurious cycles is considered to be significant. The results are reported in the table below (in which correlation coefficients are denoted by $r$ ).

From the second column of the table it can be concluded that for $\mathrm{T}=20$ the lower and upper $2.5 \%$ percentiles (of the distribution resulting from the simulations) correspond with correlation coefficients between -0.44 and +0.47 . About $4 \%$ of the coefficients are larger than 0.5 or smaller than $-0.5 \%$ for $T=20$ (see third column). For $T=30$ and $T=100$, an even much smaller part of the correlation coefficients falls in the critical ranges below -0.5 or above 0.5 . This outcome shows that for $\lambda=30$ it is unlikely that the HP-filter generates spurious cross correlations in the cyclical components of macroeconomic variables.

\section{Table AI}

Monte Carlo simulation to check for spurious correlation

between deviations from HP-trends

\begin{tabular}{|l|l|l|l|}
\hline $\mathbf{x}_{\mathbf{t}}=\mathbf{x}_{\mathrm{t}-1}+\boldsymbol{\varepsilon}_{\mathbf{t}} \mathbf{n}=\mathbf{1 0 0 0}, \boldsymbol{\lambda}=\mathbf{3 0}$ & $\begin{array}{l}\text { Cutpoints of } \mathbf{r} \text { at } \mathbf{- 2 . 5 \%} \\
\text { and 97.5\% }\end{array}$ & Percentile of $\mathbf{r} \mathbf{- 0 . 5} / \mathbf{r} \mathbf{0 . 5}$ & Standard deviation of $\mathbf{r}$ \\
\hline $\mathrm{T}=20$ & $-0.44 / 0.47$ & $0.8 \% / 97.0 \%$ & 0.24 \\
$\mathrm{~T}=30$ & $-0.42 / 0.40$ & $0.5 \% / 98.0 \%$ & 0.21 \\
$\mathrm{~T}=100$ & $-0.24 / 0.25$ & $-198.0 \%$ & 0.13 \\
\hline
\end{tabular}

3.3 The criteria proposed by Pedersen (1998a) and Kaiser and Maravall (1999) for the choice of $\lambda$

Two approaches can be distinguished in the literature dealing explicitly with the choice of $\lambda$. They both lead to relatively low values of $\lambda$. First, for a given critical length, Pedersen (1998a) proposes a value for $\lambda$ which minimises a loss function defined over compression and leakage effects. ${ }^{4}$ This criterion typically leads to low values for $\lambda$ as compared to those commonly used in applied research. For instance, it implies a value of about 4 for a critical length of 8 years for annual data. Pedersen's choice for the loss function implies that the difference between the variances of the cyclical component as defined by the ideal filter and the estimated cyclical component is minimised. It is not obvious, however, why minimising this difference should be the basis of the choice of $\lambda$.

Second, contrary to Pedersen, Kaiser and Maravall (1999) do not explicitly compare compression and leakage effects. Rather, they propose to choose the value of $\lambda$ for which the variance of the cyclical component is mostly determined by cycles around the critical length. In other terms, the

4 The loss function in Pedersen's approach is defined over compression and leakage affects as measured by the squared gain or the power transfer function of the filter, weighted with the spectrum of the series being filtered. 
spectrum of the cyclical component should exhibit a peak at the critical length. Table I shows the relationship between $\lambda$ and the critical length as advocated by Kaiser and Maravall for annual data, integrated of order I.

\section{Table A2}

Relationship between the critical length of the cycle and $\lambda$ for annual data (for I(1) data)

\begin{tabular}{|l|l|}
\hline Critical Length & $\boldsymbol{\lambda}$ \\
\hline 8 & $6-8$ \\
10 & $12-20$ \\
12 & $29-39$ \\
16 & 100 \\
\hline
\end{tabular}

According to Kaiser and Maravall $\lambda$ should be in the range of 6 to 8 if, for instance, a critical length of eight years is chosen. A value of $\lambda$ of 100 would in their approach correspond to a critical cycle length of 16 years. 


\section{A4. Derivation of the sensitivity of the budget balance in a shock scenario}

The sensitivity (or semi-elasticity) of the budget balance can be defined as the change of the balance to GDP ratio in response to a GDP change of $1 \%$ :

$$
\sigma_{\mathrm{B}}=\frac{\Delta(\mathrm{B} / \mathrm{Y})}{\Delta \mathrm{Y}_{\mathrm{r}} / \mathrm{Y}_{\mathrm{r}}}
$$

Since $B=R-X$ and for any budgetary item $B \Delta\left(\frac{B}{Y}\right)=\frac{B}{Y}\left(\frac{\Delta B}{B}-\frac{\Delta Y}{Y}\right)$, the sensitivity can easily be expressed in terms of output elasticities of total revenue and expenditure:

$\sigma_{\mathrm{B}}=\frac{\mathrm{R}}{\mathrm{Y}}\left(\varepsilon_{\mathrm{R}, \mathrm{Y}}-1\right)-\frac{\mathrm{X}}{\mathrm{Y}}\left(\varepsilon_{\mathrm{X}, \mathrm{Y}_{\mathrm{r}}}-1\right)$

Inserting $\varepsilon_{R, Y_{r}}=\sum_{j} \frac{R^{j}}{R} \varepsilon_{R^{j}, Y_{r}}$ and $\varepsilon_{X, Y}=\sum_{j} \frac{X^{j}}{X} \varepsilon_{X^{j}, Y_{r}}$ into (A4.2) gives

$\sigma_{B}=\sum_{j} \frac{R^{j}}{Y} \varepsilon_{R^{j}, Y_{r}}-\sum_{j} \frac{X^{j}}{Y} \varepsilon_{X^{j}, Y_{r}}-\frac{B}{Y}$

Output elasticities of expenditure and revenue items are computed as the product of the output elasticity of the respective macroeconomic base variable $\mathrm{V}^{\mathrm{i}}$ with the base elasticity of the respective budgetary item. Thus, rewriting (A4.3) in a more extensive form results in

$\sigma_{B}=\sum_{j} \frac{R^{j}}{Y} \varepsilon_{R^{j}, V^{j}} \varepsilon_{V^{j}, Y_{r}}-\sum_{j} \frac{X^{j}}{Y} \varepsilon_{X^{j}, V^{j}} \varepsilon_{V^{j}, Y_{r}}-\frac{B}{Y}$

The estimates of $\sigma$ presented in the main text and annexes of this paper are based on the estimates of the elasticities of budgetary items with respect to their macroeconomic bases discussed in Chapter 2 and on values of the output elasticities of the bases calculated assuming a specific shock scenario. This scenario is described in the box below. 


\section{B०X A I}

\section{Output elasticities of macroeconomic base variables in a shock scenario}

By definition, the change of real GDP equals the sum of the changes of its components viewed from the demand side or the distribution side (see Annex 1 for an extensive list of variables and other notational aspects):

$\Delta D_{p}+\Delta(X-M)+\Delta W_{g}+\Delta O t h_{g}=\Delta Y_{r}=\Delta W_{p}+\Delta W_{g}+\Delta F+\Delta R^{I}-\Delta S+\Delta Z$

where $\mathrm{D}_{\mathrm{v}}$ denotes private demand, $\mathrm{X}-\mathrm{M}$ denotes the current account, Oth $\mathrm{g}$ non wage government consumption and investment, $\mathrm{S}$ subsidies and $\mathrm{Z}$ depreciation, all in real terms. Simplifying the above equation by

Assumption 1 The net contribution of the current account to the change of real GDP is zero,

Assumption 2 Government wages and other non wage government consumption, government investment and subsidies are not sensitive to the cycle, and

Assumption 3 The contribution of depreciation is negligible (the stock of capital does not show significant cyclical fluctuations), the percentage change of real GDP can be written as

$\hat{Y}_{r}=\left(D_{p} / Y_{r}\right) \hat{D}_{p}$

$\hat{Y}_{r}=\left(W_{p} / Y_{r}\right) \hat{W}_{p}+\left(F / Y_{r}\right) \hat{F}+\left(R^{I} / Y_{r}\right) \hat{R}^{I}$.

In addition, the shock scenario is based on

Assumption $4 \quad$ Gross operating surplus and private sector compensation of employees grow at the same rate, and

Assumption 5 Private consumption $\mathrm{C}_{\mathrm{n}}$ and private demand also grow at the rate same, so that $\hat{R}^{I}=\varepsilon_{R^{I}, C_{p}} \hat{C}_{p}=\varepsilon_{R^{I}, C_{p}} \hat{D}_{p}$.

From (1) the elasticities of private demand to GDP and (by assumption 5), the elasticity of private consumption to GDP are equal to the inverse of the ratio of private demand to GDP:

$\hat{D}_{p} / \hat{Y}_{r}=\varepsilon_{D_{p}, Y}=\varepsilon_{C_{p}, Y}=Y_{r} / D_{p}$.

Using this result in equation (2), we can derive the output elasticity of the compensation of employees and (by Assumption 4), the output elasticity of operating surplus, as functions of the macroeconomic variables and elasticities:

$\hat{W}_{p} / \hat{Y}_{r}=\varepsilon_{W_{p}, Y}=\varepsilon_{F, Y_{r}}=\frac{1-\varepsilon_{R^{I}, C_{p}} R^{I} / D_{p}}{\left(W_{p}+F\right) / Y_{r}}$

For the calculation of the cyclical component in direct taxes on wages, the output elasticity of compensation of private sector employees has been split into the output elasticities of employment and average wages, using the output elasticity of employment recently re-estimated by the OECD (corrections were made to restrict it to the private sector; see Annex 6).

The shock scenario is completed by the output elasticity of the number of unemployed people

$\varepsilon_{U, Y_{r}}=\frac{\partial L-\partial E}{\partial Y_{r}} \frac{Y_{r}}{L-E}$

Assuming that the output elasticity of labour supply L is approximately zero and that government employment is not sensitive to the cycle, the output elasticity of unemployed people can be transformed to

$\varepsilon_{U, Y_{r}}=-\varepsilon_{E_{p}, Y_{r}} \frac{E_{p}}{U}$ 


\section{A5. An alternative derivation of the sensitivity}

Another way to derive the sensitivity, which has not been retained here, starts by the following definition

$$
\widetilde{\sigma}_{\mathrm{B}}=\frac{\mathrm{b}_{\mathrm{c}}}{\mathrm{y}_{\mathrm{r}, \mathrm{c}}},
$$

where $y_{r, c}$ denotes the real output gap and $b_{c}$ is defined as the cyclical component of the balanceGDP ratio. Equation (A5.I) can be easily developed by starting with the cyclical component of the GDP ratio of the $j^{\text {th }}$ budgetary item, $b^{i}$, which is defined as:

$b_{c}^{j} \equiv b^{j}-b^{j^{*}} \equiv \frac{B^{j}}{Y}-\frac{B^{j^{*}}}{Y}$.

Note that $\mathrm{B}^{\mathrm{j}}$ can be written as

$B^{j}=B^{j^{*}}+B_{c}^{j}=B^{j^{*}}+B^{j^{*}} \varepsilon_{B^{j}, V^{j}} \varepsilon_{V^{j}, Y_{r}} y_{r, c} \cdot$

Inserting (A5.3) into (A5.2) yields

$b_{c}^{j}=\frac{B^{j^{*}}}{Y^{*}}\left(\frac{Y^{*}}{Y}\left(1+\varepsilon_{B^{j}, V^{j}} \varepsilon_{V^{j}, Y_{r}} y_{r, c}\right)-1\right)$,

which is equivalent to

$b_{c}^{j}=\frac{B^{j^{*}}}{Y}\left(\varepsilon_{B^{j}, V^{j}} \varepsilon_{V^{j}, Y_{r}} y_{r, c}-1\right) y_{r, c} \cdot$

The cyclical component of the balance-GDP ratio can be obtained by summing the $b_{c}^{j}$ in (A5.5):

$b_{c}=\sum_{j} b_{c}^{j}=y_{r, c} \frac{1}{Y} \sum_{j} B^{j^{*}}\left(\varepsilon_{B^{j}, V^{j}} \varepsilon_{V^{j}, Y_{r}}-1\right)$.

The alternative definition of the sensitivity in (A5.I) together with (A5.6) implies

$\widetilde{\sigma}_{B}=\frac{1}{Y} \sum_{j} B^{j^{*}}\left(\varepsilon_{B^{j}, V^{j}} \varepsilon_{V^{j}, Y_{r}}-1\right)$,

which by definition is equivalent to 


$$
\widetilde{\sigma}_{B}=\sum_{j} \frac{R^{j^{*}}}{Y} \varepsilon_{R^{j}, V^{j}} \varepsilon_{V^{j}, Y_{r}}-\sum_{j} \frac{X^{j^{*}}}{Y} \varepsilon_{X^{j}, V^{j}} \varepsilon_{V^{j}, Y_{r}}-\frac{B^{*}}{Y} .
$$

The comparison of equation (A5.8) with equation (A4.4) reveals that the two definitions of the sensitivity differ only by the fact that the latter is derived by referring to the cyclically adjusted rather than the unadjusted budgetary items. In general, differences between the approaches are small. 


\section{A6. Comparison to OECD sensitivity estimates: adjusting macroeconomic elasticities for the private sector}

If GDP gaps are estimated within a production function framework it is generally assumed (as in the approach of the OECD) that the public sector is at its potential or, equivalently, that there is no gap in the output of the public sector: $y_{g, c}=0$. This proposition implies that there is no gap in public sector employment:

$\mathrm{e}_{\mathrm{g}, \mathrm{c}}=0$

As elasticity estimates by the OECD are generally not based on the assumption that the public sector is cyclically neutral in the sense as defined in Appendix 5, output elasticities of macroeconomic variables for the economy as a whole as estimated by the OECD should be transformed into respective output elasticities of macroeconomic variables for the private sector by applying an appropriate adjustment factor $\phi$ :

$\varepsilon_{\mathrm{V}_{\mathrm{p}}^{\mathrm{j}}, \mathrm{Y}_{\mathrm{r}}}^{\mathrm{OECD}}=\phi \varepsilon_{\mathrm{V}^{\mathrm{j}}, \mathrm{Y}_{\mathrm{r}}}^{\mathrm{OECD}}$

\section{A6.I Output elasticity of employment}

In the procedure followed by the OECD (van den Noord, 2000) output elasticities of macroeconomic variables are determined econometrically on the basis of logarithms of gaps in the regression equations. In this way, the output elasticity of employment is estimated as the parameter $\mathrm{a}_{2}$ in

$\log \left(E / E^{*}\right)=a_{0}+a_{1} t+a_{2} \log \left(Y_{r} / Y_{r}^{*}\right)+\mu^{E}$

(where $\mu^{\mathrm{E}}$ is the residual of the regression; refer to van den Noord, 2000:22). Since $\log \left(\mathrm{Y}_{\mathrm{r}} / \mathrm{Y}_{\mathrm{r}}^{*}\right) \approx \mathrm{y}_{\mathrm{r}, \mathrm{c}}$, the elasticity is actually measured as the ratio of the percentage change in the employment gap and the percentage change in the output gap

$\mathrm{a}_{2}=\varepsilon_{\mathrm{E}, \mathrm{Y}_{\mathrm{r}}}^{\mathrm{OECD}}=\frac{\Delta \mathrm{e}_{\mathrm{c}}}{\Delta \mathrm{y}_{\mathrm{r}, \mathrm{c}}}$

and can be approximated by

$\varepsilon_{\mathrm{E}, \mathrm{Y}_{\mathrm{r}}}^{\mathrm{OECD}} \approx \frac{\left(\mathrm{E}_{\mathrm{p}}^{*} / \mathrm{E}^{*}\right) \Delta \mathrm{e}_{\mathrm{p}, \mathrm{c}}}{\Delta \mathrm{y}_{\mathrm{r}, \mathrm{c}}}+\frac{\left(\mathrm{E}_{\mathrm{g}}^{*} / \mathrm{E}^{*}\right) \Delta \mathrm{e}_{\mathrm{g}, \mathrm{c}}^{*}}{\Delta \mathrm{y}_{\mathrm{r}, \mathrm{c}}}=\left(\mathrm{E}_{\mathrm{p}}^{*} / \mathrm{E}^{*}\right) \varepsilon_{\mathrm{E}_{\mathrm{p}}, \mathrm{Y}_{\mathrm{r}}}^{\mathrm{OECD}}+\left(\mathrm{E}_{\mathrm{g}}^{*} / \mathrm{E}^{*}\right) \varepsilon_{\mathrm{E}_{\mathrm{g}}, \mathrm{Y}_{\mathrm{r}}}^{\mathrm{OECD}}$

From (A6.I) it follows that $\Delta \mathrm{e}_{g, c}=0$ and thus $\varepsilon_{\mathrm{E}_{\mathrm{g}}, \mathrm{Y}_{\mathrm{r}}=0}$ in equation (A6.4). As a result, the OECD estimation of the output elasticity of employment has to be multiplied by the ratio of potential employment in the economy as a whole to that in the private sector in order to obtain the respective output elasticity of private employment: 


$$
\varepsilon_{\mathrm{E}_{\mathrm{P}}, \mathrm{Y}_{\mathrm{r}}}^{\mathrm{OECD}}=\varepsilon_{\mathrm{E}, \mathrm{Y}_{\mathrm{r}}}^{\mathrm{OECD}} \frac{\mathrm{E}^{*}}{\mathrm{E}_{\mathrm{P}}^{*}} .
$$

\section{A6.2 Output elasticity of average compensation of employees}

The output elasticity of average compensation of employees is computed in an indirect way as the product of the output elasticity of employment (see above) and the employment elasticity of wages:

$$
\varepsilon_{\omega, \mathrm{Y}_{\mathrm{r}}}^{\mathrm{OECD}}=\varepsilon_{\omega, \mathrm{E}}^{\mathrm{OECD}} \varepsilon_{\mathrm{E}, \mathrm{Y}_{\mathrm{r}}}^{\mathrm{OECD}}
$$

The transformation of (A6.6) into the respective elasticity within the private sector depends on the treatment of average compensation in the public sector. If wages in the public sector are assumed to be cyclically neutral, (A6.6) must be transformed into

$\varepsilon_{\omega_{\mathrm{p}}, \mathrm{Y}_{\mathrm{r}}}^{\mathrm{OECD}}=\varepsilon_{\omega_{\mathrm{p}}, \mathrm{E}_{\mathrm{p}}}^{\mathrm{OECD}} \varepsilon_{\mathrm{E}_{\mathrm{p}}, \mathrm{Y}_{\mathrm{r}}}^{\mathrm{OECD}}$

Within the OECD approach, the employment elasticity of the real wage is estimated as the parameter $b_{2}$ in the following regression: (van den Noord, 2000:23):

$\log \left(\omega E^{*} / Y_{r}^{*}\right)=b_{0}+b_{1} t+b_{2} \log \left(E / E^{*}\right)+\mu^{W} \quad$.

Taking into account that the OECD assumes the government sectomalways being at its potential, (i.e.: $\mathrm{e}_{g, \mathrm{c}}=0$ ) and after applying some algebraic transformations, ${ }_{\omega, \mathrm{E}}$ can be approximated as

$\varepsilon_{\omega, \mathrm{E}}^{\mathrm{OECD}}=\varepsilon_{\omega_{\mathrm{p}}, \mathrm{E}_{\mathrm{P}}}^{\mathrm{OECD}} \frac{\mathrm{E}^{*} / \mathrm{E}_{\mathrm{P}}^{*}}{\mathrm{~W} / \mathrm{W}_{\mathrm{p}}}$, implying

$\varepsilon_{\omega_{\mathrm{p}}, \mathrm{E}_{\mathrm{P}}}^{\mathrm{OECD}}=\varepsilon_{\omega, \mathrm{E}}^{\mathrm{OECD}} \frac{\mathrm{W} / \mathrm{W}_{\mathrm{p}}}{\mathrm{E}^{*} / \mathrm{E}_{\mathrm{p}}^{*}}$.

Inserting the results from (A6.II) and (A6.I5) into (A6.7) yields the following adjusted output elasticity of average compensation of employees in the private sector:

$\varepsilon_{\omega_{\mathrm{p}}, \mathrm{Y}_{\mathrm{r}}}^{\mathrm{OECD}}=\varepsilon_{\omega, \mathrm{E}}^{\mathrm{OECD}} \varepsilon_{\mathrm{E}, \mathrm{Y}_{\mathrm{r}}}^{\mathrm{OECD}} \frac{\mathrm{W}}{\mathrm{W}_{\mathrm{p}}}$. The output elasticity of compensation of $\mathcal{E}_{\mathrm{W}, \mathrm{Y}_{\mathrm{r}}}=\mathcal{E}_{\omega, \mathrm{Y}_{\mathrm{r}}} \underset{\varepsilon_{\mathrm{E}, \mathrm{Y}_{\mathrm{r}}}}{\text { employees }}$
way by using the identity 
A 6.3 Output elasticity of private consumption

With respect to aggregate consumption, the OECD specifies the regression equation

$\log \left(\mathrm{C}_{\mathrm{p}} / \mathrm{Y}_{\mathrm{r}}^{*}\right)=\mathrm{d}_{\mathrm{o}}+\mathrm{d}_{1} \mathrm{t}+\mathrm{d}_{2} \log \left(\mathrm{Y}_{\mathrm{r}} / \mathrm{Y}_{\mathrm{r}}^{*}\right)+\mu^{\mathrm{C}}$

with private consumption as the dependent variable, estimating the output elasticity of private consumption by $d_{2}$ :

$\varepsilon_{\mathrm{C}_{\mathrm{P}}, \mathrm{Y}_{\mathrm{r}}}^{\mathrm{OECD}}=\mathrm{d}_{2}$

Thus, no adjustment of the elasticity as estimated by the OECD is necessary in this case.

\section{A 6.4 Output elasticity of number of unemployed}

The elasticity of the number of unemployed as calculated by the OECD can be explained as $\varepsilon_{\mathrm{U}, \mathrm{E}}^{\mathrm{OECD}}=\varepsilon_{\mathrm{U}, \mathrm{E}}^{\mathrm{OECD}} \cdot \varepsilon_{\mathrm{E}, \mathrm{Y}_{\mathrm{r}}}^{\mathrm{OECD}}$ (see van den Noord, 2000). An adjustment for the private sector is not necessary, since by definition $\varepsilon_{\mathrm{U}, \mathrm{E}_{\mathrm{p}}} \cdot \varepsilon_{\mathrm{E}_{\mathrm{p}}, \mathrm{Y}_{\mathrm{r}}}=\varepsilon_{\mathrm{U}, \mathrm{E}} \varepsilon_{\mathrm{E}, \mathrm{E}_{\mathrm{p}}} \cdot \varepsilon_{\mathrm{E}_{\mathrm{p}}, \mathrm{E}} \varepsilon_{\mathrm{E}, \mathrm{Y}_{\mathrm{r}}}=\varepsilon_{\mathrm{U}, \mathrm{Y}_{\mathrm{r}}}$ must hold. 


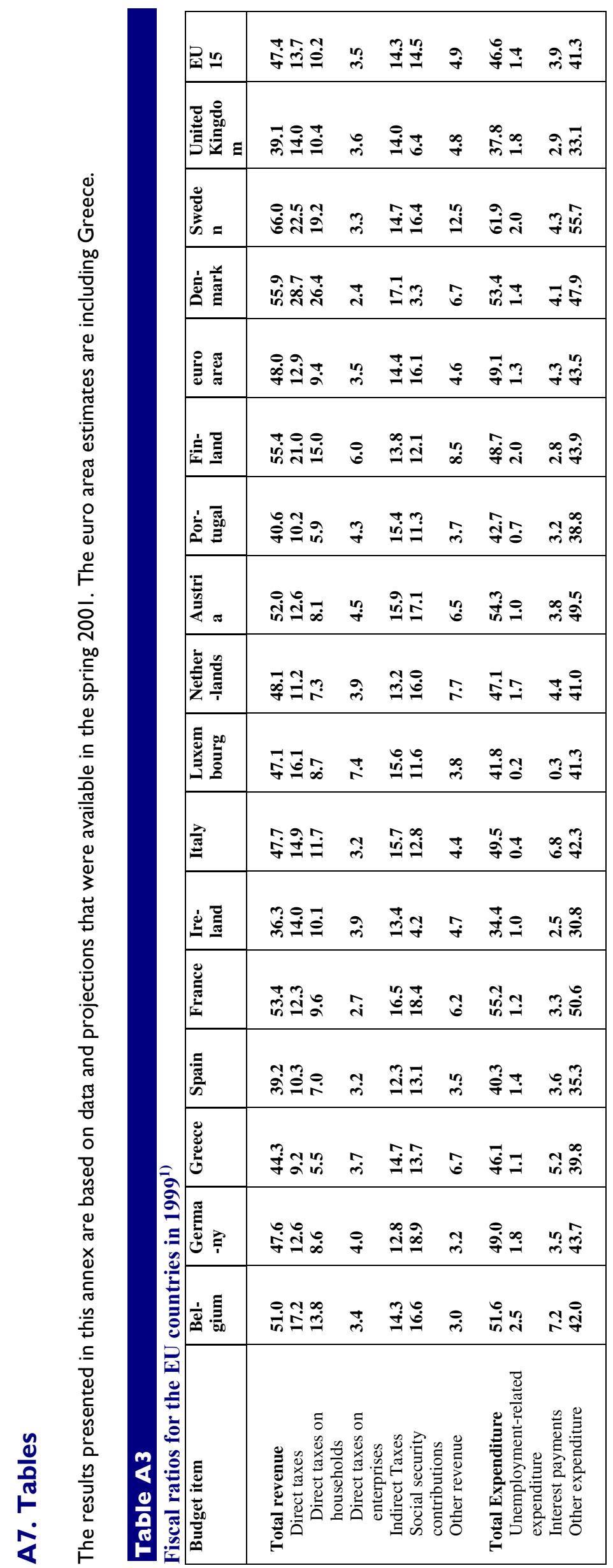



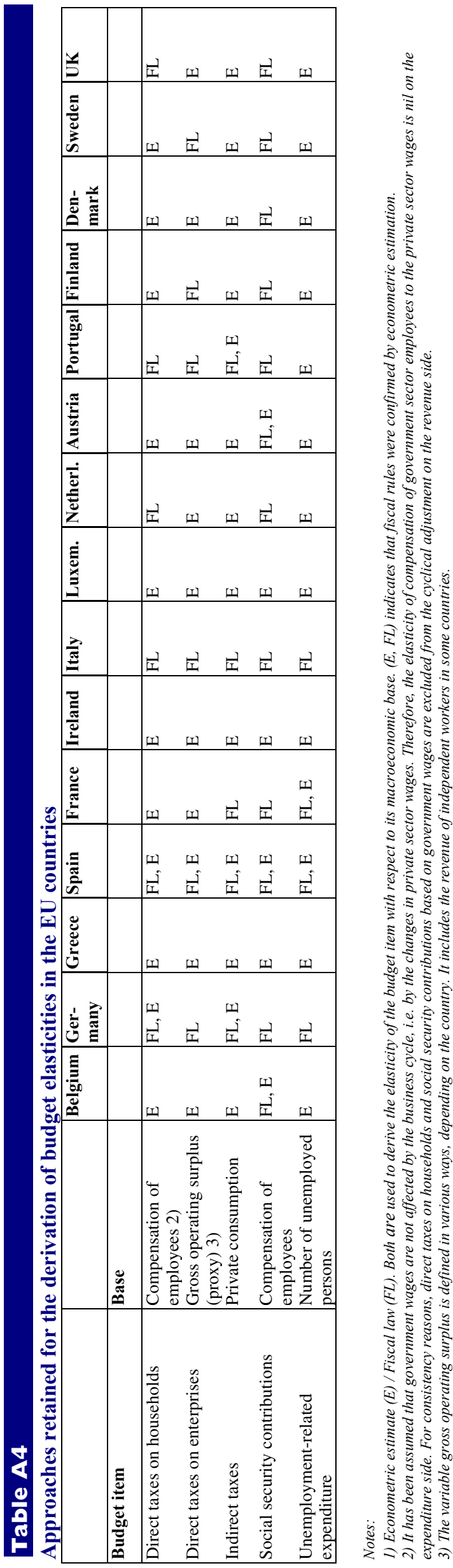


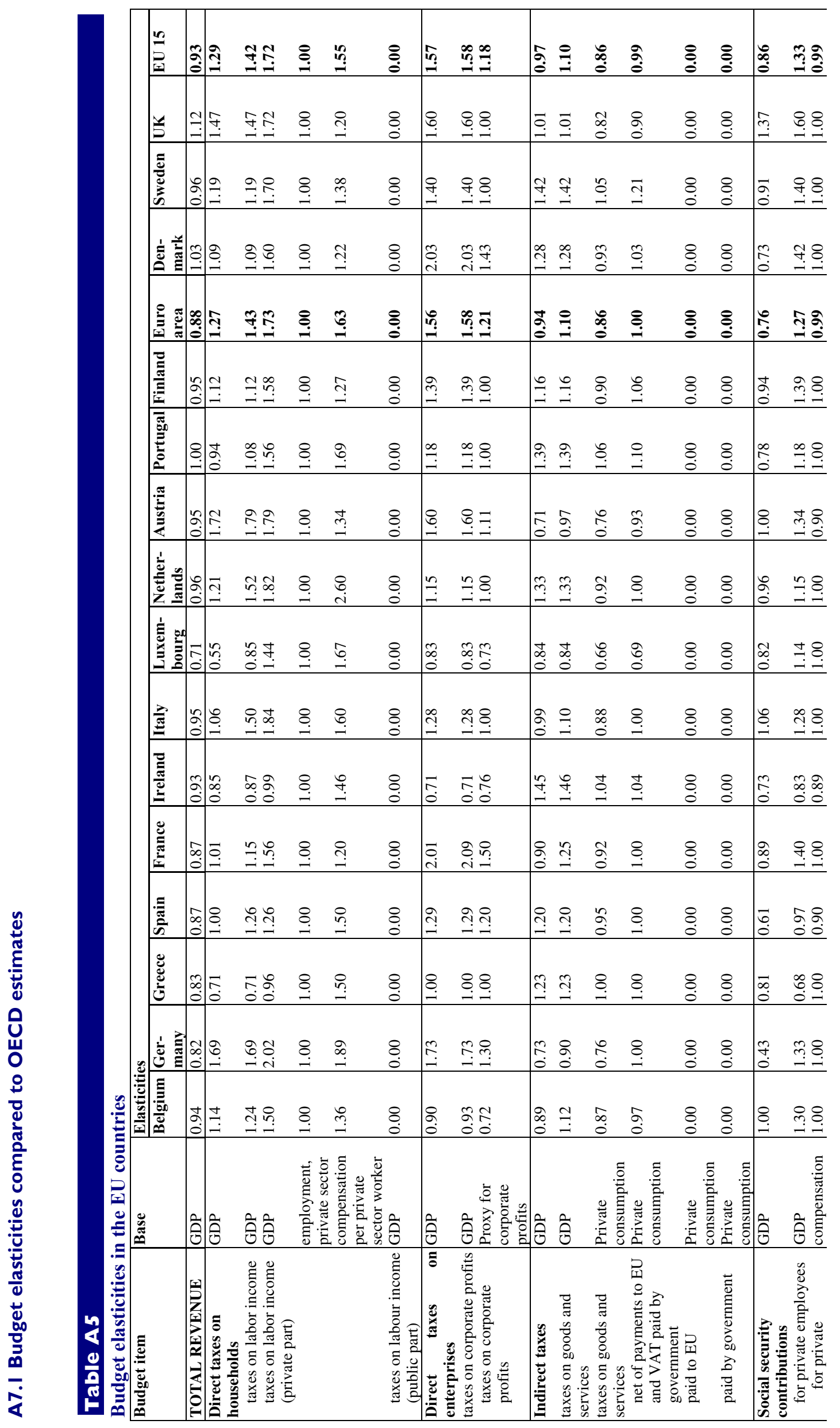




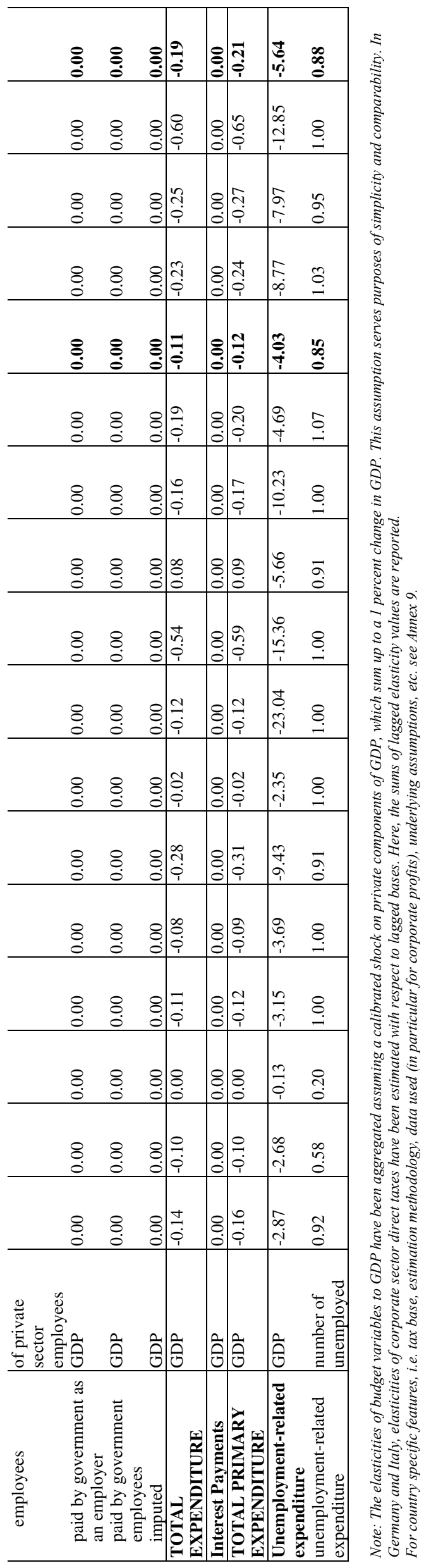




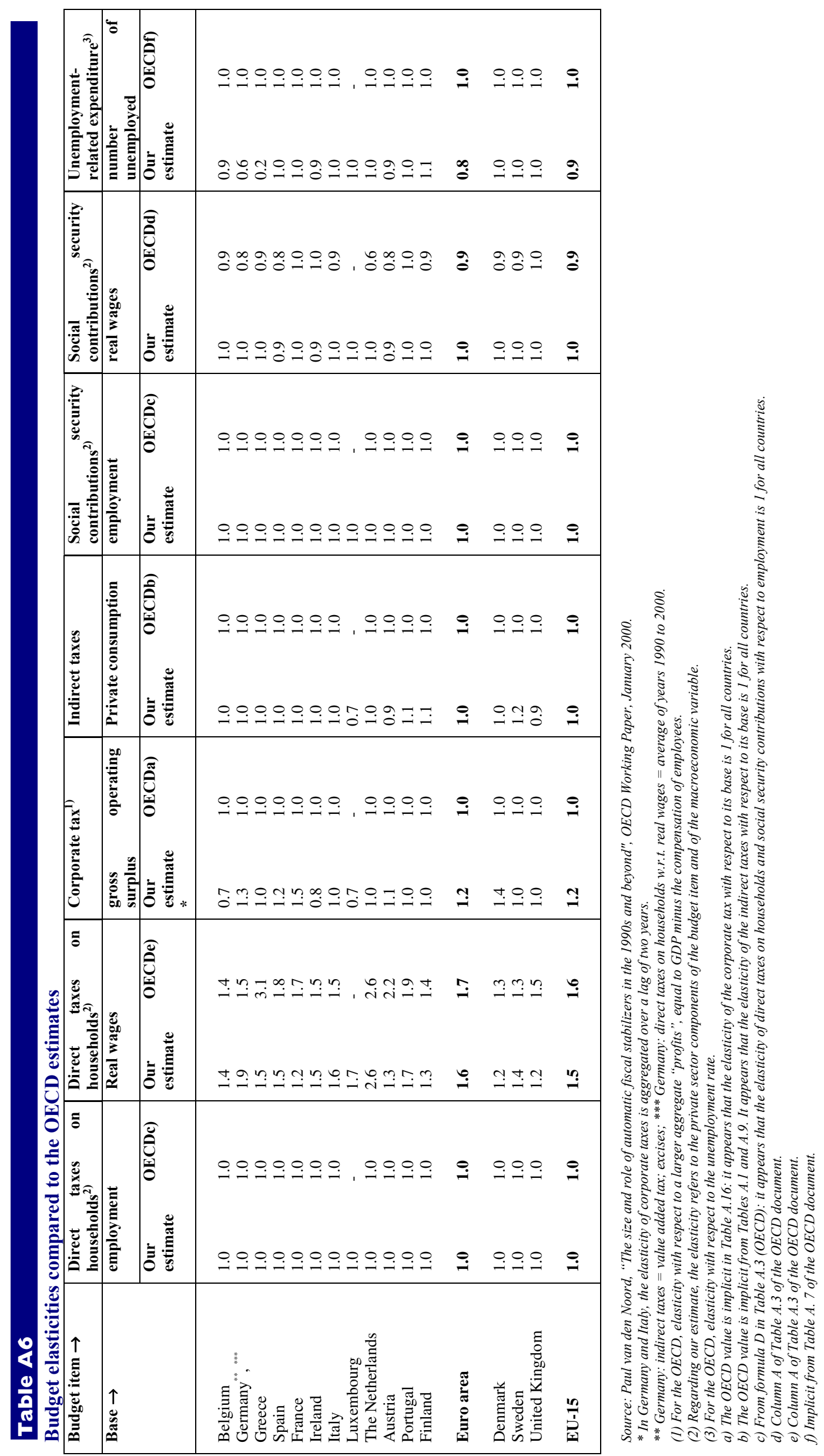




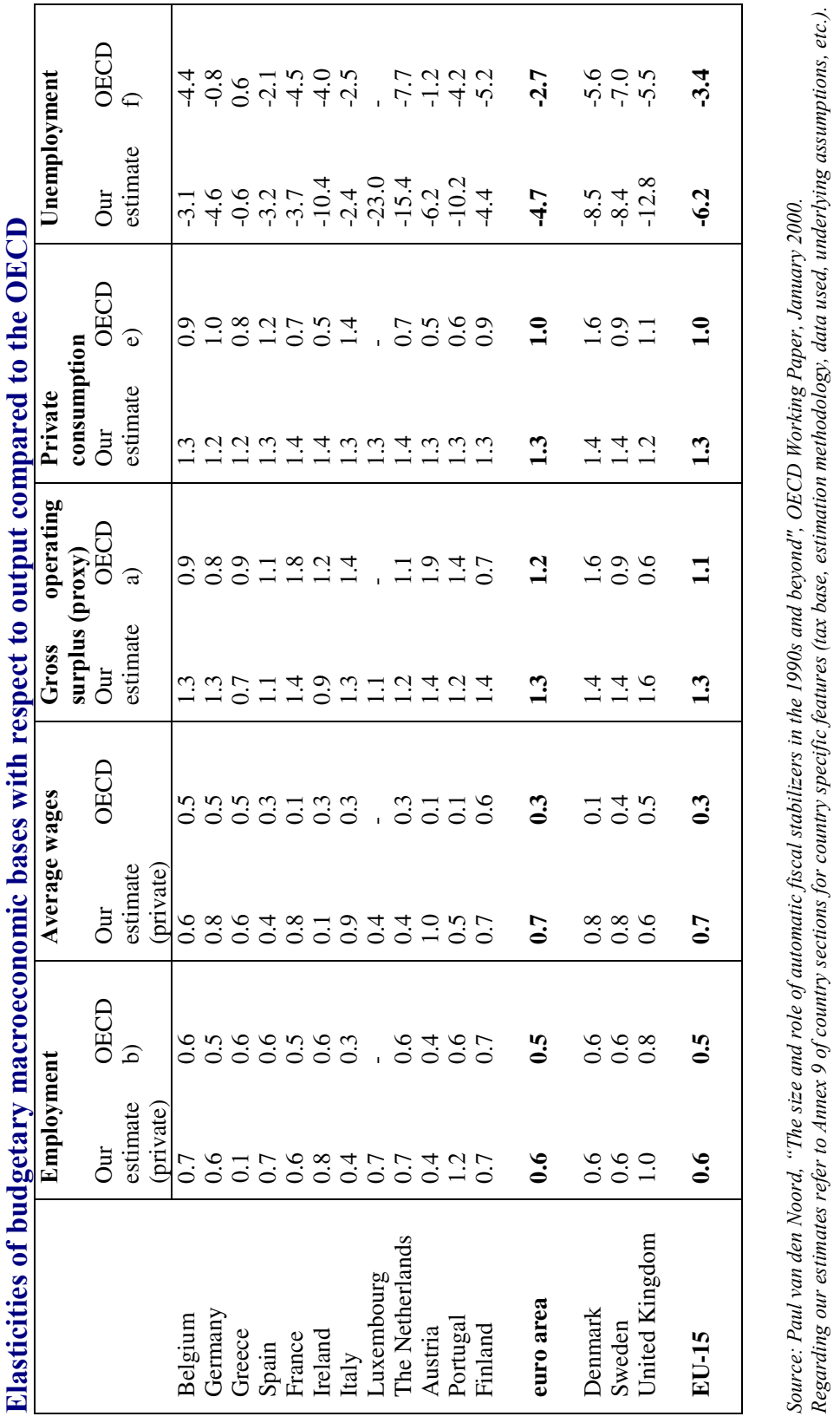


A7.2 Cyclically adjusted budget balances and comparison of cyclical components to the results of the EU Commission, the OECD and the IMF

\section{Table A8}

Cyclically adjusted balances in the EU, 1998-2000 (as a percentage of GDP)

\begin{tabular}{|l|l|l|l|}
\hline Belgium & $\mathbf{1 9 9 8}$ & $\mathbf{1 9 9 9}$ & $\mathbf{2 0 0 0}$ \\
\cline { 2 - 3 } Germany & -0.6 & -0.3 & 0.0 \\
Greece & -1.7 & -1.4 & -1.0 \\
Spain & -2.6 & -2.0 & -0.9 \\
France & -2.4 & -1.4 & -0.8 \\
Ireland & -2.1 & -1.4 & -1.5 \\
Italy & 1.8 & 1.6 & 3.8 \\
Luxembourg & -2.8 & -1.7 & -1.6 \\
The Netherlands & 4.2 & 5.2 & 5.2 \\
Austria & -0.6 & 0.6 & 0.9 \\
Portugal & -2.1 & -2.1 & -1.7 \\
Finland & -2.3 & -2.7 & -2.3 \\
euro area & 0.0 & -1.5 & 5.5 \\
Denmark & -1.9 & 2.4 & -0.9 \\
Sweden & 0.3 & 1.0 & 2.2 \\
United Kingdom & 2.3 & 1.0 & 3.2 \\
EU-15 & 0.2 & -0.8 & 2.0 \\
\hline
\end{tabular}

Note: The estimates are based on the data and projections that were available in the spring 2001. 
Table A9

Cyclical components of the budget balances in the EU, 1998-2000, compared to the EU

Commission, the OECD and the IMF (as a percentage of GDP)

\begin{tabular}{|c|c|c|c|c|c|c|c|c|c|c|c|c|}
\hline & \multicolumn{3}{|c|}{ Our approach } & \multicolumn{3}{|c|}{ EU Commission } & \multicolumn{3}{|c|}{ OECD } & \multicolumn{3}{|l|}{ IMF } \\
\hline & 1998 & 1999 & 2000 & 1998 & 1999 & 2000 & 1998 & 1999 & 2000 & 1998 & 1999 & 2000 \\
\hline Belgium & -0.3 & -0.4 & 0.0 & -0.5 & -0.6 & 0.1 & -1.2 & -1.1 & -0.3 & -1.3 & -1.1 & 0.1 \\
\hline Germany & -0.4 & 0.0 & 0.0 & -0.6 & -0.7 & -0.2 & -1.0 & -1.0 & -0.5 & -1.0 & -1.0 & -0.5 \\
\hline Greece & 0.2 & 0.1 & 0.0 & -0.4 & -0.4 & -0.1 & -1.0 & -0.8 & -0.3 & -1.8 & -1.3 & -0.6 \\
\hline Spain & -0.2 & 0.2 & 0.5 & -0.2 & 0.0 & 0.4 & -1.0 & -0.2 & 0.2 & -0.7 & -0.1 & 0.5 \\
\hline France & -0.6 & -0.2 & 0.1 & -0.5 & -0.3 & 0.0 & -0.9 & -0.4 & 0.1 & -1.0 & -0.8 & -0.4 \\
\hline Ireland & 0.3 & 0.5 & 0.7 & 0.2 & 0.7 & 1.4 & 0.4 & 0.8 & 1.4 & 0.6 & 0.9 & 1.5 \\
\hline Italy & 0.0 & 0.0 & 0.1 & -0.3 & -0.6 & -0.2 & -0.8 & -1.0 & -0.6 & -1.0 & -1.2 & -0.8 \\
\hline Luxembourg & -1.0 & -0.5 & 0.1 & -1.3 & -0.5 & 1.0 & NA & NA & NA & NA & NA & NA \\
\hline The Netherlands & -0.1 & 0.3 & 0.6 & -0.1 & 0.3 & 0.6 & 0.1 & 0.5 & 0.6 & 0.3 & 1.0 & 2.1 \\
\hline Austria & -2.1 & -2.1 & -1.7 & -0.2 & -0.2 & 0.0 & -0.1 & 0.0 & 0.6 & -0.6 & -0.5 & 0.4 \\
\hline Portugal & 0.0 & 0.6 & 0.6 & 0.1 & 0.1 & 0.3 & 0.1 & 0.1 & 0.1 & 0.0 & -0.1 & 0.0 \\
\hline Finland & 1.2 & 1.3 & 1.2 & 0.5 & 0.6 & 1.6 & -1.7 & -1.3 & 0.1 & -0.8 & -0.6 & 0.0 \\
\hline Euro area & -0.3 & $\mathbf{0 . 0}$ & 0.2 & -0.4 & -0.4 & 0.0 & -0.8 & -0.6 & -0.2 & -0.8 & -0.7 & -0.2 \\
\hline Denmark & 0.9 & 0.6 & 0.3 & 0.6 & 0.3 & 0.6 & 0.1 & 0.3 & 0.7 & 0.5 & 0.8 & 1.2 \\
\hline Sweden & -0.2 & 0.7 & 0.9 & -0.7 & 0.2 & 0.7 & -1.1 & -0.1 & 0.3 & -3.3 & -2.2 & -0.4 \\
\hline United Kingdom & 0.2 & 1.0 & 2.0 & 0.1 & 0.0 & 0.1 & 0.1 & 0.1 & 0.3 & -0.2 & 0.0 & 0.1 \\
\hline EU-15 & -0.2 & 0.1 & 0.2 & -0.3 & -0.3 & 0.1 & -0.7 & -0.5 & -0.1 & -0.8 & -0.6 & -0.1 \\
\hline
\end{tabular}

Source: Our estimates: Spring 2001 calculations. European Commission: Spring 2001 forecasts, April 2001. OECD: Economic Outlook 69, June 2001. IMF: World Economic Outlook, May 2001. 


\section{A8. References}

Baxter, M. and King, R.G. (1995), "Measuring business cycles. Approximate band pass filters for economic time series", NBER working paper No. 5022, February.

Beveridge, S. and Nelson, C. (198I), "A new Approach to Decomposition of Economic Time Series into Permanent and Transitory Components with Particular Attention to Measurement of the Business Cycle", Journal of Monetary Economics 7(2): I5I-I74.

European Commission (200I), “Spring 200I forecasts”, April.

Harvey, A.C. (1989), "Forecasting Structural Time Series and the Kalman Filter", Cambridge University Press.

IMF (200I), “World Economic Outlook”, May.

Kaiser, R. and Maravall, A. (1999), "Estimation of the Business Cycle: A Modified Hodrick-Prescott Filter”, Banco de Espana - Servicio de Estudios, Documento de Trabajo No. 9912.

Mc Morrow, K. and Roeger, W. (200I), "Potential Output: Measurement Methods, "New" Economy Influences and Scenarios for 200I-2010. A Comparison of the EUI5 and the US", European Commission, Directorate-General for Economic and Financial Affairs, Economic Working Paper No. 150.

OECD (200I), “Economic Outlook 69”, June.

Pedersen, T. M. (1998a), "The Hodrick Prescott Filter, the Slutzky Effect, and the Distortionary Effect of Filters", University of Copenhagen, Institute of Economics, Working Paper.

van den Noord, P. (2000), "The size and role of automatic fiscal stabilisers in the 1990s and beyond”, OECD Working Paper 230, January. 